Florida International University FIU Digital Commons

6-26-1996

\title{
A comprehensive assessment of self-report experiences of adoptive parents of special needs children in Florida
}

Arlene Kaplan Brown

Florida International University

DOI: $10.25148 /$ etd.FI14051853

Follow this and additional works at: https://digitalcommons.fiu.edu/etd

Part of the Social Welfare Commons

\section{Recommended Citation}

Brown, Arlene Kaplan, "A comprehensive assessment of self-report experiences of adoptive parents of special needs children in Florida" (1996). FIU Electronic Theses and Dissertations. 1888.

https://digitalcommons.fiu.edu/etd/1888 
FLORIDA INTERNATIONAL UNIVERSITY

MIAMI, FLORIDA

A COMPREHENSIVE ASSESSMENT OF SELF-REPORT EXPERIENCES OF ADOPTIVE PARENTS OF SPECIAL NEEDS CHILDREN IN FLORIDA

A dissertation submitted in partial satisfaction of the requirements for the degree of

DOCTOR OF PHILOSOPHY

IN

SOCIAL WELFARE

by

Arlene Kaplan Brown

1996 
To: Dean Mark Rosenberg College of Urban and Public Affairs

This dissertation, written by Arlene Kaplan Brown, and entitled A COMPREHENSIVE ASSESSMENT OF SELF-REPORT EXPERIENCES OF ADOPTIVE PARENTS OF SPECIAL NEEDS CHILDREN IN FLORIDA, having been approved in respect, to style and intellectual content, is referred to you for judgment.

We have read this dissertation and recommend that it be approved.

Miriam Potocky

Stan L. Bowie

Kardn Soweźs-Hoag, Major Práéssor

Date of Defense: June 26, 1996

"The dissertation of Arlene Kaplan Brown is approved.

Dean Mark Rosenberg

College of Urban and Public Affairs

Dr. Richard L. Campb申ll

Dean of Graduate Studies

Florida International University, 1996 
COPYRIGHT 1996 by Arlene Kaplan Brown

All rights reserved 
I dedicate this dissertation to my special family. To my mother, Violet Kaplan, for her unselfish lifetime of love, devotion and support, and impressing on me the importance to do whatever I do to the best of my abilities; to my husband, Johnny Brown, for all of the joy you have brought into my life and for being the loving "wind beneath my wings" by endlessly encouraging me to be the best that I can be; to my son, Matthew Wilson, for his love and for being my pride, my joy and my hope for the future; and to my stepchildren, Jamar, John, Angie, and Katina for their acceptance and love.

.1

I also dedicate this dissertation to the loving memory of my father, Samuel Kaplan, who devoted his life to his family and instilled in me the values that have' helped me to become the person I am. 


\section{ACKNOWLEDGMENTS}

I wish to thank members of my committee for the special contributions they made during my graduate education. I wish to thank Stan Bowie for his support throughout my educational endeavors and his encouragement to enter the doctoral program. I wish to thank Miriam Potocky for her timely help, patience, expertise, and especially for her dedication to ensure that this dissertation achieve the scholarly level that it has. A very special thanks is extended to Karen Sowers-Hoag, my loyal mentor and committee chair, for her consistent support throughout all of my graduate studies, as well as her encouragement, and guidance in accomplishing this goal.

This research would not have been possible without the interest and support of dedicated social service employees of the Department of Health and Rehabilitative Services. Gratitude and appreciation are extended to Linda Radigan, Dee Richter, Andrea Guy, and Richard Thum. A very special thanks to Pennie Eaddy and especially Marianne Missi for their years of loyalty, support and friendship and for unselfishly sharing with me their expertise in adoptions. I want to extend a special note of gratitude to Deena Greene for her support, allegiance and help with the survey. Thank you to Alan Braunstein for giving me the idea for my dissertation title. 
This dissertation could not have been completed without the special assistance and technical expertise provided by several people. Thank you to Fresler Gaspard for his help and extreme patience in assisting me in the design of the survey; to Jose Prendes and Fred Becker, for their computer and statistical knowledge; and to Chris Edghill for his computer assistance. I also wish to thank Laura Flagel for her invaluable assistance in generating the computer graphics .

The data could never have been analyzed without the assistance of my "bubblers". I wish to thank my boys, Matthew, Jamar and John for their help, and especially my husband Johnny for his unending and untiring assistance in "bubbling". Special thanks also goes to Eyvonne Fullone, Vinnie Fullone, Nita Coar and Regina Coar for their help "bubbling" .

، Finally, I would like to express my appreciation for the adoptive parents who took the time to fill out the survey, they are truly "special families".

This dissertation research was supported, in part, by funding from the Department of Health and Rehabilitative Services, Children and Families Program. 


\section{ABSTRACT OF THE DISSERTATION}

A COMPREHENSIVE ASSESSMENT OF SELF-REPORT EXPERIENCES OF ADOPTIVE PARENTS OF SPECIAL NEEDS CHILDREN IN FLORIDA

by

Arlene Kaplan Brown

Florida International University, 1996

Professor Karen Sowers-Hoag, Major Professor

Adoption of special needs children is now seen as a life long event whereby the adoptive child and family have unique needs. The need for postplacement resources throughout the life cycle of the adoption process is evident. This exploratory-descriptive research employed a random stratified cross-sectional design. The purpose of the study was to describe, identify, examine, and assess the relative influence of identified empirically and conceptually relevant variables of self-report experiences of adoptive parents of special needs children. Primary areas of exploration included: (1) adoptive children and families' characteristics, (2) postplacement service needs, utilization and satisfaction, and (3) adoptive parents' perceptions of their adoption experiences. A proportionate stratified random mail survey was used to obtain 474 families who had adopted special needs children from the 15 
geographic districts which make up the state adoption social service agency in Florida. A 144-item survey questionnaire was used to collect basic information on demographic data, service provision, and adoption experiences. Four research questions were analyzed to test the effect the predictor variables had on willingness to adopt another special needs child, successful adoption, satisfying experience, and realism about problems. All four research questions revealed that the full model and the child's antecedent and the adoptive parents' intervening variable blocks were significant in explaining the variance in the dependent variables. The child's intervening variables alone were only significant in explaining the variance for one of the dependent variables. The results of the statistical analysis on the fifth research question and the three hypotheses determined that (1) only one postplacement service, crisis intervention, had a statistically significant impact on the adoptive parents' perceived level of satisfaction with the adoption experience; (2) adoptive parents who rate their adoption as successful are more likely to express a desire to adopt another special needs child; (3) the more adequate information on the child the adoptive parents perceived that they had prior to placement, the more they perceived they were realistic about the problems they would encounter; and (4) six specific 
postplacement services were found to be significant in predicting successful adoptions - crisis intervention, outpatient drug/alcohol treatment, maintenance subsidy, physical therapy, special medical equipment, and family counseling. Implications for the social. work field and future research are discussed. 
I. INTRODUCTION . . . . . . . . . . . . . . . . . . 1

Background ................. . 1

Problem Statement . . . . . . . . . . 6

Conceptual Framework . . ......... . 10

Implications for Social Welfare . . . . . 22

Purpose of the Study . . . . . . . . . . . . 25

Plan of the Report............ . 26

II. LITERATURE REVIEW . . . . . . . . . . . . . 28

Special Needs Adoptions . . . . . . . . 28

Statistics . . . . . . . . . . . . . 28

Cost Savings . . . . . . . . . . . . . . 31

Paradigm and Practice Shifts . . . . . 34

Adoption Outcomes . . . . . . . . . . . 39

Adoption Disruption . . . . . . . . . . . 45

Introduction . . . . . . . . . . . . . 45

Rates . . . . . . . . . . . . . . . . 46

Predictors and Correlates . . . . . . . 48

Postplacement Services... . . . . . . . 58

Introduction . . . . . . . . . . . . 58

Need and Usage . . . . . . . . . . . . . 63

Clinical . . . . . . . . . . . . . . 67

Support Groups and Social Support . . . 69

Subsidy . . . . . . . . . . . . . . . 72

Preparation and Training. . . . . . . 77

Agency Support and Services . . . . . 80

Summary . . . . . . . . . . . . . 83

Research Questions . . . . . . . . 86

Research Hypotheses... . . . . . . 87

III. METHODOLOGY . . . . . . . . . . . . . . . . 89

Research Design . . . . . . . . . . . 89

Variables and Operational Definitions . . . 90

Study Population and Sampling Strategy . . . 95

Instrumentation . . . . . . . . . . . 100

Data Collection Procedures... . . . . . 104

Response Rate . . . . . . . . . . . . . 104

Human Subjects Review Requirements... . 105

Data Analysis . . . . . . . . . . . . 107 
IV. RESULTS . . . . . . . . . . . . . . . . . . . 108

Description of Entire Sample . . . . . . 109

Adoptive Parents' Characteristics . . . . 109

Adoptive Children's Characteristics . . . . 116

Adoptive Parents' Adoption Experiences . . . 129

Post Placement Service Need and Utilization. 139

Post Placement Service Satisfaction . . . . 143

Barriers to Service Use . . . . . . . . 145

Research Questions . . . ... . . . . . 145

Question 1 . . . . . . . . . . . 153

Question 2 . . . . . . . . . . . . 156

Question 3 . . . . . . . . . . . . 159

Question 4 . . . . . . . . . . . . . 162

Question 5 . . . . . . . . . . . . . 166

Research Hypotheses ............ . 171

Hypothesis 1 . . . . . . . . . . . 171

Hypothesis 2 . . . . . . . . . . 176

Hypothesis 3 . . . . . . . . . . . . 178

V. DISCUSSION •. . . . . . . . . . . . . . 183

Summary of the Study . . . . . . . . . 183

Discussion of the Findings . . . . . . . . 187

Implications for Social Welfare . . . . . 194

Limitations of the Study . . . . . . . . . 199

Implications for Future Research . . . . 202

LIST OF REFERENCES . . . . . . . . . . . . . 205

APPENDICES . . . . . . . . . . . . . . . 222 .1

VITA . . . . . . . . . . . . . . . . . . 241 


\section{LIST OF TABLES}

TABLE

PAGE

1. Children in Florida Waiting for Adoptive

Placement . . . . . . . . . . . . . 32

2. District Sampling Data . . . . . . . . . 99

3. Descriptive Statistics for Adoptive Families . . . . . . . . . . . . . . .

4. Adoptive Parents' Experiences as Being Foster Parents . . . . . . . . . . . . . . .

5. Descriptive Statistics for Adoptive Children . . . . . . . . . . . . . . . . 119

6. Service Provision . . . . . . . . . . . 131

7. Adoptive Families' Perception of Their Adoption Experiences . . . . . . . . . . . . . . 132

8. Responses to Open-Ended Questions Regarding What Special Services Should be Developed for Adoptive Families . . . . . .

9. Responses to Open-Ended Questions Regarding What Could Have Been Done Differently to Make the Adoption Experience More Successful and Satisfying . . . . 138

10. Responses to Open-Ended Questions Regarding the Biggest Concern of the Adoptive Parents

11. Responses to Open-Ended Questions Regarding the Biggest Concern of the Adoptive Child as Perceived by the Adoptive Parents

12. Postplacement Services Not Used But Needed . . . . . . . . . . . . . . .

13. Postplacement Services Use and Satisfaction 
14. Recoding of Categorical Variables

Used in Multivariate Analyses . . . . . . . . .

15. Summary of Significance Levels of Predictor Variable Blocks for

Research Questions (Hierarchical

Multiple Regression) . . . . . . . . . . .

16. Summary of Significant Betas for . '

Research Questions (Hierarchical

Multiple Regression)

17. Zero-Order Correlation of Dependent

Variables . . . . . . . . . . . . . . 167

18. Analysis of Adoptive Parents' Perception

of Adoption Satisfaction on Selected

Postplacement Services (Multiple Regression) • • 169

19. Analysis of Adoptive Parents' Perception

of Willingness to Adopt Again by

Perception of Success of the Adoption

Controlled by Age of the Adoptive

Parents (Multiple Regression) . . . . . . . . 174

20. Perception of Successful Adoption by

Selected Postplacement Services (ANOVA) . . . . 180

21. Perception of Successful Adoption by 6

Statistically Significant Postplacement

Services (ANOVA)

xiii 


\section{LIST OF FIGURES}

FIGURE

PAGE

1. Barth and Berry's Model of Adjustment to Adoption Based on Individual Coping Within a Transitional Task . . . . . . . . . . . 15

2. Barth and Berry's Social and Cognitive Model of Adjustment to Adoption . . . . . . . . . 17

3. Conceptual Framework ............ . 21

A-1. Map of Florida With HRS Districts . . . . . . 222

A-2. Adoption Survey Instrument and Cover Letter . . 223

A-3. Completed Adoption Survey Daily Return Response Rates . . . . . . . . . . . . 239

A-4. Completed Adoption Survey Cumulative Return Response Rates . . . . . . . . . . . . . 240 


\section{Chapter 1}

Introduction

\section{Background}

Throughout the world, adoption has become a wellregarded and widely approved social and legal process whereby children who are unable to remain with their biological family or relatives are provided with the stability of a permanent home. The Child Welfare League of America (1988) defines adoption as "the method provided by law which establishes the legal relationship of parent and child between persons who are not so related by birth, with the same mutual rights and obligations that exist between children and their birth parents" (p. 9).

The adoption process continues to evolve as evidenced by adoption philosophy and practices in the United States having changed significantly during the last three decades "in response to altered supply and demand factors, social changes, societal value changes, and legislative changes. The changing adoption process has been divided into four primary components: eligibility, matching, recruitment, and postplacement services (Barth \& Berry, 1988).

In the 1960s, the Child Welfare League of America espoused the idea that no child is unadoptable. Children who were previously thought of as "unadoptable" or "hard to place" are now considered "special needs" children and are 
placed with increasing frequency (Cohen \& Westhues, 1990). With that change in philosophy, the beginning of the special needs adoption program of today was born (Grabe, 1990). The goal of adoption has changed from finding children for families who want to adopt to finding permanent homes for special needs children, to helping families keep functioning once a special needs child has been placed (Grabe, 1990; Kadushin, 1984; Watson, 1991).

Grabe (1990) suggests that the move to place older children for adoption has challenged many of the traditional social work practices and values about adoption. Healthy white babies available for adoption are now a scarce commodity due to abortion, improved birth control measures, greater acceptability of single parents raising children, and an increased focus of social service agencies to provide services to keep families together (Brodzinsky \& Schechter, .1990 ; Cohen \& Westhues, 1990).

Special needs adoption practices have also changed over the past several decades due to both policy and legislative changes as well as societal value changes. The permanency planning efforts of social service agencies have focused on providing permanent and stable homes for all children and ensuring that children do not become forgotten in the child welfare system (Office of Inspector General, 1988).

Permanency planning is defined as "efforts to maintain a child's birthfamily whenever possible, to return a child 
to his birthfamily as soon as possible, and failing either, to establish for him legally permanent nurturant relationships with caring adults preferably through adoption" (Cole \& Donley, 1990, p. 278).

The permanency planning movement of, the $1960 \mathrm{~s}$ in concert with passage of the Adoption Assistance and Child Welfare Act of 1980 (Adoption Assistance, 1980) brought national attention, support and financial aid to the subject of special needs adoptions (Unger, Deiner \& Wilson, 1988). The Act, which was federal legislation aimed at ensuring permanency for all children placed in substitute care, furthered the change in adoption practices (Adoption Assistance, 1980).

Another significant change is that the adoption process is no longer seen as being time-limited. Previously, the perspective was that once an adoption was finalized, the family no longer wanted or needed services or intervention by a social service agency. With the recognition that adoptive families are different than biological families came a realization that adoptive families have unique needs resulting from their equally unique circumstances. Therefore, adoption is neither just a legal act or a social process. Rather, adoption is now seen as a condition which affects the adoptive child and family throughout their lives (CWLA, 1988; Bourguignon \& Watson, 1988; Watson, 1991). 
Special needs children are defined separately in each state. The definition of special needs children has changed over the years, and between 1984 and 1990, 23 states had changed their definition of what constituted a special needs child (Sedlak \& Broadhurst, 1993). However, most state definitions center around those children who are older (usually over the age of eight), emotionally disturbed, physically or mentally handicapped, of mixed or minority racial heritage, or members of a sibling group (Groze, $1986)$.

Although the definition of a special needs child often centers around the age of the child, infants and young children are more frequently entering the foster care system and subsequently being placed as special needs adoption placements. These children meet the criteria for special needs adoption due to prenatal insult, adverse parental background or minority status (Barth, 1991). The increase in substance abuse by mothers has resulted in substantial increases in infants and small children entering the child welfare system with special needs adoption being one possibility for exit out of the system.

The increase of special needs children being placed for adoption has occurred without sufficient support services being provided by the public and private adoption-placing agencies or by the community at large. The patchwork array of services for these families is so insufficient that often 
the adoption results in negative outcomes such as an unsatisfactory experience for some or all family members or an unsuccessful adoption placement. These outcomes may be manifested by regret over finalizing the adoption, dysfunctional relationships, or at worst, disruption whereby the child is removed from the home and placed back into the foster care system or into other out-of-home placements. Grabe (1990) reports that both social work professionals and adoptive parents maintain that unsuccessful adoptions are often caused by the lack of postplacement services.

The benefit of providing preventative and supportive services is twofold. First, adoption is more cost effective than foster care according to the United States Department of Health and Human Services (Rodriguez \& Meyer, 1990). Sedlak and Broadhurst (1993) cite an approximate savings of 1.6 billion dollars by the federal and state governments in relation to the 40,7000 children adopted with subsidy during the 1983 to 1987 time period. Second, adoption is unquestionably advantageous to the healthy functioning and stability of the adoptive child and family. Adoption disruption results in the disintegration of what could have been a stable loving home in which the child would experience love, guidance and security. The child and the family suffer and are destroyed due to the lack of available preventative and supportive resources to ameliorate the dysfunction. 


\section{Problem Statement}

Adoption practices have changed drastically in the last three decades. With the increased focus on permanency planning that began in the 1960's, there has been a dramatic increase in the number of special needs adoptions conducted by public child welfare agencies (North American Council on Adoptable Children [NACAC], 1990). The implementation of the Adoption Assistance and Child Welfare Act of 1980 provided a spotlight on the child welfare arena of the need to increase adoptive placements of special needs children (Adoption Assistance, 1980).

In addition, there has been an increase in the number of adoption disruptions and dissolutions in part due to adoptive families not being able to access appropriate and effective resources to help their families stabilize and have a successful outcome (Barth, Berry, Carson, Goodfield, (\& Feinberg, 1986; Brooks, 1991). The availability of adoption-related services beyond legal finalization is one of the strongest factors in preventing adoption disruptions and is a critical determinant of the success of the adoption for both the child and family (Watson, 1991).

Adoption was once considered to be one of the most successful components of the child welfare system. However, with the increasing placement of special needs children and the resulting increase in adoption disruptions, the philosophy and practices surrounding adoption have taken on 
new challenges. Brooks (1991) states that "the problem of special needs adoption is a microcosm of the problem of the child welfare system as a whole" (p. 1163).

The public child-placing agency in the state of Florida, the Department of Health and Rehabilitative Services (HRS), has primary responsibility for adoption placement of all special needs children. As of August 31, 1995 there were 974 children in adoptive placements in Florida being supervised by HRS (HRS, 1995). Postplacement adoption services are provided to the child and family for a statutorily mandated ninety days following placement. Due to the high caseloads and lack of adequate resources, this postplacement supervision usually consists of a bachelor's level social worker visiting the family only once per month for a three month period prior to finalization. For foster parents adopting their special needs foster child, there is no required supervision period.

Although many of the families receive financial and/or medical adoption subsidy, once the adoption is 'finalized, the families are left alone to resolve their problems without any on-going assistance by the agency who placed the child with them. Federal and state funds are available for medical and maintenance subsidy as well as nonrecurring expenses involved in the adoption placement such as attorney fees and court costs. However, there are no funds or social work positions provided exclusively to postfinalization 
support and therefore, when postfinalization services are offered, the funds necessary to provide the service are taken from funds originally allocated for another child welfare program. The crucial need for on-going resources once the adoption is finalized can be highlighted by statistics of HRS (1995) that reveal that in the month of August, 1995 there were 424 reported postfinalization cases which requested and/or received counseling services, information/referral, or other support services.

With the advent of permanency planning efforts, the first priority was to stop the practice of children drifting in foster care and to pursue termination of parental rights in order to place special needs children for adoption. Once this was in process, the second priority was to recruit suitable special needs adoptive parents. The task that is upon the social service profession now is to develop "effective postadoption services (Pinderhughes \& Rosenberg, $1990)$.

The need for postfinalization resources throughout the life cycle of the adoption process is evident (American Public Welfare Association [APWA], 1991a; Barth et al., 1986; Child Welfare League of America [CWLA], 1988; Gilles, 1995; Grabe \& Sim, 1990; Hartman, 1984; Levine \& Salles, 1990; NACAC, 1990). The challenge to the professional community is to determine how to increase the satisfaction with the adoption experience, increase the success of 
special needs adoptions, and provide effective and needed postplacement resources while still continuing to aggressively provide adoption placements for special needs children.

The role of the public child welfare agency in planning and providing postplacement adoption services for special needs families is still emerging. This concept is detailed in the underlying premise of a report written by watson (1991) wherein he advocates that public child welfare agencies must take responsibility for conceptualizing and defining postplacement services, and either provide those services or make sure they are provided elsewhere in the community.

Although HRS is the adoption agency that places the majority of special needs children and is responsible for paying the maintenance and medical adoption subsidies for all special needs adoptive children, the agency has no knowledge of the demographics of the families who adopt special needs children nor of the children who are placed except for race and age. The agency has no policies, procedures, or funding for postfinalization services for special needs adoptive families except for maintenance and medical subsidy and reimbursement for nonrecurring adoption finalization expenses such as attorney fees, court costs and costs related to preplacement visits. Further, the agency has not conducted any empirical research regarding 
postplacement resource needs, resource utilization, and intervention outcomes for special needs adoptive families.

There is a tremendous lack of availability of services developed specifically for the adoptive family and child who are encountering problematic placements.. Budget reductions for social services threaten to decrease the already minimal amount of services that currently exist for adoptive families. Nonetheless, social workers are continuing to pursue special needs adoptions without any meaningful descriptive or exploratory research on postplacement services for adoptive families. Further, there is an even greater paucity in the level of empirical intervention knowledge regarding the effectiveness of services to ensure successful adoption placements. Empirical interventive research is in its infancy related to special needs adoption .

\section{Conceptual Framework}

According to Brodzinsky and Schechter (1990), the existing research on adoptions is difficult to 'interpret due to its atheoretical nature. Therefore, theories from other social service areas are borrowed and applied to adoption issues. Theories related to adoption are used to make substantive predictions about the consequences of adoption (Grotevant \& MCRoy, 1990). Portions of various theories (adoption kin, attachment, fictional family, family systems, genetic, goodness of fit, psychoanalytic, cognitive, loss 
and grief, Eriksonian developmental theory, and social learning) can be extrapolated and used to explain different aspects of special needs adoptions. The theories that have the most relevance to the issue of postplacement services and special needs adoptions are adoption kin (Kirk, 1964), attachment (Ainsworth, 1979), family systems (Minuchin, 1974), and Barth and Berry's (1988) framework which draws from social learning and stress and coping theories to explain adoption adjustment.

Using social role theory, Kirk (1964) developed a theory of adoptive kinship which was the first theory to examine adoptive family relationships from a sociological perspective and was the only theory that has been developed that is unique to adoption (Barth \& Berry, 1988). The study was conducted between 1951 and 1962 on 2,000 families throughout Canada and the United States.

Kirk applied social role theory to adoptive families by stressing that adoptive families undergo situational circumstances that present role handicaps for a'doptive families and must be seen as different experiences than those that biological families undergo (Barth \& Berry, 1988; Grotevant \& MCRoy, 1990). The theory stresses that being an adoptive parent is inherently different from being a biological parent and that in order for adoptive parents to provide a stable and secure home for the adoptive child, they must acknowledge rather than reject the differences 
related to adoption versus biological parenthood. Kirk stated that adoptive parents do not have as much support or as many traditions to lean on when parenting. He gives examples such as the fact that biological parents have nine months to prepare for parenthood whereas! adoptive parents never know how long it will be until they have a child placed with them for adoption. Adoptive parents have to go through rigid screening, assessment, and supervision while biological parents do not. He stressed openness and honesty in communication which has been apparent in older child and open adoptions that are now taking place more frequently. Kirk's theory was criticized for various reasons including its conception and lack of empirical support. Kirk's concept did not acknowledge the interaction and interplay of blended family relationships and social services that occur in special needs adoptions (Barth \& Berry, 1988). Additionally, Kirk's theory related more specifically to infant adoptions and did not explain the processes that occur for children who are older when adopted whereby many maintain not only knowledge of but possibly may keep in contact with their biological families.

Although Kirk's theory was criticized, this theory was the first to normalize many of the adjustment situations that adoptive families encounter (Brodzinsky \& Schechter, 1990). Because of the many physical and emotional handicaps that special needs adoptive children have, the adoptive 
parents are presented with stressors and situations that are different than those experienced by birth families.

Attachment is identified as one of the central issues in families' decisions to adopt (Johnson \& Fein, 1991) since often the decision to adopt is based on the family already having some form of attachment to the child (Barth \& Berry, 1988; Unger et al., 1988). Attachment theory (Ainsworth, 1979 ) is based on ethological theory (Grotevant \& McRoy, 1990) and states that an infant needs to be provided safety, security and nurturance from its caregiver. The key to attachment is in the responsiveness of the caregiver to the infant. If the infant does not receive a responsive level of security from the caregiver, then throughout that child's life there may be problems with attachment.

Barth and Berry (1988) argue that existing models of attachment are informative but do not provide sufficient explanation for the relationship between adoptive child, parent, adoption agency, and informal social resources. A different point of view is held by Grotevant and McRoy (1990) who state that attachment theory holds true for adoptive families and especially for children who are older when placed for adoption. A child who has been in foster care may have experienced multiple separations and moves which often hamper that child's ability to attach to new parent figures. Children who are in substitute care may also have suffered abuse through the hands of the caregiver 
which may affect the child's level of basic trust and eventually his/her ability to attach.

Structural family system theory (Minuchin, 1974) views families, whether biological or adoptive, as a network of interdependent individuals and relationships. All members of the family are interconnected to make up a system where the impact of what happens to one member of the family affects all members. In developing the family systems theory with his colleagues, Minuchin underscored the importance of not only the family's relationship with its ecological environment, but also the structure and organization of the family itself (Hartman \& Laird, 1987).

Family systems theory related to adoption examines the family's adaptation to the new adoptive child and the mutual adaptation that occurs between adoptive parents and child. Barth (1991) relays that a family systems perspective on attachment is needed when examining the attachment to all family members by an older adoptive child.

The family systems theory holds relevance 'for special needs adoptions since the child's adoptive placement affects all members of the family system including all subsystems. This theory is relevant for professionals working with adoptive families as any intervention should be aimed at the entire family and not just the targeted adoptive child.

Barth and Berry (1988) developed a theory of adoption illustrated in Figure 1 which is based on the social and 
Figure 1: Barth and Berry's Model of Adjustment to Adoption Based on Individual Coping Within a Transitional Task

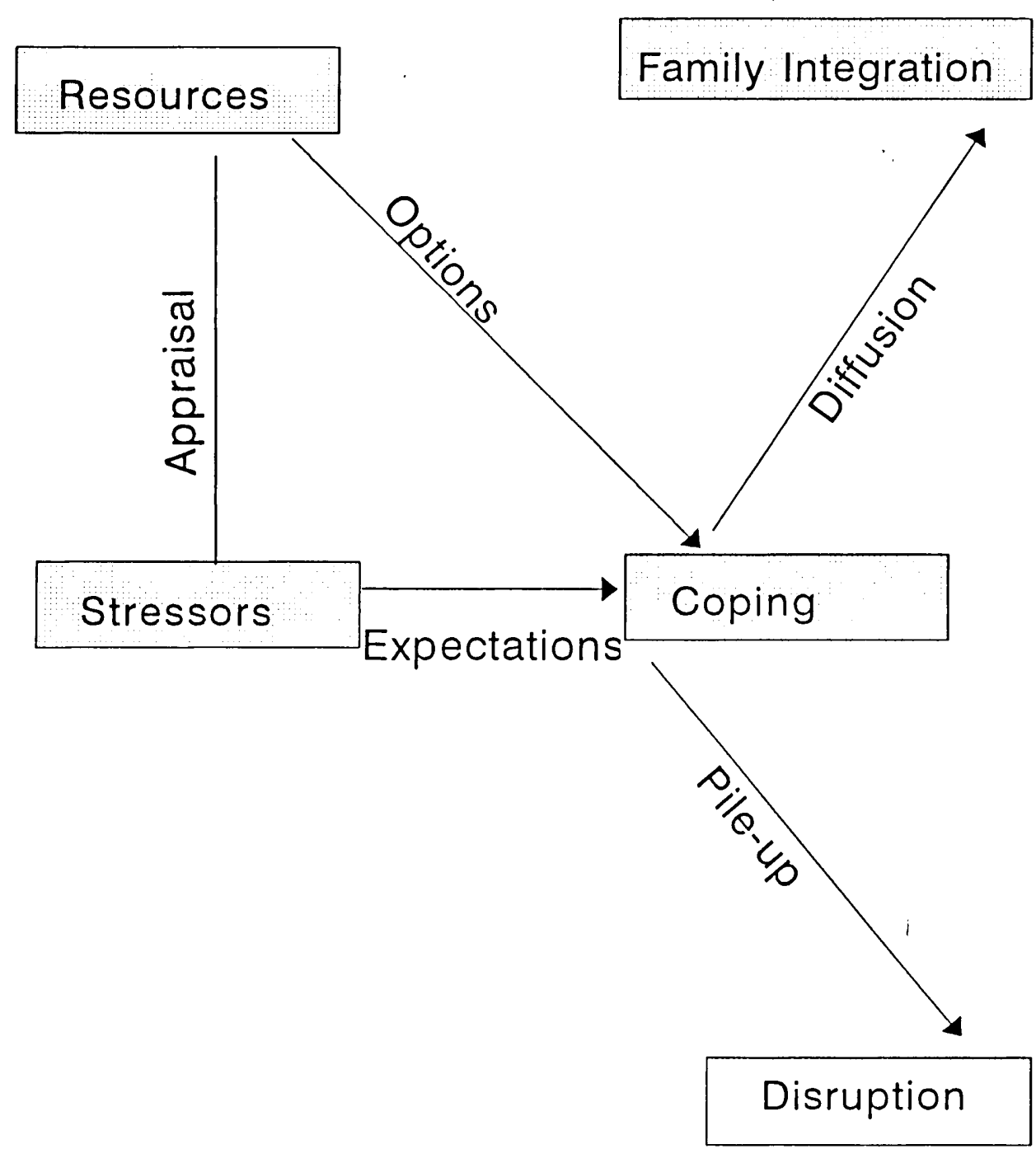


cognitive perspective of the stressors and tasks related to adoption. In this model, they suggest that adoptive children and adoptive family members have tangible and intangible resources which influence their appraisal of stress they might be encountering. The appraisal of the resources will impact the family member's coping ability by increasing or decreasing the options that are perceived to be available. Additionally, the individuals' expectations of being able to handle stressors will impact on their coping efforts. The effectiveness of how well the stressors are coped with will determine if diffusion occurs and family integration is successful or if a pile-up of unresolved stressors occurs and disruption of the adoption results.

Figure 2 identifies the common stressors which may occur due to resource deficits for the adoptive child, parent and family; the developmental or transitional tasks facing the three actors involved; and the coping resources needed to reduce the stressors. The utility of this model is in its ability to assist in the design and delivery of services to adoptive families (Barth \& Berry, 1988). Barth and Berry (1988) agree with Kirk (1964) that adoptive families face more simultaneous and unique stressors than do nuclear families. There is also agreement that the unique process of adopting results in unconventional situations that allow the adoptive families to create norms and traditions of their own. Barth and 
Figure 2. Barth and Berry's Social and Cognitive Model of Adjustment to Adoption

Actor

Child

Parent

$\begin{array}{ll}\text { Parent } & \text { Misleading expecta- } \\ \text { tations } & \text { Instant parenthood } \\ & \text { Novelty of roles } \\ & \text { Finances } \\ \text { Lack of Social } \\ \text { support }\end{array}$
permanence
Stressors Misleading expecta- Separation tions based on: Lack of social skills Low capacity for attachment Behavioral deficits

Low sense of Low sense of selfefficacy

Lack of social support and loss Role establishment Develop- . . mental tasks

Role establishment Nurturance of marital relationship
Family

Lack of family
accord
Lack of societal
norms
Lack of agency
support

Role establishment Boundary establishment Integration Attachments
Coping resources

Consistent social worker Siblings Support from biological and/or previous foster parents Preparation visits, life book Support group

Realistic, accurate information about the child Supportive, strengthening placement process

Reasonable waiting period with consistent process milestones

Subsidies Consistent social worker Support group Referrals to schools, therapists, groups

Available yet non-intrusive agency support Skills training Postlegal services Support of extended family Family therapy sensitive to adoptive issues 
Berry's theory advocates that there is not a "normal" family interaction or individual behavior that will predict the success of an adoption.

According to Barth and Berry's framework, adoptive and blended families face a shortage of supportive resources due to the unconventional status of the family. The adoptive family's ability to mesh coping styles and behavior is a major determinant of the success and viability of the adoption. Further, the adoptive parents' ability to cope with the inherent stressors involved in adopting special needs children will be greatly impacted by their expectations regarding their ability to parent (Barth \& Berry, 1988).

The adoptive parents' stressors include misleading expectations, instant parenthood, novelty of roles, finances, and lack of social support. The transitional .tasks faced by adoptive parents are role establishment and nurturance of the marital relationship. The coping resources that adoptive parents find helpful include realistic, accurate information about the child; a supportive, strengthening placement process through agency preparation prior to placement and availability during the time of placement and postplacement; reasonable waiting period with consistent process milestones; subsidies; a consistent social worker; support group; and referrals to schools, therapists, and groups (Barth \& Berry, 1988). 
The adoptive child is faced with previous life experiences in foster care and with the biological families, as well as stressors and resource deficits that nonadopted children do not encounter. The unique situations that face an adoptive child affect the child's current expectations and cognitive and behavioral responses to stress. The stressors include misleading expectations based on: lack of social skills, low capacity for attachment, behavioral deficits, low sense of permanence, low sense of selfefficacy, and lack of social support. As the child moves from foster care to adoption, the child must face transitional tasks which include separation and loss, role establishment, and developmental tasks. The coping resources that are beneficial to the child include a consistent social worker, siblings, support from biological and/or previous foster parents, preparation visits, life ,book and support groups (Barth \& Berry, 1988).

The adoptive family as an entire system may also face stressors from the larger environment including lack of family accord, lack of societal norms, and lack of agency support. The adoption agency is usually present in the early stages of adoption placement, but once finalized, the agency usually has no more contact. Often the family feels deserted and in need of support and/or resources. According to Barth and Berry, the adoption agency is the social institution of most importance during the transition and 
should consider the transition as an ongoing process and not just until finalization. Transitional tasks faced by the family include role and boundary establishment, integration, and attachment. The coping resources that have been found to be helpful include available yet nonintrusive agency support, skills training, postlegal services, support of extended families, and family therapy sensitive to adoption issues (Barth and Berry, 1988).

Based upon the professional literature of special needs adoptive families, a hypothesized relationship between variables was developed for this research study in order to examine the relevant relationships between conceptually and empirically related variables. Figure 3 illustrates the hypothesized relationship of the variables for this study.

The antecedent variables for the adoptive parent include the demographic factors of age, educational level, marital status, religious activities, employment, income, and the number of biological children. The antecedent variables for the adoptive child include speciall need classification, sex, race, sibling relationship, and intraracial placement. The antecedent variables impact on the use of and need for postplacement services, on the intervening variables and on the dependent variables.

The intervention or independent variable being used is postplacement services. The success of postplacement 
Figure 3: Conceptual Framework

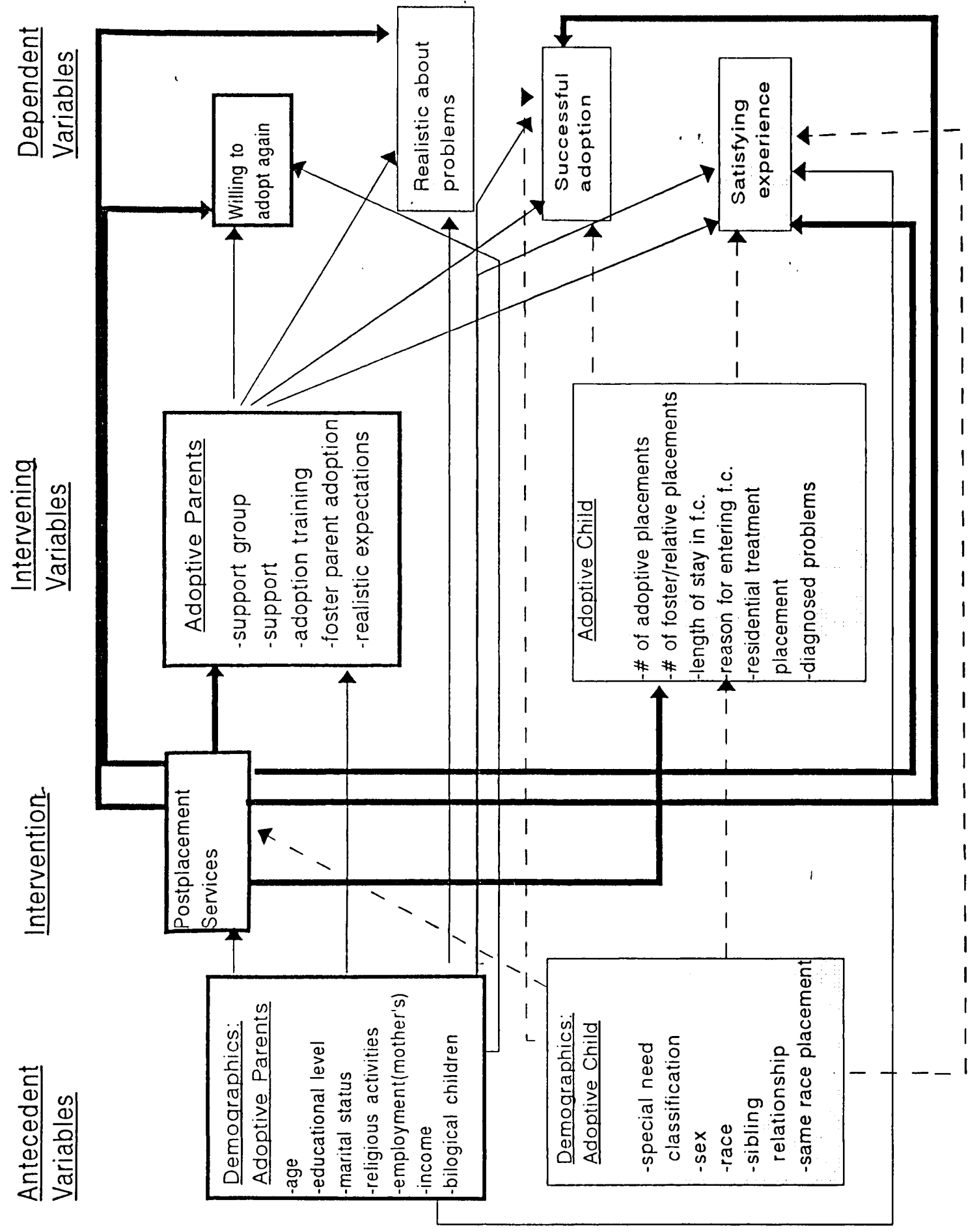


services should be designed to directly affect the dependent variables.

Intervening variables are used to help interpret the relationship between the intervention and the dependent variables. Intervening variables for the adoptive parents include support group, support, adoption training, foster parent adoption, and realistic expectations. The intervening variables for the adoptive child are number of adoptive and foster/relative placements, length of stay in foster care, reason for entering foster care, residential treatment placement, and diagnosed problems. The intervening variables are impacted by the antecedent variables and have a direct impact on the dependent variables.

Dependent variables include "successful adoption", a "satisfying adoption experience", "willing to adopt again" and "realistic about problems they would encounter". Implications for Social Welfare

Every child has the right to a permanent and stable home. Adoption of special needs children is one component of the interwoven programs within the child welfare system. Adoption is a life-long process that does not end at the point of legal finalization. Rather, the adoptive family continues to bond and formulate a new nuclear family which often needs services indefinitely. 
Special needs adoptions are increasing steadily and have become the most viable solution for the thousands of children who cannot be returned home and are languishing in foster care. According to Barth and Berry (1988), "older child adoption has become arguably the most essential component of the successful child welfare services" (p. 3). There are numerous implications for the social work profession to better understand the need for and effectiveness of postplacement services. First, with the foster care population on the rise, it is a natural outcome that special needs adoptions will continue to increase (Cole, 1995). The timeliness of intervention research is needed due to the ever increasing numbers of special needs children being placed for adoption. Second, practical necessity mandates that the social work profession address the life-long problems that adoptive families may have with "appropriate service intervention. If left untreated, the problems could conceivably result in an adoption disruption or dissolution (APWA, 1991a). Third, it is cost effective to have children adopted rather than remain in the highly dysfunctional and expensive foster care system (Barth \& Berry, 1988; Office of Inspector General, 1988; Sedlak \& Broadhurst, 1993). Postplacement resources are a more appropriate use of public funds rather than either keeping or returning a child to the foster care system. Fourth, there is an ethical responsibility to protect the 
psychological well-being of a child who has already been victimized by providing appropriate services (Ashton, 1994). As an ethical matter, the state adoption agency has a responsibility to help support and assist in resolving problems which promoted the adoption of, the special need child. If the agency did not support the placement and provide services when needed, it would be tantamount to emotional, financial, and environmental abandonment over stresses that the family has very little or no control to resolve (APWA, 1991a).

Empirical intervention research is in its infancy related to special needs adoption. The professional literature abounds with details regarding the need for intervention research on postplacement interventions. Rushton (1989) describes the need for research to determine which interventions are the most effective in maintaining adoptive placements. McDonald, Lieberman, Partridge, and Hornby (1991) relate that prior adoption research focused on characteristics of the child, the adoptive family, and agency practices. However, they state that research that evaluates the relative impact of specific services and interventions would be more useful.

According to Marcenko and Smith (1991), little is known about the services families receive and what they perceive to be their greatest need. Therefore, the area of the impact of postadoption services and supports on adoption 
outcomes is an area that these authors feel further research is warranted.

If children are our future, then inherent in the focus of the social work profession is the necessity to ensure that all children are provided with a stable nurturing family, whenever possible. The social work profession must provide a continuum of services aimed at strengthening and supporting special needs adoptive families throughout all stages of the family life cycle. To that end, the social work profession must conduct research to determine what services are needed to ensure stability and nurturance for special needs children and the families that adopt them. Barth, Berry, Yoshikami, Goodfield and Carson (1988) summarized the need for intervention research on special needs adoptions best when they stated "when older child adoptions succeed they may be the most complete and "beneficial intervention in all the human services" (p. 233 ). Purpose of the study

The design of the study is a survey to examine special needs adoptive parents' service needs and usage, and the relative influence of possible determinants of parents' perceived adoption experiences and outcomes.

The primary purpose of the proposed study is to conduct descriptive research on special needs adoptive children and their adoptive families regarding basic demographic variables. The secondary purpose of the study. is to conduct 
exploratory research to provide a beginning understanding of the adoption experiences of special needs families. Third, the research will identify and assess the relationship of empirically and conceptually relevant variables regarding special needs children and their adoptive families' characteristics, background, adoptive experiences and service utilization to postplacement adoption successes. Finally, the study will generate recommendations for further study on postplacement services for special needs adoptive families.

Plan of the Report

Chapter one of the dissertation presents an introduction and background to special needs adoption and postplacement services as well as the rationale and significance of the study. Relevant conceptual theories and a hypothesized relationship of variables created by this "author are provided.

Chapter two reviews the major research studies of special needs adoptions, adoption disruption, and postplacement services. Information is provided to demonstrate and clarify the relationship between this study's relevance and previous work conducted on the topic. The research questions and hypotheses tested in this study are presented.

The research methodology is delineated in Chapter three. Information discussed includes the study population 
and sampling procedures, variables, design and instrumentation, and procedures for data collection and analysis.

Chapter four presents the findings related to the study's research questions and hypotheses. This chapter includes demographic characteristics of the adoptive children and adoptive parents and descriptive and quantitative information related to postplacement service need, utilization, and satisfaction as well as impediments to service utilization. The data are statistically analyzed to determine the relationship between the variables. The statistical analyses include frequencies, measures of central tendency, correlations, multiple regression, and anova.

Chapter five includes an overview of the significant findings. Limitations of the study and implications for social welfare and for future research are outlined. 
Chapter 2

Literature Review

Special Needs Adoptions

Statistics.

There is a paucity of statistical information in the professional literature regarding the numbers of special needs adoptions. Cole (1987) states that statistical data on adoptions are basically nonexistent, outdated, or unreliable. As a result of the lack of local, state and national statistics on foster care and adoptions, the Inspector General's (1988) office acknowledges that effective planning and management of foster care and adoption programs is hampered.

There is no standardized method for counting adoption statistics at the state or federal levels. Therefore, differences in the numbers of adoptions reported can be attributed to the different sources of information such as vital statistics, agency reports, or petitions for adoptions finalized by the courts (Flango and Flango, 19'93).

According to Vick (1995), the United States cannot report with any degree of validation the number of children in foster care or adoptive placements, or the effectiveness of child protection and permanency planning efforts. Therefore, the literature provides different estimates on the number of special needs children in foster care waiting for adoption. 
Barth (1991) states that approximately 20,000 older child adoptions take place each year. He further estimates that the total number of special needs adoptions exceeds 200,000 .

Children have been found to remain in foster care an average of 3.5 to 5.5 years with a goal of adoption (Office of Inspector General, 1991). Grabe (1990) asserts that adoption is the best possible alternative to the impermanence of the foster care system.

The Inspector General (1991) estimates that for fiscal year 1986,138 of the children in foster care had an identified goal of adoption which compares to an estimate of 108 by the National Council for Adoption (1995). Kroll (1995) states that there are approximately 500,000 foster children and of that number, approximately 27,000 are legally free for adoption and another 49,000 have a goal of adoption but parental rights have not been terminated. This statistic has remained stable through 1995 when it is postulated that between 118 and 148 of children' in out of home care will be placed for adoption (Cole, 1995). Barth (1991) figures that a maximum of $15 \%$ of children in foster care who will not be returned home will eventually be adopted. In comparison, Brooks (1991) posits that of the 36,000 special needs children waiting for adoption, $33 \%$ will be placed for adoption in any given year. These figures contrast with the $5 \%$ of children, ages infant to twelve 
years, who were placed for adoption in Fanshel's (1978) classic five year longitudinal study of 624 children who entered foster care in 1966 in New York City.

In 1988, the Interagency Task Force on Adoption was formed by President Reagan and found that $60 \%$ of the children nationally waiting for adoption were classified as special needs children and $43 \%$ of these were minority children (Interagency Task Force, 1988). Brooks (1991) confirms the estimate that $60 \%$ of all children available for adoption are considered special needs.

The National Council for Adoption (1995) found a disproportionate number of minority children in foster care and adoption. This organization reports that although African American children constitute approximately 148 of the United States child population, they represent $30 \%$ of the children in foster care and $38 \%$ of the children waiting for adoptive placement.

Florida has a $21 \%$ higher minority population awaiting adoptive placement as compared to the national data from the National Council for Adoption (1995). Of the children placed for adoption in Florida in 1993-94, 448 were minority while an exceptionally higher figure of 598 of the children awaiting adoptive placement were minority (Health and Rehabilitative Services [HRS], 1994).

The Florida Department of Health and Rehabilitative Services [HRS] has reduced the foster care population by 128 
since 1991 due to aggressive permanency planning efforts. HRS increased adoptive placements of special needs children in a two-year period by 238 , placing 1,310 children in 199394 and 1,622 in 1994-95 (Chiles, 1995).

Statistics as of August 31, 1995 provided by HRS (1995) show that there are 7,303 children in foster care. Of that number, there are 1,697 (23.28) children whose parental rights have been terminated and for whom adoption is the active case plan. The majority (55.88) of the 1,697 children waiting for adoption placement are African American whereas African American children account for only $24 \%$ of Florida's total population. White children represent $35.2 \%$ of the children waiting for placement. The age breakdown for the same 1,697 children reveals that $32.7 \%$ of the children are five years old or under and 828 are 12 years or younger (See Table 1). Of the 1,697 children who have adoption as the active plan, 1,283 (75.68) have been waiting for an adoptive placement for 90 days or more (HRS, 1995; One Church, 1995).

\section{Cost savings.}

There is a significant cost benefit of placing a child in an adoptive home versus remaining in foster care (Barth \& Berry, 1988; Office of Inspector General, 1988; Sedlak \& Broadhurst, 1993). Research conducted in 11 states found that adoptions resulted in a 448 savings compared to foster care costs (Office of Inspector General, 1988). 
Table 1

Children in Florida Waiting for Adoptive Placement ( $N=$ $\underline{1,697)}$

Characteristic

$\mathrm{N}$

( 8 )

Race-Ethnicity

White

599

35.2

Black

947

55.8

White Hispanic

75

4.4

Black Hispanic

9

.5

Biracial

56

3.2

Other

11

.6

Age Categories

0-5 Years

555

32.7

6-12 Years

843

49.6

13-15 Years

265

15.6

. 16 and Over

34

2.0 
In a study conducted for the U.S. Department of Health and Human Services' Children's Bureau, Sedlak and Broadhurst (1993) estimated that between 1983 and 1987, 40,700 special needs children were placed from foster care into adoptive homes with subsidy. They, report that 1.6 billion federal and state dollars will be saved by placing these 40,700 children in subsidized adoptive homes rather than keeping them in foster care. The staggering costs savings of adoption compared to foster care are due to service and administrative costs that are not necessary with adoptive placements such as service referrals, preparation for and participation in judicial reviews, placement costs, case planning, case management, and licensing and recruiting foster homes (Gilles, 1995).

According to Edna McConnell (1991), the median annual cost of family foster care for one child is $\$ 17,500$. For one year in an institutional setting the cost per child could reach up to $\$ 100,000$. The state of Florida Outcome Evaluation Report completed by HRS (1992) reported that the cost per child for adoptive supervision was $\$ 11,498$. This cost of supervision is stopped once the adoption is finalized and the only on-going cost would be an adoption subsidy, if approved. In Broward County, the average monthly maintenance adoption subsidy is less than $\$ 300$ per child (HRS, 1995). 


\section{Paradigm and practice shifts.}

Adoptions have changed drastically from a practice of only placing healthy white infants with white married couples to adoption of older, minority, and handicapped children with married couples, foster parents and single parents (Cole \& Donley, 1990; Feigelman \& Silverman, 1983; McDonald et al., 1991). Panacek-Howell (1993) identifies the following variables as reasons for changing adoption practices and the increase of special needs children needing placements: the number of children coming into the child welfare system who eventually end up in foster care and then move on to adoption; the increase in crack cocaine usage which has resulted in the increase of newborns coming into foster care with medical complications; children coming into care with increasingly complex medical and emotional problems; the increase of children coming into care with the HIV virus or AIDS; and changing policies over keeping siblings together and transracial placements.

Since the 1960s, social and family changes' in five areas have impacted current adoption practices: diminishing fertility and family size; the postponement of marriages; the pattern of increasing divorce and the growing social acceptability of single-parent families; expanded availability of family welfare programs and greater tolerance of nontraditional family life-styles; and the extension of greater legal rights to children (Feigelman \& 
Silverman, 1983). Adoption practices have changed in the areas of eligibility, matching, recruitment, and postplacement services (Barth \& Berry, 1988).

Previous prohibitions regarding foster parents adopting, which were based on ideology and not research, have changed so that adoption by foster parents has become a legally and psychologically sanctioned practice (Proch, 1981). Perceptions by foster and adoptive parents verified the belief that distinctions were blurred between foster care and adoptions, two services that had previously been thought of as distinct (Proch, 1982). Similarly, Proch (1980) found that children who were adopted by their foster parents did not distinguish between foster care status and adoptive status.

The majority of special needs adoptions have become foster parent adoptions. Judith Anderson (1990) found approximately 608 of all special needs adoptions in this country are foster parent adoptions. The office of Inspector General (1988) conducted research in five metropolitan cities to examine agency practices to increase the rate of minority adoptions. They found a range of $40 \%$ to $80 \%$ of all minority adoptions were with foster parents with an average of 618. Barth and Berry (1988) report that 688 of older special needs adoptive families fostered their adoptive child and had a successful placement rate of $94 \%$. 
In 1984, the Office of Inspector General (1988) found 14 of 17 states had a foster parent adoption rate of over 508. By 1988 the percentage increased to 618 with a range from 408 to 808 .

The rate of children entering the foster care system remained stable for two years following passage of the Adoption Assistance and Child Welfare Act (Adoption Assistance, 1980). From 1982 through 1986, there was a 78 increase in the substitute care population. However, in the ten year period from 1982 to 1992, the substitute care population grew an astounding 152\%. In 1982 there were 262,000 children in substitute care and the estimated number of children served in substitute care during 1992 was 659,000 (Tatara, 1993).

By the year 2000, Cole (1995) projects that one million children will be in foster care. Therefore, as the foster care population increases, the result is an increase in the numbers of children who become available for adoption (Cole, $1995)$.

The increase in children entering the foster care system has been coupled with the problems of the children entering care being more severe than in the past due to increased severity of abuse and the impact of drug use on the children entering care. Recent trends also reveal that more sibling groups, children with multiple placements, and children with greater educational and mental health problems 
are being placed in foster care (Judith Anderson, 1990). Children are now entering the foster care system with severe emotional, psychological, behavioral, and medical conditions. In fact, in an analysis of family surveys of adoptive placements after 1990, Gilles.(1995) found that $80 \%$ of adoptees had special needs and of that number, 578 had multiple special needs.

Sedlak and Broadhurst (1993) completed an extensive case record analysis of a nationally representative sample of 2,200 children who had been adopted during the period 1983 to 1987. They found that of the estimated 69,900 children adopted nationally through public agencies, $52 \%$ were male and $48 \%$ female. White children accounted for $57 \%$ of the sample, African Americans for 298, 118 were Hispanic, and a negligible amount were of other races. Over 258 had clinically diagnosed handicaps or disabling conditions at the time of adoption. The parents revealed that $43 \%$ of the children had psychological, emotional or behavioral problems, 308 had mental limitations or learning problems, 308 had educational delays and $22 \%$ had special medical needs .

Prior to adoptive placement, the children experienced wide ranges of neglect and abuse. Sixty percent of the children experienced emotional neglect, $57 \%$ experienced physical neglect, $38 \%$ experienced physical abuse, and $36 \%$ 
had a prior need for health care (Sedlak \& Broadhurst, $1993)$.

A summary of the adoptive parents in Sedlak and Broadhurst's (1993) study found that 428 were either foster parents or a relative to the child they adopted, $84 \%$ were married or living with a partner at the time of placement, and the age ranged from 31 to 78 years with the majority being in the forties. Sixty-nine of the respondents and $77 \%$ of their spouses were white and 928 were the same race/ethnic background as the adoptive child.

The current difficulty in understanding adoption of special needs children is complicated by numerous factors. The high value Americans have placed on the traditional nuclear biological family has been a primary value that has shaped adoption in this country. Anything short of biologically-related families has often been considered a second choice for family constellation (Hartman \& Laird, 1990). Some families resent any interference by the social service system and prefer that agencies do not intrude on their family's affair (Rosenthal \& Groze, 1992). Additionally, the perceived need for secrecy regarding adoption issues and records has been an obstacle in conducting research on adoptions (Unger et al, 1988). Finally, for many years adoption professionals did not recognize the need for or provide postplacement supportive services because the professionals failed to recognize the 
central importance of adoption in the lives of the adoptive child and family.

Most of the early professional literature related to adoptions has focused on the primary areas of separation from caregiver, institutionalization, and maternal deprivation. For this reason, the majority of the early literature dealt with the prevalence and incidence of adoptees in clinical settings (Brodzinsky \& Schechter, $1990)$.

\section{Adoption outcomes.}

Most adoption outcome research is descriptive in nature and does not utilize control groups or large samples. Further, the majority of studies do not use objective or standardized techniques (Joe, 1979).

The definition for successful adoption outcome is different in all studies; however, Hoopes (1990) found an pverall 708 success rate in the literature. Rosenthal, Groze and Curiel (1990) conducted research on approximately 800 special needs families and found that 758 felt that the adoption outcome was mostly positive or very positive. This compares with a $87 \%$ success rate for special needs adoptions in a five state research project aimed at identifying factors which may lead to disruption (Urban Systems, 1985). The success of an adoption is a subjective determination based upon an individual's personal feeling. Kornitzer (1968) operationalized whether an adoption was 
successful by determining whether or not a family relationship is formed. Plumez (1982) defines success by the number of disruptions that occur. Hoopes (1990) defines success when an adoptive child demonstrates functioning within the normal range in both cognitive and emotional areas. Hartman (1984) contends that the adoptive family's ability to support the child's attachment to kin and previous foster parents is a significant variable in the success of the adoptive placement.

Rosenthal and Groze (1992) conducted research on 799 intact special needs families in Oklahoma, Illinois, and Kansas. They were unable to identify one factor that compellingly predicts a successful adoption experience.

Katz (1986) found 9 characteristics that are necessary for families adopting older children to have for successful outcomes: (1) a tolerance for one's own ambivalence and/or strong negative feelings; (2) a refusal to be rejected by the child and an ability to successfully delay gratification of parental needs; ( 3 ) the ability to find happiness in small increments of improvement; (4) parental role flexibility; (5) systems view of their family; (6) firm entitlement; (7) intrusive and controlling qualities; (8) humor and self-care; and (9) open versus closed family system. According to the author, although many of these qualities are innate in families, these qualities hold important implications for adoption placement practices. 
Sedlak and Broadhurst (1993) interviewed and conducted self administered questionnaires with 480 adopted children and parents of 306 adopted children. They found positive adoption outcomes for the adopted child, for the childfamily relationship, for the other children in the family, and for the family in general. They also found a large variance in adoptive families' views of the adoption process with most being happy with the process and having a positive outcome. Regardless of a positive or negative view, three themes were identified by the researchers: the parent's belief in adoption, their commitment to making the system work better, and their deep love for their children. The majority of parents stated they would adopt their child over again if given the opportunity.

Barth and Berry (1988) found that 948 of foster parents and $90 \%$ of all special needs adoptions have overall successful outcomes. In their study of disrupted adolescent adoptees, Berry and Barth (1990) found four predictors of successful adoptions. These predictors of success include foster parent adoption, adoptive parents being ageappropriate in relation to the child, the presence of other foster children in the home, and receipt of adoption subsidies that are sufficient to cover the child's and family's needs. Rosenthal, Schmidt, and Conner (1988) studied intact successful adoptive families and found that the factors of minority ethnic status, lower socioeconomic 
status and lower educational levels of the adoptive parents were associated with positive outcomes. The literature suggests that these characteristics are often found in families who do not have unrealistic expectations of the adoptive child and therefore may be more, likely to have more positive outcomes.

In a follow-up study of 100 families who adopted children between the ages of infant to three years, Jaffee and Fanshel (1970) postulated it was not appropriate to determine the totality of a life or adoption experience as being successful or unsuccessful. They chose instead to measure success based upon the adoptee's adjustment in 11 different areas of the adoptee's life such as social behavior, emotional pathology, quality of family relationships, etc.

In relation to adoptive parents' satisfaction with the adoption experience, Jaffee and Fanshel (1970) found that satisfaction was correlated with the degree of the child's problems. None of the adoptive parents of low to middle range problem adoptees expressed extreme dissatisfaction with the adoption experience, while extreme dissatisfaction was expressed by 378 of the parents of high-problem adoptees. Further, moderate dissatisfaction was experienced by 98 of the parents of low to middle range problem adoptees and by $24 \%$ of the parents of high-problem adoptees. 
Kadushin (1967) examined the child's personality, temperament, and disposition, in addition to the child's relationship to extended family to determine parental satisfaction. Parental dissatisfaction with the adoption was found to be predicted by the child's, poor adjustment to the adoptive placement (Kadushin, 1980).

Nelson (1985) studied 177 intact special needs families from 3 large urban areas who had adopted a total of 244 children. One aspect of the study was to determine predictors of adoptive parents' satisfaction which were reported to include the child being attached to family and peers, adequacy of agency information about the child, and the child having no previous adoptive placements. She found that $73 \%$ of the families expressed satisfaction with their adoption experience.

Nelson (1985) identified the child's psychological or social isolation from the family and peers as the biggest predictor of the adoptive family's dissatisfaction with the adoption experience. Also linked to decreased parental satisfaction was the inability to obtain needed postplacement services, usually counseling or special educational services.

Parental satisfaction with adopting a special needs child was rated highly by $75 \%$ or higher of the sample in studies (Kadushin, 1970; Rosenthal \& Groze, 1992). 
Therefore, the parental satisfaction and adoption success data tend to be similar.

While examining minority adoptions, the office of Inspector General (1988) found that 898 of the minority waiting and adoptive families were satisfied with the last agency that were associated with. However, they were not necessarily satisfied with their involvement with previous agencies.

Unger et al. (1988) researched families who had already adopted special needs children and found that $43 \%$ indicated they would not adopt another special needs child. The primary reason for adopting the special needs child was that some type of strong emotional tie, often through fostering the child, had developed. Therefore, the authors suggest that it is critical to provide an opportunity for potential adoptive families to develop some form of attachment to the adoptive child.

The North American Council on Adoptable Children (1990) reported on the outcome of the Adoption Assistance and Child Welfare Act ten years after it was passed and its impact on providing support and services to adoptive families. They found that although the Act had good intentions and has positively impacted children in the child welfare system, there are still serious concerns regarding the contents, implementation, funding, and effectiveness of the Act. 
Outcome studies for older child adoptions are sparse but generally favorable results have been reported (Barth \& Berry, 1990). In reviewing the literature related to adoption outcome studies, Barth and Berry state that the consensus is that adoption has positive effects on development of most children in the child welfare system. Adoption Disruption

\section{Introduction.}

Adoption disruption was not mentioned in the professional literature until 1965 (Cohen \& Westhues, 1990) mainly because disruption and dissolutions occurred so infrequently (Festinger, 1990). The first significant review of adoption research occurred in 1971 by Kadushin and Seidl. Prior to that time, the research only examined disruption rates of nonspecial needs children which resulted in low rates. Although foster care placements were often unsuccessful and children had to be replaced into new foster homes, adoption disruptions were initially contrary to the social worker's professional practice and expectation of adoption placements being a forever home (Unger, Dwarshuis, \& Johnson, 1983).

Adoption disruption is now seen as an inevitable aspect of the adoption placement process (Unger et al., 1983). With the change in philosophy and adoption practices toward the increased push for adoptive placements of older and special needs children, it is only obvious that the 
disruption rate has been found to increase (Barth \& Berry, 1988; Berry \& Barth, 1990; Feigelman \& Silverman, 1983; McDonald et al., 1991; Rosenthal et al., 1988). The evident increase in disruption documented in the literature exists in spite of numerous research methodological problems and differences in operationalizing terms used in the literature (Festinger, 1990).

\section{Rates.}

A review of the professional literature reveals that adoption disruptions range from a low of 78 for younger children (Berry \& Barth, 1990) to a high of $47 \%$ for older and special needs children (Barth \& Berry, 1988). In her literature review of disruptions, Festinger (1986) reports studies in which the disruption rate ranged from a low of 1.98 in 1970 to a high of 538 in 1983 for older special needs youth with severe emotional and learning problems. Urban Systems (1985) found a range of disruption rates from 78 to 208 with an average of $13 \%$. According to Barth and Berry (1988), the current disruption rate among older children is estimated to be somewhere between 48 and $40 \%$.

Festinger (1986) conducted research on 897 adopted children with an average age of 10.2 years. She examined disruption rates within the first 12 months of adoptive placement and then again during the second and third years following placement. Results indicated that disruptions occurred more frequently during the first twelve months of 
placement. The disruption rate was 8.28 during the first year and during the next 2 years, a small steady rate of disruptions occurred with an overall rate of disruption between 128 and $14 \%$.

Methodological differences in systematic reporting, collecting data and defining special needs children and disruptions make comparisons of studies and rates difficult (Barth \& Berry, 1990; Urban Systems, 1985). Routinely, disruption statistics do not include unofficial disruptions where the child's placement out of the home (with a relative, friend, runaway or residential placement) is not reported to any agency.

Caution must be used when examining and comparing disruption rates historically due to the increased placements of more special needs children with extensive behavioral, medical and emotional problems (Levine \& Salles, (1990). These authors warn that an increase in adoption disruption rates is predicted due to the older ages and special needs of adoptive children and the lack of follow-up services to adoptive families.

Festinger (1990) emphasizes that one of the problems inherent in the disruption studies conducted is that crosssectional research includes placements at any one point in time and compares new placements and children who have been in their placements for a long period of time. The comparisons do not include children who were previously in 
an adoptive placement when the latter group was placed but are not in an adoptive placement at the time of the current research. Cohen and Westhues (1990) emphasize the need to not only look at the numbers of disrupted adoptions, but to also examine the numbers of successful adoptions that would not have been made in the past due to agencies not taking risks placing special needs adoptive children.

\section{Predictors and Correlates.}

In addition to examining disruption rates, much of the literature on special needs adoption focuses on predictors or correlates of disruption. The contradictory findings in the literature regarding predictors of disruption is continued evidence that comparisons must be viewed with caution when examining the research. Rosenthal et al. (1988) warn that adoption disruptions are complex and not easily accessible to quantitative methods.

$\therefore$ Numerous situations have been listed as being

predictors of disruption. Three types of problem situations that can occur which have a high potential to result in an adoption disruption are unrecognized pre-existing problems, pre-existing problems that are known but left unexplored, and unpredictable problems which occur after placement (Unger et al., 1983).

Studies relating to special needs adoption have found strong correlations between higher disruption rates and increased age of the child (Barth, 1988; Barth \& Berry, 
1988; Barth et al., 1988; Benton, Kaye \& Tipton, 1985; Boneh, 1979; Boyne, Denby, Kettenring, \& Wheeler, 1984; Coyne \& Brown, 1985; Feigelman \& Silverman, 1983; Festinger, 1986; Groze, 1986; Kadushin \& Seidl, 1971; Nelson, 1985; Partridge, Hornby \& McDonald, 1986; Rosenthal et al., 1988; Schmidt, 1986; Urban Systems, 1985; Zwimpfer, 1983). In their study, Urban Systems found that children, ages 12 through 17, represented 118 of the total placements in their sample, but $36 \%$ of the disruptions.

The effect of gender as a correlate of disruption has contradictory findings in the literature. Boys were found to have higher rates of disruption in some studies (Barth \& Berry, 1988; Boneh, 1979; McDonald et al., 1991; Nelson, 1985; Rosenthal et. al, 1988; Sack \& Dale, 1982; Schmidt, 1986) while no statistically significant difference in gender was found in other studies (Benton et al., 1985; Boyne et al., 1984; Coyne \& Brown, 1985; Festinger, 1986; Kadushin \& Seidl, 1971; Partridge, et al., 1986; Urban Systems, 1985; Zwimpfer, 1983).

Research findings regarding race as a correlate of disruption are not in agreement. Two studies show a moderately reduced risk of disruption for minorities (Rosenthal et. al., 1988; Urban Systems, 1985) while Zwimpfer (1983) found a higher disruption rate for minority children. The majority of studies found no correlation between race of the child and likelihood of disruption 
(Barth \& Berry, 1988; Benton et al., 1985; Boneh, 1979; Boyne et al., 1984; Coyne \& Brown, 1985; Festinger, 1986; McDonald et al., 1991; Partridge et al., 1986; Rosenthal \& Groze, 1992).

Studies have consistently shown that the number of placements in foster and/or group homes and previous adoption disruptions are predictors of disruptions. The more foster care and/or group care placements a child has prior to adoptive placement, the more likely the adoption is to disrupt (Barth, 1988; Barth \& Berry, 1988; Barth et al., 1986; Barth et al., 1988; Boneh, 1979; Boyne et al., 1984; Festinger, 1986; Groze, 1986; Nelson, 1985; Partridge et al., 1986; Schmidt, 1986).

The presence and severity of behavioral and/or emotional problems was strongly linked with higher disruption rates (Barth, 1988; Barth \& Berry, 1988; Barth et .al., 1988; Benton et al., 1985; Boneh, 1979; Boyne et al., 1984; Festinger, 1986; Kadushin \& Seidl, 1971; Kagan \& Reid, 1986; Partridge et al., 1986; Rosenthal \& Groze', 1992; Rosenthal et. al, 1988; Sack \& Dale, 1982; Schmidt, 1986). A higher disruption rate was found for children with emotional handicaps but not for children with physical handicaps (Urban Systems, 1985).

Emotional and behavioral problems may be the rule rather than the exception for older child adoptions due to the youngster's history of family trauma and foster home 
placements (Berry \& Barth, 1990). Grabe (1990) identifies the children who have spent years in impermanent family settings such as foster homes as "system kids" and reports that these children often suffer from improper attachment, lack of attention to grieving needs, developmental delays, and a host of other emotional and developmental problems. Urban Systems (1985) identified that 198 of the older children placed for adoption had emotional problems yet they accounted for 398 of the disrupted placements. Barth and Berry (1988) state that 528 of adoptive children in their study had known emotional or behavioral problems at the time of adoptive placement.

Other forms of disabilities have been linked to higher disruption rates. Physical or developmental disabilities of adoptive children were found to be higher predictors of disruption in four studies (Boneh, 1979; Nelson, 1986; Rosenthal \& Groze, 1992; Rosenthal et al., 1988).

There are contradictory findings regarding the overrepresentation of adoptees seeking clinical' services (Brinich \& Brinich, 1982). Disruptions have proven in some studies to be deleterious for children who have experienced an adoption (Sack \& Dale, 1982; Schmidt, Rosenthal \& Bombeck, 1988). In contrast, Brinich and Brinich (1982) found a slight (2.8\%) overrepresentation of adoptive children seeking psychiatric services; however, there were 
less than expected $(.68)$ adult adoptees seeking psychiatric treatment.

The literature on predictors of disruption when adoptive children are placed with their siblings is contradictory. Five studies (Benton et. al, 1985; Boneh, 1979; Kadushin \& Seidl, 1971; Nelson, 1986; Urban Systems, 1985) found a higher disruption rate when siblings were placed together. Urban systems found that children placed with siblings represented 208 of their placements, but $43 \%$ of the disruptions. Three studies report a low disruption rate when siblings are placed together (Festinger, 1986; Rosenthal et al., 1988 for the Colorado sample; Schmidt, 1986). Four studies show sibling placement is not related to disruption (Barth \& Berry, 1988; Boyne et al., 1984; Groze, 1986; Rosenthal et al., 1988 for Oklahoma sample). In a study of 235 adoptions that ended in disruption, . variables that predicted disruption were found more often in variables related to the child rather than family or agency variables (McDonald et al., 1991). This supports the findings of Howard and Smith (1994) who found that 958 of cases referred to a voluntary program for postplacement services in Illinois were due to child related behavior and/or mental health problems. Howe (1988) found that $88 \%$ of cases referred for postadoption services involved problems related to the adoptive child's behavior. In contrast, Rosenthal et al. (1988) found that the adoptive 
family rather than the adoptive child's characteristics were more closely associated with disruption. Meezan and Shireman (1982) propose that in all special needs adoption disruptions, the problem can be traced back to questionable assessment of the family and child by the social worker.

Several authors highlight the importance to an adoptive family of having a stable working relationship with one adoption agency. Multiple agency involvement was found to be a predictor of disruption in three studies (Barth \& Berry, 1988; Boneh, 1979; Rosenthal et al., 1988).

A finding that has been replicated in numerous studies is the relationship between nonfoster parent adoptions and the failure of previous adoptive placements with higher disruption rates (Barth, 1988; Barth \& Berry, 1988; Barth et al., 1986; Boyne et al., 1984; Festinger, 1986; Groze, 1986; Meezan \& Shireman, 1982; Nelson, 1985; Partridge et al., 1986; Rosenthal et al., 1988). Barth and Berry (1988) suggest that one explanation for the lower disruption rates by foster parents is that foster parents who decide to adopt are more likely to pursue adoption if there has been a satisfactory adjustment to the placement.

The length of the current adoptive placement has an impact on the likelihood of disruption. A higher rate of disruption has been associated with recent adoptive placements (Barth, 1988; Coyne \& Brown, 1985; Festinger, 1986; Schmidt, 1986). 
Findings regarding the income of adoptive families are contradictory. Families with lower income levels had a lower rate of disruption in one study (Rosenthal et al., 1988) a higher rate in one study (Zwimpfer, 1983) and no effect in five studies (Benton et al, 1.9.85; Boyne et al, 1984; Partridge et al, 1986; Rosenthal \& Groze, 1992; Schmidt, 1986).

The race of adoptive parents show contradictory findings in relation to the predictability of disruption. Four studies found white families had a higher disruption rate (Berry \& Barth, 1990; Benton et al., 1985; Rosenthal et al., 1988; Urban Systems, 1985). Minority parents represented 258 of the sample in Urban System's research but only 88 of the disrupted placements. Minority families were found to have a higher disruption rate in two studies (Partridge et al., 1986; Zwimpfer, 1983). No relationship 'was found between adoptive parents' race and disruption in four studies (Boyne et al., 1984; Festinger, 1986; Kadushin \& Seidl, 1971; Schmidt, 1986). Transracial pla'cements were not related to a higher disruption rate (Boneh, 1979; Festinger, 1986; Partridge et al., 1986) which contrasts to a higher rate found by Zwimpfer (1983).

Contradictory results were found regarding the marital status of adoptive parents and the likelihood of disruption. Single parents had higher disruption rates in two studies (Boneh, 1979; Partridge, et al., 1986) while Feigelman and 
Shireman (1983) found lower rates with single parents. Marital status was not a factor in disruption in six studies (Barth \& Berry, 1988; Benton et al., 1985; Boyne et al., 1984, Festinger, 1986; Rosenthal \& Groze, 1992; Urban Systems, 1985). Westhues and Cohen (1990) found that the adoptive father played a pivotal role in maintaining successful placements.

Findings regarding the educational level of one or both parents in relation to predicting disruption were contradictory. Higher disruption rates were found for parents who had higher educational levels by five studies (Barth, 1988; Barth \& Berry, 1988; Festinger, 1986;

Rosenthal et al., 1988; Urban Systems, 1985). Festinger summarized that the high rate of adoptions by foster parents with lower levels of education may account for her findings. Seven studies found no correlation between adoptive parents' educational level and disruption (Benton et al., 1985; Boneh, 1979; Boyne et al., 1984; Festinger, 1986; Partridge et al., 1986; Rosenthal \& Groze, 1992; Schmidt,'1986). Adoptive parents' age had contradictory results. Two studies (Boneh, 1979; Kadushin \& Seidl, 1971) found older adoptive parents had higher disruption rates while four studies found older parents had lower disruption rates (Groze, 1986; Rosenthal et al., 1988; Urban Systems, 1985; Zwimpfer, 1983). Three studies show adoptive parents' age 
had no effect on disruption (Benton et al., 1985; Boyne et al, 1984; Festinger, 1986).

The presence of biological or other children in the adoptive home had mixed findings. Higher disruption rates were found when other children were in the home in two studies (Boneh, 1979; Kadushin \& Seidl, 1971), two studies showed lower disruption rates when other children were in the home (Barth \& Berry, 1988; Groze, 1986) while three studies showed no effect (Boyne et al., 1984; Festinger, 1986; Zwimpfer, 1983).

The level of religious affiliation was examined in two studies. Families who attended religious activities were found to have lower disruption rates (Barth \& Berry, 1988; Nelson, 1986).

The combined results from four studies suggest that families who are less flexible in relation to family rules, roles, and decision making have higher disruption rates (Boneh, 1979; Rosenthal \& Groze, 1992; Rosenthal et al., 1988; Sack \& Dale, 1982). Meezan and Shireman '(1982) suggest that disruptions are higher in families who have excessive expectations.

The lack of preparation or training prior to placement and a lack of sufficient background information on the child and the child's biological family has been found to increase disruptions (Barth \& Berry, 1988; Nelson, 1985; Schmidt et al. 1988; Urban Systems, 1985). When adoptive parents had 
unrealistic expectations of the adoptive child or unmet needs by the child, disruption was strongly predicted (Barth \& Berry, 1988; Festinger, 1986; Gill, 1978; Kadushin \& Seidl, 1971; Nelson, 1986; Partridge et al. 1986; Schmidt et al. 1988; Urban Systems, 1985).

Agency services were found to be too scanty and short and to have a minor effect in predicting the success of the adoption experience. However, in $58 \%$ of the disruptions, the agency did not become aware of the adoptive families' problems until 2 months or less prior to the disruption. The involvement of multiple agencies in the adoption process was found to be associated with higher disruption rates (Rosenthal et al., 1988).

Adoption subsidies were found to mitigate risk of disruption by Barth and Berry (1988) who determined that there was not a significant difference in disruption rates between special needs and nonspecial needs children when controlling for subsidies. They further found that there was a higher disruption rate for older than younger children in unsubsidized children compared to subsidized children. In their 1990 study of disrupted adolescents, Berry and Barth report a higher disruption rate for families receiving lower adoption subsidy payments. 


\section{Postplacement Services}

\section{Introduction.}

The Child Welfare League of America's Standards for Adoption Service (1988) describes adoption as a life long experience for the child, adoptive parents, and biological parents. Since adoption is a unique condition and a lifelong process, services must be continued for the duration of the placement and especially throughout the adolescent years (APWA, 1991a). Barth (1988) summarizes that the purpose of postplacement services is "to offer needed and desired assistance to the family and child, in both the development of the parent-child relationship and in the resolution of problems inherent in adoption" (p. 29).

Services for adoptive families, both postplacement and postfinalization, are an essential and critical component of the adoption process. Spenser (1985) advocates that reconceptualized postplacement services will improve positive outcomes for adoptive families. With the paradigm shift of placing special needs children and the resulting increase in adoption disruption rates, social service agencies have begun to realize that services to the adoptive child and family do not have to stop after placement or finalization of the adoption (Grabe \& Sim, 1990).

The need for postadoption services during the lifetime of the adoptive family is stressed by Judith Anderson (1990). She emphasizes that postplacement services need to 
be "available, accessible, timely, and appropriate, not just in theory but in active practice" (p. 46).

Gilles (1995) notes that one of the most dramatic trends in the current special needs adoption arena in the United States is the need for services to adoptive families and children once the adoption is finalized. Nonetheless, Gilles notes that dramatic gaps exist in postplacement service provision to special needs adoptive families.

LePere (1987) proposes that adoptive families are more vulnerable to encounter problems due to the way the family was formed. Levine and Salles (1990) conclude that the adjustment to adoption is highly taxing both emotionally and behaviorally for all members of the family. The need for postadoption services is partially due to the vulnerability of special needs children and the inelasticity of the financial resources of the adoptive families according to .Waldinger (1982). Therefore, it is imperative that child welfare agencies support and provide resources to families formed by adoption.

Hartman (1984) views postplacement services from an ecologically oriented family-centered approach. Postplacement services in Hartman's model of adoption is that adoptive families will need support and assistance from persons outside of the family throughout the life cycle. This intervention is often needed due to the adoptive family 
and child taking on complex and difficult life changes different from those experienced by biological families.

Barth et al. (1986) state that postplacement services are often neglected yet are a crucial determinant of placement success. Brooks (1991) agrees with Barth et al. and contends that the provision of postadoption services to adoptive children and adoptive families often can make the difference between a successful and an unsuccessful placement. The disappearance of services once the adoption is finalized lends credence to the belief that "at-risk" special needs children who move from foster care to adoption are penalized and are "at-risk" again without services (Ashton, 1994).

The Child Welfare League of America advocates for child welfare agencies to spend greater time and emphasis on supporting the adoptive parents and developing their potentials rather than on the initial adoption period of assessment and selection of adoptive applicants. Marcenko and Smith (1991) contend that postplacement services are not readily available because adoption agencies allocate the majority of their funding to children in pre-adoptive status. The fact that adoption services are not a priority in the traditional social service system is emphasized by Wimmer and Richardson (1990).

The average length of time from adoption placement to disruption ranged from four months (Cohen, 1984) to 18 
months (Barth \& Berry, 1988). Given the length of time in the latter study, the emphasis on extended and on-going postplacement adoption services is indicated. Since most disruptions occur after the mandatory adoption supervision period has concluded, Barth (1988) suggests that agencies should provide more intensive and lasting services when needed rather than put all resources in the initial placement period. McDonald et al. (1991) found that services continued to families until approximately nine months following adoptive placement at which time there was a sharp reduction in service delivery and usage.

Brown (1995) discovered that 648 of the special needs families in her study had contact with the adoption agency since the adoption finalization. Of those contacts, 698 called to ask for some type of assistance even though $65 \%$ stated they felt they knew where to go to access needed services for their adoptive child.

Barth and Berry's (1988) study revealed that 658 of the families advocated for ongoing contact with the adoption agency after finalization in order to address continuing problems. This was confirmed by Brown (1995) who found that 738 of the special needs adoptive families surveyed advocated for mandatory follow-up by the adoption agency following the legal finalization of the adoption.

Following the completion of a three-year demonstration project aimed to find adoptive homes for handicapped 
children in Ohio, the U.S. Department of Health and Human Services (1980) concluded that the value of preparation and preplacement services is necessary. However, the study confirmed the critical nature of providing services postplacement by their statement that "the real work begins after placement" (p. 26).

Cole and Donley (1990) divide postplacement services for special needs families into three general categories: remedial' work, crisis intervention, and on-going supportive services. Watson (1991) delineates four categories of postfinalization services:

(1) An extension of agency service beyond consummation to a family with whom an agency has placed a child,

(2) Agency intervention at the request of families who adopted and who later experience difficulties,

(3) Agency-initiated services offered to adoptive families on a planned basis in response to developmental needs, and

(4) Service to individuals, or to their relatives, who are seeking information about or contact with others who were a part of that adoption. (p.2) Neither Title IV-E of the Social Security Act nor any other federal guidelines mandate the type or amount of postplacement services to be offered to special needs adoptive families. In fact, there is no federal level 
incentive for states to develop postplacement services (Judith Anderson, 1990). The result is a considerable diversity among the states in relation to the array of services provided. Some states have a well-organized continuum of services while other states have no specific services for special needs adoptive families. When the latter occurs, families must utilize services developed for the general community by providers who have no specialized experien'ce working with this target population. Even for the states with an extensive and distinct program component for postplacement services, service availability and quality often vary between cities and counties within the same state (APWA, 1991a).

\section{Need and Usage.}

There has been limited research on what postplacement services special needs adoptive families perceive that they need, what services they actually receive, the impact of these services and the outcomes. One study that did address these issues was a needs assessment survey of parents who had adopted a special needs child and who were receiving adoption subsidy in Illinois (Walsh, 1991; Watson, 1991). The research was conducted by the Illinois Department of Children and Family Services to help determine the role of the public child welfare agency in delivering post adoption services and to obtain information about the array of 
service needs and the utilization of services by special needs adoptive families.

Surveys were sent to a random sample of 1,000 families which represented $23 \%$ of all special needs adoptive families. There were 395 families that responded which represented 98 of all special needs adoptive families receiving subsidy from Illinois. The seven services most often stated as being needed, in order, by special needs adoptive' families were: (1) special education, (2) medical services beyond the usual, (3) money in addition to current subsidy, (4) family counseling, (5) after school activities, (6) respite care, and (7) support groups (Walsh, 1991; Watson, 1991).

As expected, a much greater need for services was found as compared to the use of relevant services. Special education and medical care services had the greatest congruence between service need and service utilization. The greatest disparity between perceived need and actual service utilization was for respite care and the use of support groups. For both respite care and support groups, four times as many families reported needing the service as reported using the services.

The two most often noted impediments to obtaining needed services were listed as not knowing what services were available (32\%) and not knowing where the right service was located (298) (Watson, 1991). Walsh (1991) 
acknowledges that the findings should be interpreted with caution since respondents included not only what was "necessary" for the child's well-being under the category of need, but also those services which the parents might find "useful" to the child's well-being.

The adoptive parents' level of satisfaction with services they received was measured using a five-point Likert scale format. Over half (518) indicated satisfaction with the services they were getting, 198 expressed dissatisfaction, 208 were neutral and 58 had no opinion. (Watson, 1991).

One of the variables that was identified in Gilles' (1995) study of families who receive adoption assistance and had an adoptive placement after 1990 was service use. He found that of the families who receive financial assistance, in the form of a monthly subsidy check, $55 \%$ also receive additional postplacement services. The breakdown of service usage is: $58 \%$ get counseling; 228 get respite care; 218 get regular day care; $17 \%$ get tutoring or special educational services; 158 get special equipment or adaptation devices; 108 get therapeutic day care; and 48 get residential care or treatment.

Gilles (1995) conducted research on the effectiveness of adoption assistance programs in 20 states using a sample of 532 adoptive families, 140 adoption front-line workers, and at least 20 administrators/policymakers. He concluded 
that there are serious gaps in service provision for special needs adoptive families in all of the states he surveyed.

The gaps in services cited as needed the most to meet the basic needs of the adoptive child were counseling and mental health services (278), respite care (238), tutoring/educational services (20\%), day care (18\%) and special equipment and/or adaptation devices (4\%) (Gilles, 1995). In contrast to adoptive families' list of needed services', Gilles found that adoption administrators and front-line staff felt that an important need and service gap was residential treatment for the adoptive child.

Interestingly, adoptive parents did not perceive a high need for residential treatment services.

Another study that addressed adoptive parents' postplacement needs was Marcenko and Smith (1991). They evaluated the postadoption needs of families who adopted children with developmental delays and found that the postplacement process is a continuing process that evolves as time goes by. Contrary to Watson's (1991) findings regarding. support group utilization, Marcenko and Smith's study revealed that families most utilized support groups; however, 208 stated they were not involved in a support group but would like to be. In two areas, respite care and level of satisfaction with services, Marcenko and Smith's findings supported those of Watson. Marcenko and Smith found that respite care was the service most often needed 
(23\%) and that the families were generally satisfied with services they had used. The services with the least amount of satisfaction were educational (138) and counseling for the child (108).

\section{Clinical.}

The non-directive approach of traditional psychotherapy and the lack of success with individual passive therapists was universally found to be ineffective with adoptive families' (Barth \& Berry, 1988). Barth (1988) warns that many social workers recommend clinical intervention when families are experiencing problems; however, his study did not find that conventional nondirective psychotherapy for children was effective. Marcenko and Smith (1991) also found adoptive parents were dissatisfied with counseling as an intervention.

Josephine Anderson (1990) confirms the ineffective outcome of conventional clinical intervention and states that traditional child therapies have proven to be ineffective with children who are older when placed for adoption. Bourguignon \& Watson (1988) state that since adoptive families are not "conventional families", many conventional therapies such as non-directive counseling, behavior management, and play therapy may not be successful with adoptive families.

Although the effectiveness of clinical services with adoptive families does not seem warranted, special needs 
families often utilize or request clinical services (Brown, 1995; Gilles, 1995; McDonald et al., 1991; Walsh, 1991; Watson, 1995). McDonald et al. (1991) discovered that the most frequently used postplacement services were individual and/or group psychotherapy which was used by $41 \%$ of the sample. In a study of service needs and usage conducted by Brown (1995), child and/or family counseling was one of the most mentioned services as both used by adoptive families and not used but needed. Gilles found counseling to be the most used service in his study with 588 of the sample utilizing this intervention.

Rosenthal et al. (1988) found adoption outcomes were negatively correlated for those adoptive parents seeking therapy. One possible explanation for this relationship is that families who are not experiencing problems do not usually feel a need to seek therapy.

A problem identified by Rosenberg (1992) regarding clinical intervention is that there is a bias to minimize problems encountered by adoptive families since adoption has traditionally been seen as a "perfect solution from which no special problems were expected" (p. 147). Further, she contends that there is a lack of clinical professionals who have extensive experience related to adoption issues.

There is currently a paucity of professional literature on special needs adoptions addressed to mental health practitioners. The result is a shortage of adequately 
trained mental health practitioners experienced and trained to work with adoptive children and families to provide intensive postplacement and postfinalization services (Backhaus, 1989).

The Connecticut Council on Adoption trained 50 mental health practitioners and 50 child welfare professionals in adoption issues, and intervention and treatment techniques with the goal of supporting and strengthening the adoptive families of special needs children. The training consisted of six sessions of two days each with emphasis placed on identifying the specific problems of special needs children and their adoptive families and the use of specific techniques to aid the family members. Although the project did not utilize a pre-test post-test evaluation, Backhaus (1989) concluded the training improved postplacement services by providing an opportunity for therapists to become more knowledgeable of the issues and needs of special needs adoptive families as well as initiated the establishment of a peer group practice.

Support groups and social support.

Support groups for adoptive families began in 1948 in Los Angeles with the founding of The Adopted Children's Association of Los Angeles (Kirk, 1964). Support groups were intended to help adoptive families normalize many of the activities and problems they encounter in the adoption process. 
Rosenberg (1992) proposes that support groups focus on the threads of commonality that adoptive families experience during the adoption process. The three advantages for adoptive parents of supportive services compared to clinical therapeutic intervention are the lack of a negative stigma that is attached to therapy, ability to link families with other services, and the lack of available therapeutic services in all areas (Rosenthal \& Groze, 1992).

Gili (1978) reports on the success of a postplacement adoption support group for parents adopting older childrren wherein only five disruptions in approximately 900 placements occurred over a ten year period. Caution must be used when evaluating the success of the support group in this study by examining the disruption rate. It can be presumed due to the date of the article and the adoption practices that occurred in 1970s, that the majority of families did not adopt a special needs child. Therefore, the possibility strongly exists that the children adopted by these families did not have as numerous or severe problems as the special needs children being adopted today. Nevertheless, the strength of the support group was found by Gill (1978) to be the encouragement of expressions of common postplacement concerns and the provision of strong support for problem situations. Not surprisingly, a common concern of the adoptive parents that was noted during the support group was related to postplacement issues. 
Tremitiere (1979) has experienced success and low disruption rates by using experienced adoptive parents to provide postplacement support to other adoptive families beyond legal finalization. Support groups are provided for all adoptive families, but especially for special needs adoptive families in order to encourage awareness and prevent isolation.

Levine and Salles (1990) view adoption from a psychosocial and psychodynamic perspective and have identified five phases that adoptive children and families pass through during the adoption process. They argue that supportive therapy for the target adoptive child rarely is successful. Instead, they advocate for accurate assessments to determine if the problems are within the family system or due to the child being damaged emotionally prior to the adoptive placement. Support to family members, on-going therapy, and behavioral management strategies, and at times residential placement, for the child are needed. They believe that preventative therapy in the form of support groups for children and parents throughout the adoption process is strongly warranted.

A study of 91 special needs adoptive children was conducted by Groze (1986) who found that the opportunity provided by support groups for adoptive parents to express postplacement concerns increased the likelihood of a successful adoption outcome. In their study of intact 
special needs adoptive families, Rosenthal and Groze (1992) found that adoptive support groups were more helpful to successful adoptive parents than individual and family therapy yet participation in support groups was the least commonly utilized postplacement service.

The majority of the empirical knowledge regarding adoption outcomes does not address the influence of social support and informal services on the adoption outcome (Barth et al., 1986). Instead, most of the literature revolves around variables related to characteristics of successful adoptive children and families.

One study that did address support from relative and friends found that $98 \%$ of respondents stated their relatives and friends supported their decision to adopt (Rosenthal et al., 1990). Murray (1984) suggests that the support and reactions that adoptive families receive from their extended families impacts on the adoptive child's adjustment.

\section{Subsidy.}

One of the most effective interventions that has been developed to increase special needs adoptions is the availability of adoption subsidy as a postplacement resource. Adoption subsidies are provided only to special needs children and are not available in other methods of adoption such as relative or private adoptions (Avery \& Mont, 1992). Subsidies, which are determined by the unique needs of the child, are considered an entitlement the child 
is eligible for to ensure continued care for the child's needs rather than a payment to the adoptive family. Barth and Berry (1988) found that subsidies are one-third the level of foster care rates and that higher risk placements do not result in a higher subsidy payment.

Subsidies are identified as the primary means to remove financial barriers to the adoption of special needs children and remove the disincentive of lack of financial support for the special needs of the child (Avery \& Mont, 1992;

Bussiere, 1990). Although the idea of adoption subsidies was first addressed by the Child Welfare League of America in 1958, state and federal subsidies were not begun until 1968 and 1981 respectively (Cole, 1990; Rodriguez \& Meyer, 1990).

The broad criteria for adoption subsidies are found in the Adoption Assistance and Child Welfare Act; however, each state sets their own guidelines and their own definition of special needs in relation to subsidies. Therefore, each state has different subsidy programs based on different definitions of special needs (Brooks, 1991).

With. the increase in numbers of special needs children being placed, there has been a corresponding increase in the amount of subsidy distributed for special needs children. In a two year period from 1981 to 1983, federal adoption subsidies increased from $\$ 442,000$ to seven million dollars (Fales, 1985). 
Besides monthly maintenance and medical subsidies, adoptive parents of special needs children are eligible, according to a change in the Title IV-E of the Social Security Act in 1986 , to be reimbursed for one-time only costs related directly to adoption of a special needs child (Bussiere, 1990). Examples of these costs are attorney fees, court costs, medical examinations, travel, or any other cost directly related to the adoption (APWA, 1991b). Not only does the advent of subsidies enable the child welfare system to act in an ethically and morally appropriate manner by providing one means of permanency for special needs children, it is cost effective. By paying a subsidy, the costs to the state for foster care services are reduced since more children would remain in the foster care system if they were not entitled to an adoption subsidy. Since 1980, over 100,000 special needs children have received adoption subsidy according to the North American Concil on Adoptable Children (1993). Rosenthal, Groze and Curiel (1990) report that in 1985 there were 43,000 adoptive families who received adoption subsidy.

The North American Council on Adoptable Children estimates that at least 788 of agency-facilitated adoptions involve the provision of adoption subsidy with some estimates ranging as high as 90-958 (Naatrin Update, Spring, 1995). A study of 120 special needs adoptions found that 
$60 \%$ received a monthly stipend with a median monthly payment of $\$ 229$ (Barth \& Berry, 1988).

The ability to determine the effectiveness of adoption subsidies is difficult and there has been no comprehensive national study of this issue due to numerous reasons (Bussiere, 1990). First, there is a tremendous lack of reliable data about adoptions and subsidies. In order to test the effectiveness of an intervention, researchers must at least' be able to accurately count the children involved (Kroll \& Frank, 1990). Second, the advent of subsidy was a part of a larger effort, the permanency planning movement, which mandated numerous other interventions besides subsidies in order to find children permanent homes. Societal values and agency practices were changing so that adoption subsidy was not seen as an isolated force. Third, anticipated monetary allocations from the federal government, including Title Xx appropriations, to support adoptive parents are significantly less than originally anticipated. Fourth, the federal government has not provided sufficient guidance to the states and in fact delayed promulgating final regulations to implement adoption assistance. The federal government did not provide states with any guidelines or sample contracts for adoption assistance until 7 years after the passage of the Adoption Assistance and Child Welfare Act mandating the implementation of subsidies (Kroll \& Frank, 1990). All of 
these issues have made it difficult to assess the impact of adoption assistance since the states have not received the full benefits that Congress had originally intended.

Gilles (1995) concurs with Bussiere (1990) that there has been no assessment of the effectiveness of adoption assistance. He also contends that there is a lack of descriptive research about the children and families who receive assistance, the types and sufficiency of benefits, and the 'impact of various policies and systems on the distribution of the benefits.

There is contradictory literature relating to the perception adoptive parents have in relation to receiving adoption subsidy. The National Adoption Information Clearinghouse reports that neither adoptive parents nor adoptive children feel a stigma attached to receiving adoption assistance (Ragan, 1994). In contrast, a study of foster parents who adopted special needs children and received adoption subsidy payments found that the adoptive parents compared the subsidy to public assistance and felt stigmatized by accepting financial payments for their child (Waldinger, 1982). It is suggested by waldinger that adoption subsidy payments should be viewed as an entitlement grant for a "special at-risk" population similar to the way social security is viewed.

Nelson (1985) reported that adoptive parents saw adoption assistance as an essential factor in determining 
the success of special needs adoptions. This finding was confirmed by Gilles (1995) wherein his study of 532 adoptive families emphasized the overall effectiveness of adoption assistance as an incentive to find permanent homes for children.

In contrast, Bartholet (1991) conducted a study for the Department of Health and Human Services and found that adoptive parents were offered adoption subsidy in two-thirds of the adoption cases. Surprisingly, the majority of the families stated that although it would have been more difficult, they would have still adopted the child without any type of adoption subsidy.

Preparation and Training.

Studies have shown that adoptive parents often feel the adoption agency was either untruthful or withheld important information regarding the background or problems of the adoptive child or biological family (Barth \& Berry, 1988; Nelson, 1985; Schmidt et al., 1988; Urban Systems, 1985). These four studies have found that an adoptive parent's belief that they received inadequate history and background information is associated with increased risk of disruption.

Another perception of many adoptive parents is that they are not adequately prepared to adopt by their social worker or adoption agency. Two predictors of parental satisfaction with the adoption that have been found are adequacy of agency information about the child and adequacy 
of agency preparation (Nelson, 1985). The literature suggests that the level of preparation provided to adoptive parents prior to placement is associated with more successful outcomes (Judith Anderson, 1990).

Rosenthal and Groze (1992) revealed that $35 \%$ of the families studied perceived that the background information on their adoptive child was insufficient and $42 \%$ felt the information was not accurate. Nelson (1985) notes that 488 of the families studied felt the information provided by the agency was not accurate or sufficient. Brown's (1995) s.tudy found that 428 of the special needs adoptive families felt the adoption agency did not tell them all that they knew about the adoptive child. Brown's study also revealed that 448 of the families did not feel they had enough information about their child with medical, behavioral, and biological family background being the three areas of information most wanted.

In a follow-up study of 927 adoptions, Barth (1988) explains that a positive relationship was found between sufficient information being provided to the parents and the stability of the placement. He also reports that the least accurate preplacement information was provided to those families who were adopting the highest risk children. In these instances, the information provided was reported to be too positive and unrealistic. 
In a study of families who adopted special needs children in two urban areas in Florida, Brown (1995) found that 928 of the families did not feel that the agency overstated the child's problems to them prior to placement. In the same study, Brown revealed that 438 of the families did not feel they were realistic about the problems they would encounter adopting a special needs child.

Brooks (1991) studied 91 special needs adoptive families'in Tennessee and found that $48 \%$ of the respondents felt that the information they received on their adoptive child was inadequate. Brooks found that parents who adopted children with behavior and learning problems felt they were less prepared to adopt and were told less information about their adoptive child than families who adopted children without these problems.

Sedlak and Broadhurst (1993) found that two-thirds of the parents who adopted children who had been sexually abused did not find out about the sexual abuse from the adoption agency. Additionally, a large portion of parents who adopted children with psychological, emotional or behavioral problems did not learn of the child's problems until after the child was in their home.

Berry (1990) reviewed the literature on preparing and supporting special needs adoptive families and found that a large percentage of families were not satisfied with the preparation they received to adopt. She found that 
satisfaction with agency preparation was the second most critical predictor of adoptive parents' satisfaction with the entire adoption.

Sedlak and Broadhurst (1991) found that the adoptive families received little preparation or training prior to adoptive placement. In their study, 598 of the parents indicated that their adoption agency did not offer any type of group preparation or training for adoptive parents. In 'Brook's (1991) study, only a third of the families attended a preparatory group to assist prospective adoptive parents with information and adoption preparation. Of this number, 568 felt the preparation was adequate. Comparing the perceptions of foster parents who adopted and "outrighter" adoptive parents, he found the foster/adoptive parents did not feel they were as prepared to adopt as compared to the "outrighter" adoptive parents.

Agency support and services.

Research has found that special needs adoptive parents who have a strong, helpful link with the child welfare agency are more likely to have successful adoptions (Barth, 1988). In contrast, McDonald et al. (1991) determined that agency services do not play a significant role in the outcome of the adoption.

Cohen and Westhues (1990) suggest that adoptive families are reluctant to share their concerns and negative feelings about the adoption until it is too late. Berry 
(1990) found that adoptive parents felt supportive services were necessary but were often unavailable.

One research study examined the relationship between agency and social worker support with disruption. Although it was a small qualitative study of 18 adoptive families who had experienced a disruption, 16 families contended that the adoption agency or worker was a source of stress during the placement (Valentine, Conway \& Randolph, 1987).

Rosenthal and Groze (1992) conducted a study of 809 adoptive families from Oklahoma, Kansas and Illinois and found that 558 of the families indicated they were satisfied with services they received. Only $14 \%$ reported that the services they received were not helpful. Nelson (1985) found that the inability to obtain needed postplacement services was correlated with decreased satisfaction with the adoption experience.

In a study of postplacement services for both foster and adoptive families, it was found that agencies provide little support because of the low priority given to maintaining placements when compared to the traditional child welfare agencies' role of child protection and investigation (Rushton, 1989). The study found that the extent of the problems the children have, the incidence of placement breakdown, and the level of stress encountered by many of the parents is justification for the need for postplacement support services. 
Phillips (1988) studied postadoption services in Scotland and found that the majority of families did not want formal involvement with the social worker once the adoption was finalized. However, the families were in favor of informal contact initiated by a representative of a postadoption centre which is a voluntary agency, first opened in 1986 in England, where multiple services are offered to adoptive children, adoptive families, and birth parents (Howe, 1990b).

A survey of 127 users of the post-adoption centre . revealed that 918 were either very satisfied or satisfied with services received. The consumers of the centre rated the most helpful aspects of the centre as practical advice, guidance and information; a time to talk and people to listen, being understood, support and availability, and meeting other users of the centre. In a three year follow-up study of the centre, Howe (1990a) found that adopted people, primarily between the ages of 18 and 25 years, were the main users of the centre followed by birth parents and then adoptive parents.

Although adoptive parents comprised the smallest group of users of the centre, they involved the greatest use of time of staff at the centre (Sawbridge, 1990). The main reason for adoptive parents to seek services was due to behavior problems of their adopted child. 
A postadoption services center where support services can be offered for all members of the adoption triad in order to enhance family adaptation and adjustment is advocated for by spencer (1987). The intent of the support services is that through effective intervention, support and problem-solving the life-long issues surrounding the adoption experience can be positively addressed.

\section{Summary.}

The' literature review has provided an opening into the paradigm shift of placing special needs children for adoption and the need for continued research. The literature has been characterized by a lack of concurrence regarding statistical data on adoptions, rates of disruption, and adoption outcome predictors. However, several variables have been consistently found to be predictors of adoption outcomes.

Contradictory empirically based findings regarding the association of adoption outcomes and the following variables have been identified: adoptee's gender and race; presence of other children in the home; placement with siblings; mental health problems of adoptees; and the adoptive family's income, age, race, marital status, and educational level. The following variables have also consistently been found to have an impact on adoption outcomes: adoptee's age; presence and severity of behavioral or emotional problems; presence of physical or developmental disabilities; number of 
previous placements and failed adoptions; variables related to the child rather than the family or agency; foster parent adoptions; length of current adoptive placement; adoptive parents' religious affiliation and flexibility with family rules and roles.

The increase in children entering foster care and the resulting increase in special needs adoptive placements necessitates that the social work profession provide practical, appropriate, and cost effective postplacement services. Further, because of the children's increasingly problematic special needs, effective means must be utilized to recruit appropriate adoptive families who are realistic about the problems that will be encountered during the life long adoption process.

The literature was reviewed regarding service provision in the areas of clinical treatment; support groups and social support; subsidy; preparation and training; and agency support and services. Although postplacement services have been suggested to be important in influencing placement success, gaps currently exist in service provision to these families. Empirical studies identifying service need and usage by special needs adoptive families are minimal.

Relevant theory and empirical research that identify the different stresses faced by special needs adoptive families and the unique and life long process involved in 
adoption are evidence of the need for on-going postplacement services. Services must be aimed at strengthening, supporting, and nurturing special needs adoptive families throughout all stages of the family life cycle.

This study extends the existing research by examining and focusing on the influence of specific postplacement services on adoption outcomes. In a system of dwindling dollars allocated to social services, resource and budget allocations to continue existing programs or to develop new programs must be examined in relation to empirical research based on adoption outcomes. The results of this study can be used by funding agencies and policymakers to determine which services are most appropriate to fund and develop. The findings of this study can also be used by direct practitioners to assist in the determination of which services to refer special needs adoptive families to when the families are experiencing problems. Finally, the identification of specific variables and services that are indicated by this study to have a relationship with adoption outcomes expands the professional knowledge base and provides hypotheses for further empirical research.

There is a complete paucity of empirical intervention research in the areas of special needs adoption postplacement services. Although the need for intervention research on postplacement services has been identified (Barth et al., 1988; Marcenko \& Smith, 1991; McDonald et 
al., 1991; Rushton, 1989), no studies have been conducted to review the effectiveness of specific services on adoption outcomes. Therefore, the conclusions derived from reviewing the research and literature on special needs adoptions validate and support the research questions and hypotheses guiding this study.

Research Questions

Figure 3 presents the antecedent variables (demographic data) and intervening variables (issues related to the foster care and adoption process) identified for the adoptive parents' and adoptive child. The independent variable was defined as postplacement services. Following a review of the literature and conceptually related theories, five questions were examined in this research.

(1) What is the influence of the adoptive parents' and adoptive child's antecedent variables, the adoptive parents' and adoptive child's intervening variables, and the independent variable upon the adoptive parents' level of willingness to adopt another special needs child?

(2) What is the influence of the adoptive parents' and adoptive child's antecedent variables, the adoptive parents' and adoptive child's intervening variables, and the independent variable upon the adoptive parents' level of 
being realistic about the problems they would encounter?

(3) What is the influence of the adoptive parents' and adoptive child's antecedent variables, the adoptive parents' and adoptive child's intervening variables, and the independent variable upon the adoptive parents' perception of the level of success of the adoption?

(4) What is the influence of the adoptive parents' and adoptive child's antecedent variables, the adoptive parents' and adoptive child's intervening variables, and the independent variable upon the adoptive parents' level of satisfaction with the adoption experience?

(5) Does the type of postplacement service used impact on the adoptive parents' level of satisfaction with the adoption experience?

\section{Research Hypotheses}

Based on the literature review and the conceptual framework previously presented, the following three hypotheses were developed and tested in this research study:

(1) Adoptive parents who rate their adoption as successful are more likely to express a desire to adopt another special needs child.

(2) Adoptive parents who believe that they received adequate information about the child prior to 
placement are more likely to perceive that they are more realistic about the problems they encounter during the adoption process.

(3) Adoptive parents who use and are satisfied with postplacement services are more likely to perceive their adoption as successful. 


\section{Chapter 3}

Methodology

\section{Research Design}

This study utilized a cross-sectional survey design for descriptive and exploratory purposes to examine perceived adoption experiences, outcomes, service needs and service usage among special needs adoptive parents. This design was employed in order to be able to examine the data by taking a cross section of it at one point in time for descriptive and exploratory purposes within the same research study and, to be able to generalize the findings to a larger designated population. A stratified random mail survey was chosen to implement the research design.

A concern related to cross-sectional designs is that they lack high internal validity. In order to compensate for this limitation, alternative variables were controlled by employing multivariate statistical procedures in an attempt to rule out potential rival hypotheses (Rubin \& Babbie, 1993).

The descriptive aspects of the cross-sectional design provided demographic data on the adoptive child and adoptive parents and their service needs and utilization. The exploratory aspect of the study provided an opportunity to obtain a beginning understanding of the parents' perceived experiences with the adoption process and their need for and utilization of various postplacement services. Following 
appropriate statistical analysis, the descriptive and exploratory aspects of the study allowed for the formation of recommendations for future research, especially in the domain of intervention research related to postplacement services.

Variables and Operational Definitions

The four dependent variables that were used are based on the adoptive families' perception of four distinct outcomes' of their adoption of a special needs child as measured by a 7-point Likert scale ranging from strongly disagree to strongly agree. The four dependent variables were: (1) whether their adoption was successful; (2) whether the adoption process was a satisfying experience;

(3) whether they were realistic about the problems they would encounter during the adoption process; and (4) whether they would like to adopt another special needs child.

Since this was a self-administered questionnaire, these variables were defined independently and individually by the person completing the instrument. The literature does not contain a standardized definition for either success or satisfaction. Rather, success and satisfaction are subjective concepts operationalized by the respondent according to their own beliefs and attitudes about their adoption experiences. Factors discussed in the literature when operationalizing success and satisfaction include 
formation of a family relationship, disruption rate, the child functioning in the normal cognitive and behavioral ranges, support of the child's previous relationships, commitment to the adoption, and love of the child (Hartman, 1984; Hoopes, 1990; Kornitzer, 1968; Plumez, 1982; Rosenthal \& Groze, 1992).

The literature on special needs adoptions seems to raise questions regarding the direct or indirect effect that various antecedent and intervening variables have on adoption outcome. Numerous studies, as cited in the literature review chapter, have reported conflictual findings related to certain antecedent and intervening variables for the adoptive parents and adoptive child.

In this study, antecedent variables for the adoptive parents included age, educational level, marital status, religious activities, employment, income, and number of biological children. Antecedent variables for the adoptive child include special needs classification, sex, race, sibling relationship, and same race placement. These antecedent variables provided a descriptive profile analysis of the demographics of adoptive children and their parents. Additionally, the variables were statistically analyzed to determine if they had an impact on the adoption outcome.

Intervening variables are utilized in social service research to help interpret the relationship between the independent variables and the four dependent variables. 
Intervening variables in this study related to the adoptive parents included participation in an adoption support group or adoption training, social support, foster parent adoption, and realistic expectations. The child's intervening variables included number of adoptive and foster/relative placements, length of stay in foster care, reason for entering foster care, residential treatment placement, and presence of any diagnosed problems.

The following terms appear in the survey completed by adoptive parents and are operationalized for the purpose of this study.

Special needs children were operationalized as children who met at least one of the following criteria: were either over the age of eight, emotionally disturbed, physically or mentally handicapped, of mixed or minority racial heritage, or a member of a sibling group.

The independent variables, postplacement services, were defined as any service that was offered to either the adoptive child or any member(s) of the adoptive family after the child was placed on adoptive status in the home. Services included in the survey completed by the adoptive parents were those found in the literature or those normally associated in the social work field as supportive services. The 36 separate services listed in the survey fell into the following categories: respite care; life planning; support group; baby-sitting; homemaker services; advocacy, parent, 
job and/or child care training; regular and therapeutic day care; residential placement; medical support and care; marital, child and/or family counseling; transportation; educational services; medical and/or dental care; speech, occupational, and/or physical therapy, in-home services, subsidy, outpatient/inpatient drug or alcohol treatment.

Disruptions were operationalized as adoptions of special needs children who were placed in an adoptive home and whose adoption had broken down prior to legal finalization of the adoption and had resulted in the child being replaced into the foster care system or into another adoptive home.

Dissolutions were operationalized as adoptions of special needs children who were placed in an adoptive home and whose adoption had broken down after legal finalization of the adoption and had resulted in the child being replaced into the foster care system or into another adoptive home. MAPP is an acronym for Model Approach to Partnership in Parenting which is a ten week adoption specific preservice training offered to all families who had a home study completed by HRS in order to adopt a special needs child. The training is given free of charge by HRS and is routinely required to be completed as part of the official homestudy process. Exceptions to requiring attendance at MAPP training may be made on a case by case basis by each 
district responsible for studying and approving the adoptive family.

Maintenance adoption subsidy was defined as any monetary allotment sent to the adoptive family each month in order to help defray a portion of the cost to adopt a special needs child. The subsidy may be renewed each year until the child reaches age eighteen at which time it is terminated. The amount of the subsidy is determined by negotiation between the adoptive family and HRS prior to the adoptive placement; however, the amount may not be higher than the amount of payment the agency would have spent on the child if the child remained in foster care.

Medical subsidy was defined as payment for services for any prediagnosed medical condition that has been identified at the point of placement. Medical subsidy is paid only after all Medicaid and private third party insurance payments have been exhausted. The subsidy may be renewed each year until the child reaches age eighteen at which time it is terminated.

Nonrecurring adoption expenses is reimbursement for any approved costs that the adoptive family incurred in the process of adopting a special needs child. These expenses can include court costs, attorney costs, and travel for preplacement and presentation visits. 
The study population was families who have had an adoption placement of at least one special needs child and who currently receive maintenance and/or medical adoption subsidy from the Florida Department of Health and Rehabilitative Services (HRS) for at least one adoptive child. Children who are eligible for a subsidy are special needs children who were previously removed from their family or guardian due to abuse, neglect or abandonment and placed in the custody of HRS or a private child placing agency, The child must be between the ages of 0 and 18 in order for the family to receive the subsidy. The child may have been placed with the adoptive family by either HRS or a private licensed child placing agency that contracts with HRS.

The State of Florida is divided into fifteen districts each with its unique geographical and socioeconomic configuration. Figure $A-1$ displays a map of the state of Florida divided into the 15 HRS districts and illustrates what counties make up each district. Five of the districts (Districts $4,5,6,10,11$ ) contain at least one large metropolis and are primarily considered urban areas with the remaining districts primarily considered either rural or a mixture of rural and small urban.

The sampling frame consisted of a complete list from each of the $15 \mathrm{HRS}$ districts of families receiving adoption subsidy for at least one special needs child. The unit of 
analysis was special needs adoptive families. The total sampling frame contained 5,333 special needs adoptive families.

A stratified sampling method was utilized by stratifying the sample by the HRS district that was paying the adoption subsidy. The district that was paying the subsidy was determined by which district had legal custody of the special needs child prior to adoptive placement. The district responsible for payment does not change regardless of where the adoptive family resides either subsequent, to or at the time of placement. Although often the adoptive parents live in the same district as the child at the time of placement, it is not uncommon for the family to move to either a new district or even out of state subsequent to the adoptive placement. Additionally, a child's original custody prior to placement and subsidy payment may be from one district, but placement can occur with an adoptive family from another HRS district or with a family from another state.

Stratified sampling allows the researcher to obtain a greater degree of representativeness in a sample by organizing the population into homogeneous subsets (Rubin \& Babbie, 1993). The advantages of using a stratified sample is that it increased the probability of obtaining an adequate representation of the districts, the sample sizes in the strata were controlled by the researcher rather than 
being randomly determined by the sampling process, and the stratification decreased the sampling error (Fowler, 1993; Kalton, 1983; Weisberg, Krosnick \& Bowen, 1989). Even though the survey was sent to a random sample stratified by district, it is not known if the returned surveys were a random representation of those families sampled.

Stratification by district was advantageous in this study because the districts are distinctly different due to the urban, rural and geographical mixture of the districts. It was anticipated that these differences in the districts might be apparent in the educational levels, income levels, and type of employment for those families who still live in the same district as they did when they adopted the child. The most important variable that was anticipated to be different between the districts was the availability of adoptive postplacement resources with urban districts having more services available as compared to rural or geographically mixed districts.

A proportionate stratified sampling method was used to more closely represent reality of all special needs adoptive families in each of the HRS districts. The HRS district paying the subsidies constituted the strata from which separate samples were drawn.

An a priori power analysis was completed to determine the necessary sample size in order to demonstrate significant results as well as to reduce Type II error. 
Type II errors occur when the null hypothesis is not rejected even though it is false which means that an effect existed, but was not detected (Rudestam \& Newton, 1992). It was determined that a sample size of 230 was necessary to demonstrate standard statistical power of .80 for a level of significance of .05 and an effect size of $\mathrm{R}^{2}=.10$ (Cohen, 1988). The required response rate for each district was calculated by multiplying the district's percent of the state's total families by the total number of surveys needing to be returned.

As of August 31, 1995 there were 5,333 families statewide receiving maintenance adoption subsidies according to the lists submitted by each district. HRS reports that as of the same date there were 8,232 special needs children receiving subsidy (HRS, 1995). A sample size of 1,500 families was used which represents a $28 \%$ sample. A larger sample than was necessary was sent out in order to compensate for nonresponse. Table 2 provides a breakdown by district of the number of families receiving subsidies, each district"s percent of the state total of families, the number of families that were sampled, the minimum number of responses needed from each district, the number of surveys returned, the district's percent of total surveys returned, and the response rate for each district. It appears that each district's percent of total surveys returned 
Table 2. District Sampling Data

$\begin{array}{lllll}\text { District } & \text { Families of State } & \text { Families } & \text { Minimum \# Surveys } & \text { Total } \\ \text { Receiving } & \text { Total } & \text { Sampled } & \text { Surveys } \\ \text { Subsidy } & & & \begin{array}{l}\text { Required } \\ \text { to be } \\ \text { Returned }\end{array}\end{array}$

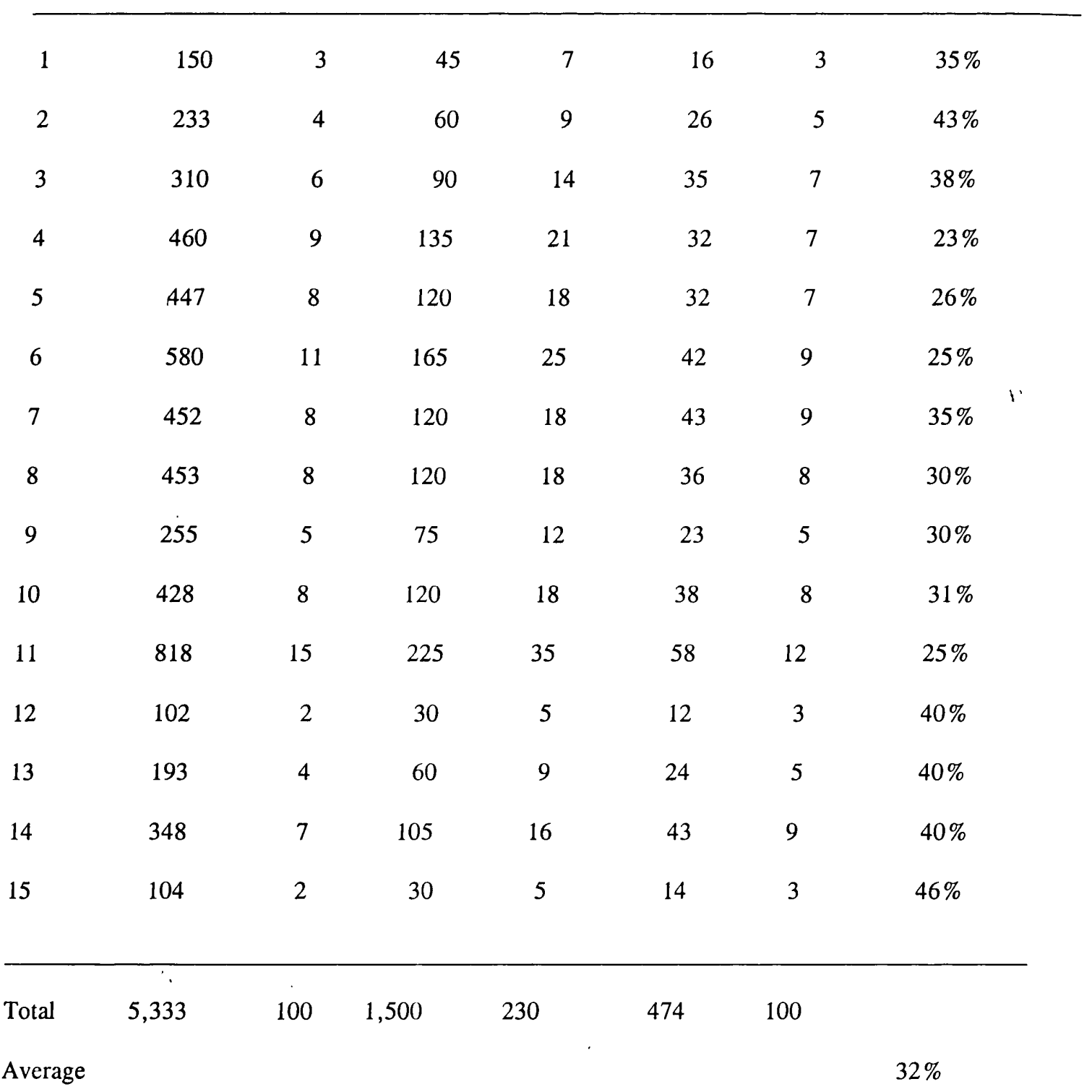


approximates that district's percent of the state total of distribution of families, thus indicating stratification by district was successful.

Systematic random selection with a randomized start was used once the population was stratified by districts (Fowler, 1993). The lists from each district were configured differently with some districts listing the families in alphabetical order, some by date of adoption placement, and some by type of funding.

A concern about results obtained with systematic , samples with a random start exists if a sampling frame is ordered in some way as to make the results systematically different with a random start than from one resulting from another type of sampling (Fowler, 1993). Kalton (1983) stresses caution in the use of systematic samples with a random start if the sampling interval coincides with a multiple of the length of the cycle. After careful consideration and examination of all issues related to sampling and the lists provided by each HRS district, there was no apparent indication that the length of the cycle or the ordering of the sampling frame would compromise the findings in this study. Therefore, it was determined that the use of a systematic sample with a random start in this study was appropriate.

Instrumentation

There are no existing standardized instruments with 
proven reliability and validity to sample special needs adoptive families regarding postplacement service needs. Therefore, this researcher developed a questionnaire of open and closed-ended questions that were specific for the purpose. Some questions asked in the survey were patterned or modified from questions asked in previous studies (Marcenko \& Smith, 1991; Walsh, 1991). This combination of open and closed-ended questions was utilized because of the descriptive and exploratory purposes and nature of this research project. The instrument had face validity since it adequately measured the concept of special needs adoption outcomes. The survey is located in Figure $\mathrm{A}-2$.

Many families adopt more than one special needs child; however, due to the length of the instrument and the number of variables being studied, it was not possible to gather information on more than one adoptive child per family. When families had more than one adopted child, the adoptive parents were instructed to complete the survey in relation to the oldest special needs adoptive child still living in the home for whom they receive adoption subsidy. It was hypothesized that the adoptive families would have had more opportunity to encounter a need and use of postplacement services with older children as compared to sampling any other category of special needs children in the family.

The instrument was divided into 5 sections: service provision, adoption experience, child information, adoptive 
parent information, and open-ended questions. There were a total of 144 questions ( 140 closed-ended and 4 open-ended). A number of the questions required the respondent to check all the answers that applied in one given question and the open-ended questions were coded with the top two answers given for each question.

The service provision section consisted of 36 services wherein the adoptive parent was asked to rate their experience with each service based on a 4-point Likert scale ranging from used and dissatisfied, used and satisfied, not used but needed, to not needed. There were an additional 8 service provision questions requiring a yes, no or not applicable/not sure response.

The adoption experience section contained 22 statements regarding adoption and the parent was asked to rate their agreement or disagreement with each statement using a 7-point Likert scale ranging from strongly disagree to strongly agree. Fifteen problems that occur which present barriers to service usage were listed and the respondent was asked to rate their experience with each barrier using a 4-point Likert scale ranging from no problem to a big problem.

The child information and the adoptive parent information sections contained 27 and 29 multiple choice and fill in the blank questions respectively. The four openended questions pertained to the perceptions related to 
concerns of the child and the parents since finalization, the social worker's and agency's roles, and suggestions for services that need to be developed for adoptive families. The last variable coded was the HRS district paying the adoption subsidy. This information was obtained from the sampling frame and was precoded on the surveys by the researcher prior to sending the surveys out.

The questionnaire was field tested in the winter of 1993 on 'HRS employees who were familiar with the area of special needs adoptions. The questionnaire was revised and field tested again in the spring of 1994 using a sample of 237 special needs adoptive families. The sample consisted of all adoptive families in HRS Districts Four and Ten (Jacksonville and Ft. Lauderdale areas) who previously, but no longer, received maintenance and/or adoption subsidies for a special needs child. These families were selected for the instrument field testing since they no longer received subsidies and therefore would not be part of the population eligible to be sampled in the current study.

Due to an initial low response rate of $15 \%$, the survey and cover letter were sent out again to the entire sample two months from the initial mailing in hopes of increasing the response rate. One hundred one (101) surveys were returned undeliverable as the people had moved and the forwarding address had expired. Fifty five (55) completed surveys were returned between the two mailings which equated 
to a 428 response rate for deliverable surveys. Further modifications to the questionnaire were made as a result of the feedback from the field testing. Questions were reworded for clarification purposes and those questions which did not have a significant relationship to the variables being studied and which did not show much variance among the responses were deleted.

\section{Data Collection Procedures}

The' instrument was a self-administered questionnaire which was mailed to the 1,500 families included in the sample. A cover letter (see Figure A-2) that was sent with the actual questionnaire explained the purpose of the study, the anonymous nature of responses, and that all services and subsidies that were currently being provided and/or requested would not be influenced by participation in the study. A stamped preaddressed envelope was included to increase the response rate.

The Assistant Secretary for HRS' Children and Families in Tallahassee had given her approval for this research study and.co-signed with this researcher the cover letter that was sent to the adoptive families with the questionnaire. Response Rate

As previously discussed, 230 returned responses were necessary in order to have sufficient power to analyze the findings. A total of 474 responses were completed and 
returned for an overall response rate of 328 with one mailing. The response rate was over double the number of responses which were required in order to have sufficient power for the analyses performed. The response rate was calculated by dividing the number of families who returned surveys (474) by the number of surveys sent out $(1,500)$. According to Fowler (1993), there is no agreed-upon standard for a minimum acceptable response rate for mail surveys. Although a researcher strives for a large response rate, it should be noted that the response rate for the single mailing in the current study was double that returned in the initial mailing for the field testing of the instrument. In this study, each district exceeded the minimum response rate needed. Table 2 presents the response rate for each district. Figure A-3 presents a graph of the number of surveys returned daily and Figure A-4 presents a graph the number of surveys cumulatively received each day following the mailout.

\section{Human Subjects Review Requirements}

All applicable human subjects review requirements were met and approved. The Human Rights Advocacy Committee for the District Ten HRS reviewed the dissertation proposal to ensure the appropriateness, anonymity, and safety of the research on human clients. They ruled that the research was not a threat or harm to any clients. The Human subjects Review Committee from Florida International University also 
approved the research proposal and found it to be of no potential harm to the respondents.

Precautions were taken to ensure that there were no known risks to the subjects. The only possible risk might have been anxiety from disclosure of information or from the decision not to participate in the study. Any possible anxiety due to the family's decision not to participate should have been allayed by the cover letter stating that participation was voluntary and nonparticipation would not affect subsidies or service provision. Additionally, since the survey was totally anonymous and the name of the adoptive family was not listed anywhere on the questionnaire, those families who did not return the survey were not able to be identified.

The copy of the cover letter (see Figure A-2) that was sent with the survey instrument addressed the issue of informed consent by explaining that return of the questionnaire would be considered consent to participate in the study. Explanation was provided in the cover letter regarding, the importance of why the particular person was singled out for participation and the benefits that could be expected from the research. Explanation was given that there was currently very little research or information on the subject of special needs postplacement adoption services. Therefore, the letter explained that it was important for adoptive families to make their needs known. 
By completing the questionnaire, they would assist social service professionals in learning about adoptive families so that appropriate and effective resources could be developed and made available when needed. The approximate time that it would take for the subject to complete the questionnaire was given.

Data Analysis

Specific analytic strategies for each research question and hypothesis are described in the Results section. Data analyses were conducted by use of the mainframe and personal computers using SPSS-X and SPSSPC+ statistical data analysis software packages (Norusis, 1990). 


\section{Chapter 4}

\section{Results}

This study was designed to generate and examine data on the perceptions of adoptive families who have adopted a special needs child from Florida. Primary areas of exploration include: (a) adoptive children and families' characteristics, (b) postplacement service utilization and satisfaction, and (c) adoptive parents' perceptions of their adoption' experiences.

This chapter presents the results of analyses conducted in the study. First, a descriptive presentation of the demographic data for the adoptive parents and children using frequencies for categorical variables and measures of central tendency for continuous variables is provided. The quantitative descriptive presentation consists of demographic summaries for the antecedent and intervening variables related to the adoptive parents and adoptive children, as well as summary data for the independent variables. The chapter concludes with further multivaj:iate statistical analyses of the antecedent, intervening, independent and dependent variables to determine the relationship between the study variables. The analyses of the data are organized by and parallel to the order of the research questions and hypotheses identified in Chapter: II. For each research question and hypothesis, an analysis of 
the statistical procedure and the findings are presented. Description of Entire Sample

A total of 474 families responded by completing and returning the survey. The response rate was double the number of responses required in order to have sufficient power for the statistical analyses performed. Either total or partial demographic data were provided on 469 adoptive mothers, 373 adoptive fathers, and 474 adoptive children. The personal demographics for the adoptive parents and the adoptive children are provided in Table 3 . Table 4 presents information regarding adoptive parents' experiences being foster parents. The child's demographic information is displayed in Table 5.

\section{Adoptive Parents' Characteristics}

Marital Status. The majority (738) of the respondents were married. The marital status of the rest of the sample was $10 \%$ divorced, 78 single, 68 widowed, 38 separated, and .98 were living with a partner.

Age. The age of the adoptive mothers ranged from 25 to 77 , with 758 of the mothers being between the ages of 34 and 52. The average age of the mothers was $44(S D=9.12)$. The age of the adoptive fathers ranged from 26 to 81 . The frequency of ages for the fathers was slightly more dispersed than with the mothers with 718 being between the ages of 34 and 52. The average age of the fathers was 46 $(S D=10.13)$. 
Table 3

Descriptive Statistics for Adoptive Families $(N=474)$

Variable

Adoptive Mother's Race

White

Black

White Hispanic

Black Hispanic

Biracial

Native American

Asian

Other

Not applicable/missing
311

118

20

0

5

5

1

1

13
67.5

25.6

4.3

$---$

1.1

1.1

1.2

.2

Adoptive Father's Race

White

Black

White Hispanic

Black Hispanic

Biracial

Native American

Asian

Other

Not applicable/missing

71.4 20.1

5.7

.3

.5

.8

.3

.3

Adoptive Mother's Education

Less than High School

High School

Some College

College

Post College

Not applicable/missing

37

143

125

87

70

12
8.0

31.0

27.1

18.8

15.2 
Adoptive Father's Education

Less than High School

High School

Some College

College

Post College

Not applicable/missing
43

98

107

69

51

106
11.7

26.6

29.1

18.8

13.9

Marital, Status

Single

Living with Partner

Married

Separated

Divorced

Widowed

Missing

\section{3}

343

13

47

28

6

$$
\begin{array}{r}
7.1 \\
.9 \\
73.3 \\
2.8 \\
10.0 \\
6.0
\end{array}
$$

Adoptive Mother's Religious Activities

Active

Moderate

Not Active

Not applicable/missing
255

117

68

34

58.0

26.6

15.5

Adoptive Father's Religious Activities

Active

Moderate

Not Active

Not applicable/missing
180

86

81

127
51.9

24.8

23.3

Adoptive Mother's Employment

None Outside of the Home Nonprofessional

Professional

Not applicable/missing

42.0 
Adoptive Father's Employment

None Outside of the Home Nonprofessional Professional

Not applicable/missing
43

133

180

118
12.1

37.4

50.6
Meàn

44.13

46.13

1.64

$0-10$

$0-5$

.58

Range

$25-77$

$26-81$

10.13

Number of Biological Children

Biological Children Still at Home
Number of Children Adopted

$$
\text { mode } \begin{array}{r}
2.30 \\
1.00
\end{array}
$$

Adoptive Children still at Home $\bmod$
1.91

1.00
$1-3$

$1-3$

$$
1.46
$$

$0-12$

$1-33$

2.29

Number Disrupted Adoptions

Number Dissolved Adoptions

Postplacement Services Utilized

Gross Income

$$
\begin{aligned}
& \$ 20,000-\$ 30,000 \quad \$ 10,000-\$ 100,000+2.09 \\
& \text { mode } \$ 10,000-\$ 20,000
\end{aligned}
$$


Race. The majority of the adoptive mothers (67\%) were white. Twenty six percent were African American, 48 were White Hispanic and the remaining 38 fell into the categories of biracial, Native American, Asian or other. The breakdown of the father's race was 718 white, 208 African American, 68 White Hispanic, and the remaining fathers classified themselves as Black Hispanic, biracial, Native American, Asian or other.

Religious Activities. Adoptive parents were asked to rate their religious activities as active, moderate or not active. Adoptive mothers reported being slightly more active (58\%) than adoptive fathers (52\%). Similarly, adoptive fathers were more frequently not active (238) as compared to adoptive mothers who were not active (15\%).

Biological Children. The number of biological children that the adoptive parents had was rather low with $74 \%$ of the families having two or fewer biological children and $34 \%$ having no biological children. The mean number of biological children was $1.64(S D=1.74)$. In 638 of the families, there were no biological children living in the home at the time of the survey. A maximum of 3 children were living in the home at the time of the survey in 998 of the cases. The mean number of biological children still living at home was .58 $(\mathrm{SD}=.90)$.

Education. The largest number of adoptive mothers (318) had completed high school while the largest number of 
fathers (298) attended some college. Overall the mean level of education was higher for the adoptive fathers. College graduates accounted for $34 \%$ of the adoptive mothers and $33 \%$ of the adoptive fathers.

Employment. In order to ascertain the type of employment, adoptive parents were asked to provide their job title. To ensure consistency, the author subjectively coded, according to her best judgment of whether the job title appeared to require a college degree, all responses into the categories of none/not employed outside of the home, nonprofessional, and professional. For example, all clerical and salesclerk positions were coded as nonprofessional and teaching or administrative positions were coded as professional. Women were not employed outside of the home in $38 \%$ of the families, $20 \%$ were in nonprofessional jobs and 428 were employed in professional positions. The adoptive fathers were in professional positions in 518 of the families, nonprofessional in 378, and no employment outside of the home in 128 of the respondents.

Income. In terms of total gross family income, the largest number of families (27\%) had income between $\$ 10,000$ and $\$ 20,000$. Over half of the respondents (51\%) had total income under $\$ 30,000$ and 718 had income under $\$ 40,000$. Adoptive Placements. When asked how many children had ever been placed for adoption with the respondents, $69 \%$ have 
had either one or two adopted children placed with them. The number of adopted children placed with the respondents ranged from 1 to 33 with a mode of 1.00 . The mean number of adoptive children continuing to reside in the respondents home was $1.9(\mathrm{SD}=1.41)$ and ranged from 0 to 12 with a mode of 1. Seventy eight percent (78\%) of the families still had between 0 and 2 adoptive children residing at home at the time of the survey.

Independent Adoptions. The vast majority of families (908) had no previous experience adopting a child independently through an attorney or physician. Of the families who had previously adopted independently, 498 felt that independent adoptions were easier than agency adoptions, $16 \%$ felt that independent adoptions were more difficult, and 368 felt they were the same.

Disruptions and Dissolutions. Of the 474 families responding, 38 (88) experienced a previous adoption disruption or dissolution. Twenty families (4\%) had one disrupted adoption and 10 families (2\%) had either one or two dissolved adoptions.

of those adoptions that either disrupted or dissolved, 548 involved a sibling group. In 658 of the adoptions that disrupted or dissolved with a sibling group, the adoptive parents were able to maintain the adoption of at least one of the siblings while the other child(ren) disrupted or dissolved. Therefore, in 358 of the cases sibling groups 
were subsequently separated after initially being placed for adoption together.

Foster Parenting. Table 4 provides data on the adoptive parents' involvement in being foster parents. When asked whether they had ever been a foster parent, the largest segment (418) had previously been foster parents, but were no longer fostering. The proportion of respondents who were currently foster parents was 228 and those who were never foster parents was 37\%. The two most frequent reasons given for becoming a foster family were to help children followed by it being an easy way to adopt.

The majority of the respondents (638) were at one time foster parents. Of that number, $84 \%$ were foster parents to their adoptive child. The two most common reasons given for adopting their child rather than fostering were that they became attached to the child and they wanted to adopt a child versus fostering.

The length of time the respondents fostered their adoptive child ranged from less than one year (248) to three families fostering for over 10 years. The modal length of time fostering was one to two years. The vast majority (918) of the families had fostered for four years or less. Adoptive Child's Characteristics

The adoptive parents were asked to complete the information for only their oldest adoptive child for whom they receive adoption subsidy and who was still living in 
Table 4

Adoptive Parents' Experiences as Being Foster Parents

Variable

Frequency

Percent

Have ever been a foster parent

No

Currently am

Previously, but not now

Missing

Reason for fostering

Help children

Religious calling

Playmate for other children

Companionship for parent

Child is a relative

Already knew the child

Easy way to adopt

Other

Missing or not applicable
173

100

191

10

184

19

4

2

14

13

46

14

178
37.3

21.6

41.2

Were a foster parent to their adoptive child

No

Yes

Missing or not applicable
49

251

174
62.2

6.4

1.4

.7

4.7

4.4

15.5

4.7

Length adoptive parents fostered their adoptive child

Less than 1 year

1 to 2 years

3 to 4 years

5 to 6 years

7 to 8 years

9 to 10 years

More than 10 years

Missing or not applicable

$\begin{array}{rr}63 & 24.4 \\ 92 & 35.7 \\ 79 & 30.6 \\ 16 & 6.2 \\ 4 & 1.6 \\ 1 & .4 \\ 3 & 1.2\end{array}$

216
16.3

83.7

-- - 
the home at the time of the survey completion. Table 5 summarizes the demographic characteristics of the adoptive child.

Age. The current ages of the adoptive children ranged from less than 1 year to 21 years. The mean age was 9.8 years $(S D=4.51)$. There were 378 of the children under the age of eight. Three quarters of the sample (75\%) were 13 years of age or younger.

Gender. There were more male adoptive children than females in the sample. Males accounted for 548 of the sample and females for 468 .

Race. The majority of the children (51\%) were white. The racial breakdown for the remaining children was African American (32\%), biracial (10\%), and White Hispanic (5\%). Each of the categories of Native American, Black Hispanic, Asian and other had less than 18 for each category.

Intraracial/Transracial Placements. Adoptive parents were asked whether the adoptive child was the same race as their family. In $85 \%$ of the responses, children were placed in homes where the parents were reported to be the same race as the child.

Special Needs Classification. The adoptive parents were asked to identify all of the reason(s) their adoptive child was classified as a special needs child. In order for a child to receive adoption subsidy in Florida, the child 
Table 5

Descriptive Statistics for Adoptive Child ( $N=474)$

Variable

Special Need Classification **

Minority

Mentally/Emotionally Handicapped

Sibling Group Member

Other Special Needs Classification

Over age eight

Physically Handicapped

Not Considered Special Needs
231

178

166

115

96

55

48
48.7

37.6

35.0

24.3

20.3

11.6

10.1

Number of Special Needs Subcategories Child Fits Into

0
1
2
3
4
5

Reason for Entering Foster Care * * Neglect

Abandonment

Physical Abuse

Sexual Abuse

Other Reason

Don't know the Reason
1
174
203
77
17
2

285

194

158

89

87

35

60.1

40.9

33.3

18.8

18.4

7.4

Adoptive Child's Sex

Male

Female

Missing
240

206

28
53.8

46.2

Note. ** denotes subcategories that are not mutually exclusive. The percents equate to the number of children being classified as yes in that subcategory. 
Adoptive Child's Race

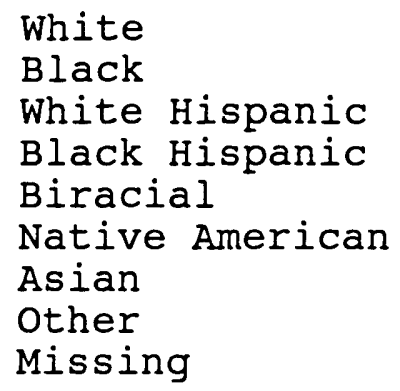

White

Black

White Hispanic

Black Hispanic

Biracial

Native American

Asian

Other

Missing

239

149

25

4

46

3

3

3

2

50.6

31.6

5.3

.8

9.7

.6

.6

.6

Child Same Race as Adoptive Parents

No

Yes

Missing
73

400

1
15.4

84.6

Adoptive Child's School Placement

Regular Classes or Home School

Emotionally Handicapped

Severely Emotionally Disturbed

291

37

10

31

Special or Alternative

Vocational School

College

Not in School

Missing

62.7

8.0

2.2

6.7

8.0

1.3

.6

10.6

- - -

Adoptive Child's Grade

Elementary (Preschool - 5th grade)

Middle ( 6 th -8 th grade)

High ( 9 th - 12th grade)

95

50.8

College

93

20.0

Not in School

4

19.6

37

.8

Missing 
Child Ever Placed in a Residential Treatment Center

No

Yes, Prior to Adoptive Placement

Yes, Since Adoptive Placement

Don't know

Missing
373

32

33

34

2
79.0

6.8

7.0

7.2

Any Biological Siblings

No

Yes

Missing

Placed for Adoption with Siblings

No

Yes

Missing or Not Applicable
75

386

13
16.3

83.7

Contact with Siblings

No

Yes

Missing or Not Applicable
254

99

121
72.0

28.0

Diagnosed Psychological or Emotional Problems

Previously had but no longer

Currently has the problem

Never had the problem

Missing
61

187

158

68
15.0 46.1

38.9

Diagnosed Behavioral Problems

Previously had but no longer Currently has the problem Never had the problem Missing
52

204

158

60
12.6

49.3

38.2 
Diagnosed Medical Problems

Previously had but no longer

Currently has the problem

Never had the problem

Missing
48

103

238

85
12.3

26.5

61.2

Diagnosed Developmental Problems

Previously had but no longer

42

10.4

Currently has the problem

126

31.3

Never had the problem

Missing

235

58.3

71

- - -

Diagnosed Educational Problems

Previously had but no longer

8.2

Currently has the problem

169

42.1

Never had the problem

199

49.6

Missing

Tests Completed on Child Prior to Adoption Placement **

Physical Exam

Psychological/Emotional Testing

Hearing Exam

Eye Exam

Dental Exam

Educational Testing
359

241

179

178

175

144
75.7

50.8

37.8

37.6

36.9

30.4

Previous Adoptive Placements

No

Yes

Don't know

Missing
401

51

21

1
84.8

10.8

4.4 
Total Number of Adoptive Placements

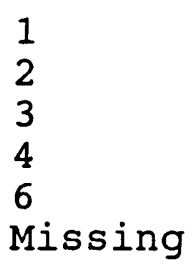

Child's Current Age

Age at Foster Care Entry

Age at Adoption Placement

Age at Adoption Finalization

Years in Foster Care

Number of Foster Care or

Relative Placements

Number of Special Needs

Subcategories Child Fits Into

Child's Grade Level
410

35

9

2

1

17
89.7

7.7

2.0

.4

.2

Mean

Range

SD

9.80

$0-21$

4.51

2.26

$0-12$

2.93

4.55

$0-16$

3.86

5.34

$0-16$

3.72

1.57

$0-10+$

1.09

$1-6+$

1.69

2.52

1.88

$0-5$

.84

4.89 Kind -16 th

3.75 
must meet at least one of the following classifications: minority race, over the age of eight, mentally/emotionally handicapped, physically handicapped or member of a sibling group.

Almost half (498) were classified by their adoptive parents as minority, $38 \%$ were mentally or emotionally handicapped, 358 were members of a sibling group, $20 \%$ were over the age of eight, and 128 were physically handicapped. Almost one quarter (24\%) listed other and of this category, the majority specified substance exposed newborns. Although HRS must have classified the adoptive child into one of the above five categories to receive subsidy, $10 \%$ stated their child was not considered special needs.

Since many of the children have multiple special needs, statistical analysis was conducted to determine how many children fit the classification of having at least two or more special needs. Results indicated that $63 \%$ were identified by the adoptive parents as meeting more than one special need category. The mean number of special needs classifications the sample of children met was 1.88 ( SD = $.84)$.

Diagnosed Problems. Adoptive parents were given a list of 5 problems and asked for each one if the child had previously been diagnosed with the problem but no longer had the problem, currently had the problem, or never had the problem. The five diagnosed problems included behavioral, 
psychological or emotional, chronic medical condition, developmental disability, or educational disability.

Current problems rated from the most frequent to the least frequent included behavioral (498), psychological or emotional (468), educational (428), developmental (318), and medical (27\%). The highest rated problem that previously was diagnosed but which the child no longer had was psychological or emotional (15\%), followed by behavioral (13\%), medical (128), developmental (10\%) and educational (88) problems.

Problems rated as never being present in the child from the most frequent to the least frequent included medical (61\%), developmental (58\%), educational (50\%), psychological or emotional (398), and behavioral (38\%). Thus, diagnosed psychological or emotional and behavioral problems are rated as the most prevalent problems the adoptive children have had previously and which they currently still have.

Testing Completed Prior to Adoptive Placement. Since the children placed for adoption with subsidy must have prediagnosed factors which meet the criteria for special needs classification, the intent of any adoption agency should be to have the child tested to either rule in or rule out any specific problems. Adoptive parents were asked which type of testing their child had received prior to adoption placement. The largest group (76\%) received a physical exam followed by 518 who received 
psychological/emotional testing. Hearing exams were completed on $38 \%$, eye exams on $38 \%$, dental exams on $37 \%$ and educational testing on 308 .

School Placements. The majority of the children (518) were in preschool or elementary school. The distribution between middle and high school was equal with 208 being in middle school and $20 \%$ being in high school. Only 4 children (.8\%) were in college. Eight percent (8\%) were listed as not being in school.

The adoptive children were primarily (63\%) placed in either regular classrooms or were participating in home schooling. Although 388 of the parents classified their child as emotionally handicapped in relation to special needs, only $8.0 \%$ were placed in emotionally handicapped school placements. School placements for the rest of the children included 88 in special or alternative placements, 78 in severely learning disabled, 28 in severely emotionally disturbed; and 18 in vocational school.

Reason for Entry into Foster Care. Children normally enter the foster care system due to sexual or physical abuse, neglect, or abandonment. The adoptive parents were asked to check all of the reasons their child entered the foster care system. The most common cause was neglect (60\%) followed by abandonment (418) and physical abuse (338). Sexual abuse accounted for 198 and $18 \%$ were listed as other for the reason coming into foster care. Of the families 
responding, 78 did not know why their child entered foster care.

Although the legal definition of abandonment is quite stringent and few children actually enter the foster care system under the legal definition of abandonment, 418 were rated as abandoned. It is hypothesized that the majority of these children entered the system for one of the other reasons and due to the biological family not stabilizing themselves sufficiently, the child was placed for adoption. In this situation, the adoptive parents may have felt that the biological family abandoned the child even though they did not in the true legal sense.

Over half $(578)$ entered the foster care system at one year of age or younger while $90 \%$ entered at age 6 or younger. The mean age of entry into foster care was 2.26 $(S D=2.93)$.

Length of Stay in Foster Care. The mean length of time the child spent in foster care prior to adoptive placement was 1.6 years $(S D=1.09)$. The findings of this study reveal that 148 remained in foster care less than one year and 388 remained for three years or less. Of the families responding, 68 did not know how long their child had remained in foster care.

The Adoption Assistance and Child Welfare Act of 1980 mandates children not remain in foster care over 18 months. 
However, in this sample 628 of the children remained in foster care anywhere from three years to over ten years. Foster Care or Relative Placements. The mean number of foster care or relative placements the child resided in prior to placement in the respondent's home was 2.52 (SD $=$ 1.69). It was determined that the majority (558) had two or fewer placements. Ten percent (10\%) of the children had 6 or more placements. Of the families responding, $10 \%$ did not know how many placements their children resided in prior to being placed with them.

Residential Treatment Placement. Placement in a residential treatment facility was examined. Of the responses, 798 of the children had never been placed in a residential treatment center. Seven percent ( $7 \%)$ were placed in a residential treatment center prior to adoptive placement and 78 were placed in a residential treatment facility since adoptive placement. Of the families responding, 78 did not know if their child had ever been placed in such a facility.

Biological Siblings. The adoptive parents were asked whether their child had any biological siblings and if yes, were they placed for adoption together. Over three quarters (848) had biological siblings yet only $23 \%$ were placed for adoption together. Of those who had siblings and were not placed together, 728 did not keep in any type of contact with their sibling. 
Previous Adoptive Placements. The majority of children (908) did not have any previous adoptive placements. Five percent (5\%) of the families did not know if their child had ever been placed in another adoptive home prior to placement in their home. For those children who were reported to have had prior adoptive placements, $8 \%$ had one previous placement, $2 \%$ had three previous placements, $.4 \%$ had four previous placements, and .28 had six previous placements. Age at Adoptive Placement. The mean age at adoption placement was $4.55(\mathrm{SD}=3.86)$ with a range between birth and age 16. An overwhelming majority (848) were placed for adoption at age 8 or younger. The mean age at adoption finalization was $5.34(\mathrm{SD}=3.72)$. The majority $(798)$ were age 8 or younger at the time of adoption finalization. Adoptive Parents' Adoption Experiences

Information regarding the adoptive parents' perceptions of their adoption experience were asked in various question formats. Four open-ended questions were asked in order to obtain qualitative responses that may not have been anticipated and which may more closely relate to the respondents' true feelings (Fowler, 1993). Eight closedended categorical response questions and 22 questions using a seven-point Likert scale were also utilized. Responses on the Likert scale ranged from one being strongly disagree, 4 being neutral and 7 being strongly agree. 
Table 6 presents findings from the closed-ended categorical questions regarding service provision. Table 7 summarizes the means and standard deviations regarding the adoptive parents' perception of their adoption experiences. Each of the four open-ended questions asked for one response which was categorized into similar topics and was coded by the same author to ensure consistency in interpretation (see Tables 8, 9, 10, and 11).

Adoption Training and Preparation to Adopt. The majority (67\%) attended MAPP training or some other type of adoption specific preservice training. Of those that did attend any type of training, 718 felt the training adequately prepared them to adopt. On average, the adoptive families somewhat agreed that they were realistic at the onset about the problems they would encounter throughout the adoption experience.

Information.

Adoptive parents somewhat agreed overall that the adoption agency told them all known information about the child. This parallels the findings that three fourths of the parents stated that after the adoptive placement, they did not learn from the agency any new information about their child that was already available to the agency.

Adoptive parents were asked what specific type of information they felt they needed prior to placement. Thirty three percent (338) of the parents stated they did 
Table 7

Adoptive Families' Perceptions of their Adoption Experiences

Adoption Experience

Mean

SD

1. Adoptive child understands the difference between adoption and foster care.

6.04 .088

2. Agency revealed all the information they knew about the child.

$4.96 \quad .103$

3. Agency exaggerated the adoptive child's problems.

$3.02 \quad .106$

4. Had enough information about the child prior to placement.

$4.88 \quad .099$

5. Agency was helpful prior to finalization. 5.51 077

6. Agency has been helpful since finalization.

$4.70 \quad .103$

7. There should be mandatory follow-up after finalization.

$4.84 \quad .096$

8. Know where to go to access needed services

$4.66 \quad .101$

9. Satisfied with services received.

$4.93 \quad .090$

10. Community has enough services for special needs children and families. $\quad 4.05 \quad .104$

11. Service providers understand the problems of special needs families.

$4.15 \quad .100$

12. Maintenance subsidy is helpful in providing for child's basic needs.

$5.78 \quad .077$

13. Received support from family to adopt. $6.25 \quad 056$

14. Received support from friends to adopt. $6.14 \quad .061$

15. Was realistic about the problems that would be encountered.

$5.03 \quad .091$ 
Table 6

Service Provision

Variable

Frequency

Percent

Participation in adoption support group

Never

Yes, currently

Previously, but not now

Missing
397

26

50

1
83.9

5.5

10.6

$---$

Attended adoption specific preservice training

No

Yes

Missing
155

314

5
33.0

67.0

Of those who attended, did adoption training adequately prepare families

No

Yes

Missing or Not Applicable
78

193

203 28.8

71.2

New information learned from agency since finalization

No

Yes

Missing
349

120

5
74.4

25.6

---

Maintenance adoption subsidy offered prior to placement

No

Yes

Missing
162

303

9
34.8

65.2

--.-

Medical adoption subsidy offered prior to placement

No

Yes

Missing
207

255

12
44.8

55.2

Same social worker from point of placement to finalization

No

Yes

Missing
149

322

3
31.6

67.9 
16. Would have adopted this child without maintenance subsidy.

$5.88 \quad .079$

17. Would have adopted this child without medical subsidy.

$5.65 \quad .095$

18. Experience adopting has been satisfying.

5.79

.079

19. Adoptive child would rate the experience as satisfying.

$6.12 \quad .066$

20. Retrospectively looking back, would adopt this child again.

$5.72 \quad .084$

21. Adoption was successful.

$6.09 \quad .069$

22. Would like to adopt another special needs child.

$4.13 \quad .111$

Note. Participants asked to score responses on a Likert scale ranging from 1 to 7 . 
not need any other information. In relation to the types of information that would have been helpful, adoptive parents listed in order of most desired biological family background (468), medical (308), behavioral (278), psychological/psychiatric (238), social/background (218), educational (118) and other (98).

\section{Support.}

Adoptive parents were asked whether they ever belonged to an adoption support group. Only $6 \%$ belonged to a support group at the time of the survey, 118 had previously belonged but no longer did, and 848 never belonged to a support group.

If the families had ever attended adoption training or participated in a support group, they were asked if they still kept in contact with any of the families who also participated. Over half, (638) did not keep in contact with any of the other adoptive families. On average, adoptive parents agreed that their families and friends supported their idea to adopt.

\section{Adoption Subsidy.}

When asked if maintenance and medical subsidy was offered to them prior to the child's adoptive placement, 658 reported yes for maintenance subsidy and 558 reported yes for medical subsidy. The parents agreed that the maintenance adoption subsidy was helpful in providing for the child's basic needs. However, the respondents were also 
in agreement that they would have adopted the same child even if they had not received maintenance or medical subsidy.

Service Satisfaction and Utilization.

The respondents were neutral in the perception that their community had sufficient services for special needs families and that the service providers that did exist understood the problems of special needs families. When asked if they knew where to go to access needed services, overall they were neutral to somewhat in agreement. As a whole they were somewhat satisfied with the services they received.

Adoptive parents were asked for suggestions on what type of services should be developed for adoptive families (see Table 8). Surprisingly, the most common answer given by $15 \%$ was none. The next most common responses were support groups (128), more counseling (98), other (88), and more training (68).

\section{Agency Related Issues.}

Out of all of the questions, the one that the adoptive parents disagreed the most with was the statement that the agency had exaggerated the child's problems prior to placement.

The adoptive families had the same adoption social worker from the time of placement all the way throughout the adoption finalization in $68 \%$ of the responses. 
Table 8

Responses to Open-Ended Questions Regarding What Special

Services Should be Developed for Adoptive Families

Answers

Frequency

Percent

None

Support groups

More counseling

Other

More training

More interaction with social worker

Child care

List of postadoptive services

Respite

Follow-up by agency

Hot line for information

\& referral / assistance

Subsidy should have cost of living increases

More information on biological family

Medical care

Advertise / recruit more for adoptive parents

Recreational opportunities

More information on child

Don't know

Communication with or help in locating biological family

Help working through the school system

Scholarships or financial

$$
\text { aid for college }
$$

More educational services for child

Medical coverage if move out of

state for non IV-E children

Adoptive parent mentor

Continue subsidy while child is in college

Legal advice

Newsletter

Transportation

Help with residential placement
55

44

32

27

21

18

16

14

14

13

12

11

10

8

8

8

8

8

7

6

5

5

2

2

2

2

1

1

1
15.2

12.2

8.9

7.5

5.8

5.0

4.4

3.9

3.9

3.6

3.3

3.0

2.8

2.2

2.2

2.2

2.2

2.2

1.9

1.7

1.4

1.4

.6

.6

.6

.6

.3

.3

.3 
Adoptive parents felt more strongly that the adoption agency was more helpful to them prior to finalization than after finalization.

They were somewhat in agreement that there should be mandatory follow-up by the adoption agency after adoption finalization.

Adoptive parents were asked what the adoption agency or social worker could have done differently to make their experience more successful and satisfying (see Table 9). The largest group (47\%) stated their experience was good and that nothing else could have been done to improve it. The next most popular responses suggested the social workers should have been more accessible (98) and more experienced or professional (8\%), and provided more information about the biological family (7\%).

Satisfaction With Adoption Experience.

The adoptive parents were satisfied with the entire experience in adopting their child and they felt that their adoptions were successful. Overall, they also felt that the adoptive children would rate their adoption experiences as satisfying.

The parents agreed that they would adopt their child again even if they knew at the beginning what they know now. However, the adoptive parents were neutral as to whether they would like to adopt another special needs child. 
Table 9

Responses to Open-Ended Questions Regarding What Could Have Been Done Differently to Make the Adoption Experience More Successful and Satisfying

Nothing - good social worker and agency experience

Social worker to be more available, accessible, keep in touch more

Social worker to be more experienced / professional

More information about biological family

Be more truthful

More postfinalization services

More information about child's problems

Termination of parental rights and adoption process too long

Provide more for needs of child

Other

Provide resources sooner Pictures of child's past More preplacement visits

6.6

21

6.1

20

5.3

20

5.1

14

3.5

12

3.0

7

6

1.8

1.5

6

1.5

Agency be more open to transracial placements

social worker to have lower caseloads

1.3 


\section{Concerns.}

Adoptive parents were questioned about what has been their biggest concern since finalization (see Table 10). Being a good parent (13\%) and no concerns (12\%) were almost equally responded. The next most frequent answers were the biological family trying to get the child back (98) and the outcome or success of the child ( 88$)$.

When the adoptive parents were asked what they thought their adoptive child's biggest concern had been since finalization, 418 stated no concern (see Table 11). The next most frequent concerns that the parents perceived their child had were rejection or fear of disruption (13\%), other (108), loss or grief issues (8\%) and lack of information about their biological family (58). Postplacement Service Need and Utilization

Adoptive parents utilized a mean of $5.6(\mathrm{SD}=3.97)$ and a mode of 5 postplacement services. In $8 \%$ of the families, no postplacement services were used. The utilization of postplacement services by families ranged from 0 to 33 .

Table 12 presents the distribution of 36 postplacement services that adoptive parents felt that they needed but were not used for whatever reason. The most frequent response, answered by $37 \%$ of the respondents, was for tutoring. The second and third most noted needs were for money other than the monthly maintenance subsidy (36\%) followed by support groups (318). After school activities 
Table 10

Responses to Open-Ended Questions Regarding the Biggest

Concern of the Adoptive Parents

Answers

Frequency

Percent

Being a good parent

None

Biological family trying to get child back

Outcome / success of child

Financial

Lack of information about biological family

Unexpected problems with child

Child's behavior problems

Inadequate adoption system

Child's emotional problems

Continuation of adoption subsidy

Other

Medical care

Inadequate resources

Interaction with biological family

Lack of resources

Separation of siblings

Child wanting to have contact

with biological family

Child's acceptance of adoptive family

Child's lack of trust, support
52

51

12.5

12.3

36

35

32

8.7

8.4

7.7

27

25

23

23

19

19

16

13

11

10

10

7

6.5

6.0

5.5

5.5

4.6

4.6

3.9

3.1

2.7

2.4

2.4

1.7

3

.7

.5

.2 
Table 11

Responses to Open-Ended Questions Regarding the Biggest Concern of the Adoptive Child as Perceived by the Adoptive Parents

Answers

Frequency

Percent

None

Rejection / fear of disruption other

Loss / grief or anxiety regarding biological family

Lack of information about biological family

Torn loyalty between biological and adoptive family

Biological family going to take them back

Anger, out of control

Trust

Concern over siblings

Medical problems

Embarrassed about being adopted

No pictures from the past

Maintaining relationship with

foster parents

Child being labeled

lack of information about child's past 2
162

50

39

30

19

17

16

14

9

9

8

7

4

3

3
41.3

12.8

9.9

7.7

4.8

4.3

4.1

3.6

2.3

2.3

2.0

1.8

1.0

.8

.8

.5 
Table 12

Postplacement Services Not Used But Needed

Postplacement Service

Frequency

Percent

1. Tutoring

2. Money (Besides Subsidy)

3. Support Group

4. After School Activities

5. Baby-Sitting

6. Special Educational Services

7. Child Counseling

8. Respite Care

9. Family Counseling

10. Dental Care

11. Life Planning

12. Crisis Intervention

13. Parent Education Training

14. Advocacy Training

15. Day Care

16. Speech or Language Therapy

17. Legal Aid

18. Therapeutic Day Care

19. Job Training

20. Medical Subsidy

21. Health Insurance for Child

22. Nonrecurring Final Expenses

23. Occupational Therapy

24. Homemaker Services

25. Training to Care for Child

26. Marital Counseling

27. Transportation

28. Residential Placement

29. Intensive Home-Based Services

30. Physical Therapy

31. Routine Medical Care

32. Outpatient Drug/Alcohol

33. Special Medical Equipment

34. Maintenance Subsidy

35. Inpatient Drug/Alcohol

173

170

149

142

135

123

100

99

94

90

85

84

83

79

76

74

70

66

66

62

62

36.5

35.9

31.4

30.0

28.5

25.9

21.1

20.9

19.8

19.0

17.9

17.7

17.5

16.7

16.0

54

53

50

44

44

44

43

41

15.6

36. Home Nursing

14.8

13.9

13.9

13.1

13.1

11.4

11.2

10.5

9.3

9.3

9.3

9.1

8.6

8.4

8.2

29

6.5

6.1

28

5.9

27

5.7

23

4.9 
was noted by $30 \%$, baby-sitting by 298 , and special educational services by $26 \%$.

Services that were anticipated to be mentioned high as a priority need were counseling and respite services. These services were rated by the respondents as the seventh through ninth priorities with child counseling (218), respite (218) and family counseling (208).

The services mentioned least often as not used but needed included home nursing (58), inpatient drug/alcohol treatment (68), maintenance adoption subsidy (6\%), and special medical equipment (68).

Postplacement Service Satisfaction

Table 13 provides the distribution of the 36 postplacement services for those families who used a specific service and were satisfied. The three services the majority of families used and were satisfied with was maintenance adoption subsidy (65\%), routine medical care (528) and health insurance for the child (50\%). The next five services used and satisfied with were dental care (498), nonrecurring adoption finalization expenses (45\%), medical adoption subsidy (398), child counseling (268), and speech or language therapy $(218)$.

In examining Table 13, the services that adoptive parents rated least used and satisfied with can be analyzed by reviewing the services with the lowest percentages. The services rated least used and satisfied with included 
Table 13

Postplacement Service Use and Satisfaction

Postplacement Service

Frequency

Percent

1. Maintenance Subsidy

2. Routine Medical Care

3. Health Insurance for Child

4. Dental Care

5. Nonrecurring Final Expenses

310

247

65.4

239

52.1

231

213

6. Medical Subsidy

184

7. Child Counseling

8. Speech or Language Therapy

9. Special Educational Services

122

99

87

10. Parent Education Training

11. Family Counseling

12. Training to Care for Child

78

70

50.4

13. Day Care

59

58

14. Support Group

15. Special Medical Equipment

16. After School Activities

17. Occupational Therapy

18. Physical Therapy

19. Respite Care

20. Baby-Sitting

21. Transportation

22. Residential Placement

23. Money (Besides Subsidy)

56

48

43

42

41

38

38

37

33

33

24. Tutoring

25. Life Planning

26. Marital Counseling

27. Legal Aid

28. Advocacy Training

29. Crisis Intervention

30. Intensive Home-Based Services

30

27

26

25

24

22

14

31. Therapeutic Day Care

32. Home Nursing

33. Job Training

34. Homemaker Services

35. Inpatient Drug/Alcohol

36. Outpatient Drug/Alcohol

48.7

44.9

38.8

25.7

20.9

18.4

16.5

14.8

12.4

12.2

11.8

10.1

9.1

8.9

8.6

8.0

8.0

7.8

7.0

7.0

6.3

5.7

5.5

5.3

5.1

4.6

3.0

2.7

1.7

1.1

.8

.4

.2 
outpatient drug/alcohol treatment (.28), inpatient drug/alcohol treatment (.48), homemaker services (.8\%), and job training (18). The services that were rated as least used and satisfied with are services that would be primarily used by older children. Since the mean age of children in this study was 9.8 years, the results are consistent with logical use of services.

\section{Barriers to Service Usage}

Adoptive parents were asked to rate specific barriers to service usage on a four point Likert scale ranging from it being no problem to a big problem. Combining those responses that identified a barrier as being anywhere from a small problem to a big problem, the following barriers were identified as the five largest problems: do not know what services are available (60\%), no money (56\%), services are not located in a convenient location (478), no baby-sitter $(428)$, and service does not exist (41\%).

Research Questions.

The first four research questions examined the influence of the adoptive parents' and child's antecedent and intervening variables as well as the independent variable on the dependent variables as previously discussed in the conceptual framework diagrammed in Figure 3.

Multiple regression analysis is appropriate for analyzing the collective and separate effects of two or more categorical or continuous independent variables on a 
continuous dependent variable (Pedhazur, 1982). In hierarchical regression, also known as variance partitioning, the total variance is obtained and then the computations partition the explained variance totals accounted for by each successive entry of the predictor variables in the equation. Since there was a theoretical concept of the logical sequence of variables, incremental partitioning of the variables was appropriate.

All categorical variables were dummy coded in order to perform the hierarchical multiple regression analyses. The new codes are summarized in Table 14 .

A new variable "service" was computed as the independent variable instead of the 36 different postplacement services. The variable "service" was computed by first coding each service as " 1 " (used and satisfied) and "O" (all others). Then, the sum of each case's utilization of the 36 postplacement services was obtained, resulting in a number ranging from 0 to 36 . A new variable "support" was computed by adding the variables of family support and friend support.

Due to the fact that the demographic antecedent variables of age, religious activities and education were highly correlated between the adoptive mothers and fathers, new variables were devised. "Parrelgn" was developed to denote the parents' religious activities with 1 indicating either parent being religiously active. "Parage" was 
Table 14

Recoding of Categorical Variables Used in Multivariate Analyses

\begin{tabular}{|c|c|c|}
\hline $\begin{array}{l}\text { Variable } \\
\text { Label }\end{array}$ & Variable & Code \\
\hline \multicolumn{3}{|c|}{ Demographics - Adoptive Parents } \\
\hline PAREDUC & parents' education & $\begin{aligned} 0= & \text { High school or } \\
& \text { less } \\
1= & \text { Some college or } \\
& \text { higher }\end{aligned}$ \\
\hline MARITAL & marital status & $\begin{array}{l}0=\text { Not married } \\
1=\text { Married single }\end{array}$ \\
\hline PARRELGN & parents' religion & $\begin{array}{l}0=\text { Not active } \\
1=\text { Active }\end{array}$ \\
\hline MOMEMPLO & mother's employment & $\begin{array}{l}0=\text { Not employed } \\
1=\text { Employed }\end{array}$ \\
\hline
\end{tabular}

Demographics - Adoptive Child

EIGHT

over age eight

$0=$ No

1 = Yes

HANDICPE

mentally/emotionally handicapped

$0=$ No

1 = Yes

PHYHANDI

physically handicapped

$0=$ No

1 = Yes

SIBLGOUP

sibling group member

$0=$ No

$1=$ Yes

NOSPECAL

not considered special needs

$0=$ No

1 = Yes

CHILDSEX

child's sex

$0=$ Male

1 = Female

CHLDRACE

child's race

$0=$ White

$1=$ Nonwhite

ANYBIOSI

any biological siblings

$0=$ No

$1=$ Yes 
SAMERACE

intraracial placement $\quad 0=$ No

1 = Yes

Intervening Variables - Adoptive Parents

SUPGROUP

belong to parent

support group

$0=$ No

SUPPORT

family and friend support

1 = Yes

MAPPTRAI

mapp training

$0=$ No

$1=$ Yes

FOSTERAD

foster parent adoption $\begin{aligned} & 0=\text { No } \\ & 1=\text { Yes }\end{aligned}$

$0=$ No

$1=$ Yes

Intervening Variables - Adoptive Child

PHYSABUS

physical abuse

$0=$ No

$1=$ Yes

SEXABUS

sexual abuse

$0=$ No

$1=$ Yes

NEGLECT

neglect

$0=$ No

1 = Yes

ABANDON

abandonment

$0=$ No

1 = Yes

OTHREAS

other reason for

entering care

$0=$ No

$1=$ Yes

TRTMTCTR

placement in residential treatment center

$0=$ No

behavioral problems

$1=$ Yes

BEHVRAL

$0=$ No

$1=$ Yes

MEDICAL

medical problems

$0=$ No

$1=$ Yes

EDUCTAL

educational problems

$0=$ No

1 = Yes

Independent Variable - Intervention

SERVICE

postplacement services

$0=$ all others

1 = used/satisfied 
computed to be the mean of the parents' ages. "Pareduc" was devised for the parents' educational level with 1 being coded for either parent having higher than a high school diploma. Mother's employment was used rather than computing a new variable for parents' employment because the vast majority of fathers were employed and there was more variance among the employment status of the adoptive mothers.

Hierarchical multiple regression analysis was computed to determine the effect the predictor variables had on the dependent variables (Devore \& Peck, 1993). A separate multivariate equation was computed for each of the four dependent variables. The variables that were included in the multiple regression equations were selected based upon the professional literature and the conceptual framework. Zero-order correlations were calculated for all of the predictor variables. When two variables were found to be highly correlated (above .30) conceptual relevance was determined and the less relevant variable or the variable that was similar to another variable in practical significance was eliminated unless the variable had extenuating practical and conceptual relevance. Table 15 presents a summary of the significant results for the hierarchical multiple regression equation for the first four research questions and Table 16 presents a summary of the 
Table 15

Summary of Significance Levels of Predictor Variable Blocks for the Research Questions (Hierarchical Multiple Regression Analysis)

Dependent Variable

\begin{tabular}{|l|c|c|c|c|}
\hline $\begin{array}{l}\text { Variable } \\
\text { Block }\end{array}$ & Adopt Again & Realistic & Success & $\begin{array}{l}\text { Satisfac- } \\
\text { tion }\end{array}$ \\
\hline $\begin{array}{l}\text { Parents' } \\
\text { Antecedent }\end{array}$ & No & No & No & No \\
\hline $\begin{array}{l}\text { Child's } \\
\text { Antecedent }\end{array}$ & Yes & Yes & Yes & Yes \\
\hline $\begin{array}{l}\text { Parents' } \\
\text { Intervening }\end{array}$ & Yes & Yes & Yes & Yes \\
\hline $\begin{array}{l}\text { Child's } \\
\text { Intervening }\end{array}$ & No & No & No & Yes \\
\hline $\begin{array}{l}\text { Independent } \\
\text { Variable }\end{array}$ & No & No & No & No \\
\hline
\end{tabular}


Table 16

Summary of Significant Betas for the Research Questions (Hierarchical Multiple Regression Analysis)

Dependent Variable

\begin{tabular}{|l|l|l|l|}
\hline $\begin{array}{l}\text { Willingness to } \\
\text { Adopt Again }\end{array}$ & $\begin{array}{l}\text { Realistic About } \\
\text { Problems }\end{array}$ & $\begin{array}{l}\text { Successful } \\
\text { Adoption }\end{array}$ & $\begin{array}{l}\text { Satisfied } \\
\text { with } \\
\text { Adoption } \\
\text { Experience }\end{array}$ \\
\hline Realistic + & Support + & Realistic + & Realistic + \\
Behavior - & Behavior - & Behavior - & $\begin{array}{l}\text { Behavior - } \\
\text { Sibling } \\
\text { Group - }\end{array}$ \\
\hline
\end{tabular}

+ : denotes positive relationship between dependent variable and variable with significant beta weight

- : denotes negative relationship between dependent variable and variable with significant beta weight 
significant betas for each of the first four research questions.

The multiple regression equations for the dependent variables willingness to adopt again, successful adoption, and satisfying experience had 35 independent variables entered ( 7 parental antecedent variables, 10 child antecedent variables, 5 parental intervening variables, 12 child intervening variables, and 1 independent variable). The equation for realistic about problems had one less parental intervening variable included because in the other three equations realistic about problems was included as a parental intervening variable.

The multiple regression equations were conducted using the "enter" method, whereby the researcher could control the order of entry of the variables. In all four regression equations, in order to predict the influence of the variables on the dependent variables, all predictor variables were entered simultaneously by entering the exogenous variables first, then the endogenous. The specific type of variables were entered in the following order: (a) adoptive parents' antecedent variables, adoptive child's antecedent variables, (c) adoptive parents' intervening variables, (d) adoptive child's intervening variables, and (e) independent variable. One hundred twenty-one cases were deleted from the analysis due to missing data using the pairwise deletion technique. 
Question 1: Influence of Antecedent, Intervening, and

Independent Variables Upon the Adoptive Parents' Level of

Willingness to Adopt Another Special Needs Child

The full model which included the two sets of

antecedent variables, two sets of intervening variables, and the independent variable was examined first. The results showed that this model explained 428 of the variance in the adoptive parents' level of willingness to adopt another special needs child, which was a significant proportion $(\mathrm{F}(35,317)=6.66, \mathrm{p}=.000)$. Therefore, it was appropriate to proceed to interpretation of the main effects.

The results of the adoptive parents' antecedent variables alone on the dependent variable of willingness to adopt another special needs child were not significant $(F(7,345)=1.39, p=.208$. Only 38 of the variance in the adoptive parents' perception of their willingness to adopt can be explained by the adoptive parents' antecedent variables $\left(R^{2}=.027\right)$.

In the next block, the child's antecedent variables were added. The effect of the adoptive child's intervening variables were analyzed by testing the increment in the proportion of variance of the dependent variable that the child's antecedent variables accounted for beyond that accounted for by the adoptive parents' antecedent variables. The results indicated that the adoptive child's antecedent variables accounted for an additional 7.98 beyond that 
accounted for solely by the adoptive parents' antecedent variables alone. This was a significant change $(F(10,342)=$ $2.97, \mathrm{p}=.001$. In this model 118 of the variance in the dependent variable can be explained by the adoptive parent and adoptive child's antecedent variables $\left(\mathrm{R}^{2}=.107\right)$.

Next, the effect of the adoptive parents' intervening variables was analyzed by testing the increment in proportion that it accounted for beyond that accounted for by the parents' and child's antecedent variables. The results indicated that the adoptive parents' intervening variables accounted for an additional $29 \%$ of the variance beyond that accounted for by the antecedent variables alone. Again, this was a significant change $(F(5,347)=30.97$, $\mathrm{p}=.000$. When adding the adoptive parents' intervening variables to the equation, 398 of the variance in the adoptive parents' willingness to adopt was explained $\left(\mathrm{R}^{2}=\right.$ $.392)$.

The effect of the adoptive child's intervening variables was analyzed next by testing the increment in proportion that it accounted for beyond that accounted for by the antecedent variables and the adoptive parents' intervening variables. The results indicated that the child's intervening variables accounted for an additional $3 \%$ of the variance beyond that accounted for by the antecedent variables and the adoptive parents' intervening variables. This was not a significant change $(F(12,340)=1.46$, 
$\mathrm{p}=.137$. When adding the adoptive child's intervening variables to the equation, $42 \%$ of the variance in the adoptive parents' willingness to adopt again was explained $\left(R^{2}=.424\right)$.

The effect of adding the independent variable, service, was analyzed by testing the increment in proportion that is accounted for beyond that accounted for by the parents' and child's antecedent and intervening variables. The results indicated that the independent variable accounted for no additional percent of the variance beyond that accounted for by the antecedent and intervening variables alone ( $R$ square change $=.000)$. This was not a significant change $(F(1,351)=.011, \mathrm{p}=.917$.

Beta weights are the coefficients of the independent variables when all of the variables are expressed in standardized form (Norusis, 1990). The beta weights in the full model were analyzed to determine the relative importance of the variables. The largest beta weight was .418 and was obtained for the variable of whether the adoptive parents were realistic about the problems they would encounter. The second and third highest beta weights were family and friend support (.219) and child's behavioral problems $(-.163)$. The remaining beta weights were all less than .09 .

The analysis of the beta weights reveals that as the adoptive parents' level of realism and support increased, 
the more likely they were to express a willingness to adopt another special needs child. The reverse was true for the child's behavioral problems. The more likely the child was reported to have behavioral problems, the less likely the parents were to adopt again.

In summary, only the blocks of variables for the child's antecedent and parents' intervening variables alone significantly contributed to explaining the variance in the adoptive parents' perceived willingness to adopt another special needs child. Additionally, the full model significantly explained the variance in the dependent variable.

Question 2: Influence of Antecedent, Intervening, and Independent Variables Upon the Adoptive Parents' Level of Being Realistic About the Problems They Would Encounter The full model explained 248 of the variance in the adoptive parents' level of being realistic about the problems they would encounter, which was a significant proportion $(F(34,318)=2.90, p=.000)$. Therefore, it was appropriate to proceed to interpretation of the main effects.

The results of the adoptive parents' antecedent variables alone on the dependent variable of level of realism about problems they would encounter were not significant $(F(7,345)=1.77, p=.093$. Only $3 \%$ of the variance in the adoptive parents' perception of their level 
of being realistic about the problems they would encounter was explained by the adoptive parents' antecedent variables $\left(R^{2}=.035\right)$.

In the next block, the child's antecedent variables were added. The results indicated that the adoptive child's antecedent variables accounted for an additional 8.58 beyond that accounted for solely by the adoptive parents' antecedent variables alone. This was a significant change $(F(10,342)=3.25, p=.001$. In this model 128 of the variance in the dependent variable can be explained by the adoptive parent and adoptive child's antecedent variables $\left(R^{2}=.120\right)$.

Next, the effect of the adoptive parents' intervening variables was analyzed. The results indicated that the adoptive parents' intervening variables accounted for an additional $8 \%$ of the variance beyond that accounted for by the antecedent variables alone. Again, this was a significant change $(F(4,348)=8.28, p=.000$. When adding the adoptive parents' intervening variables to the equation, 208 of the variance in the adoptive parents' level of being realistic about the problems they would encounter was explained $\left(R^{2}=.200\right)$.

The effect of the adoptive child's intervening variables was analyzed next. The results indicated that the child's intervening variables accounted for an additional $3 \%$ 
of the variance beyond that accounted for by the antecedent variables and the adoptive parents' intervening variables. This was not a significant change $(F(12,340)=1.11$, $\mathrm{p}=.352$. When adding the adoptive child's intervening variables to the equation, 238 of the variance in the adoptive parents' level of being realistic about the problems they would encounter was explained $\left(R^{2}=.232\right)$. The effect of adding the independent variable, service, was added next. The results indicated that the independent variable accounted for a minimal increase in the percent of the variance beyond that accounted for by the antecedent and intervening variables alone $(R$ square change $=.004)$. This was not a significant change $(F(1,351)=1.85, p=.175$. The beta weights in the full model were analyzed to determine the relative importance of the variables. The largest beta weight $(.275)$ was obtained for the variable of family and friend support. The second and third highest beta weights were the child's age (-.195) and child's behavioral problems (-.159). The remaining beta weights were all less than .09.

The analysis of the beta weights reveals that as the adoptive parents' support increased, the more likely they were to be realistic about the problems they would encounter. However, as the child's age increased and behavior problems occurred, the less likely the parents were to be realistic about problems. 
In summary, only the blocks of variables for the child's antecedent variables and the parents' intervening variables alone significantly contributed to explaining the variance in the adoptive parents' perceived level of being realistic about the problems they would encounter. Additionally, the full model was significant in explaining the variance in the dependent variable.

Question 3: Influence of Antecedent, Intervening, and Independent Variables Upon the Adoptive Parents' Perception of the Level of Success of the Adoption

The full model explained $39 \%$ of the variance in the adoptive parents' level of willingness to adopt another special needs child, which was a significant proportion $(\mathrm{F}(35,317)=5.88, \mathrm{p}=.000)$. Therefore, it was appropriate to proceed to interpretation of the main effects.

The results of the adoptive parents' antecedent variables alone on the dependent variable of adoptive parents' perception of the level of success of the adoption can be explained by the adoptive parents' were not significant $(F(7,345)=.288, p=.958$. Only .68 of the variance in the adoptive parents' perception of the level of success of the adoption can be explained by the adoptive parents' antecedent variables $\left(R^{2}=.006\right)$.

In the next block, the child's antecedent variables were added. The results indicated that the adoptive child's antecedent variables accounted for an additional $7.5 \%$ beyond 
that accounted for solely by the adoptive parents' antecedent variables alone. This was a significant change $(F(10,342)=2.75, p=.003$. In this model 88 of the variance in the dependent variable can be explained by the adoptive parent and adoptive child's antecedent variables $\left(R^{2}=.081\right)$.

Next, the effect of the adoptive parents' intervening variables was analyzed. The results indicated that the adoptive parents' intervening variables accounted for an additional $28 \%$ of the variance beyond that accounted for by the antecedent variables alone. Again, this was a significant change $(F(5,347)=29.603, p=.000$. When adding the adoptive parents' intervening variables to the equation, 368 of the variance in the adoptive parents' perception of the level of success of the adoption can be explained $\left(R^{2}=.366\right)$.

The effect of the adoptive child's intervening variables was analyzed next. The results indicated that the child's intervening variables accounted for an additional $3 \%$ of the variance beyond that accounted for by the antecedent variables and the adoptive parents' intervening variables. This was not a significant change $(F(12,340)=1.11$, $\mathrm{p}=.354$. When adding the adoptive child's intervening variables to the equation, 398 of the variance in the adoptive parents' perception of the level of success of the adoption was explained $\left(R^{2}=.391\right)$. 
The effect of adding the independent variable, service, was added next. The results indicated that the independent variable accounted for an additional $3 \%$ of the variance beyond that accounted for by the antecedent and intervening variables alone $(R$ square change $=.004)$. This was not a significant change $(F(1,351)=1.85, p=.175$.

The beta weights in the full model were analyzed to determine the relative importance of the variables. This question had the same three variables with the highest beta weights as the first research question. The largest beta weight was obtained for the variable of whether the adoptive parents were realistic about the problems they would encounter $(.376)$. The second and third highest beta weights were family and friend support (.296) and child's behavioral problems $(-.120)$. The remaining beta weights were all less than .09.

The analysis of the beta weights reveals that as the adoptive parents' level of realism and support increased, the more likely they were to perceive that their adoption was successful. The reverse was true for the child's behavioral problems. The more likely the child was reported to have behavior problems, the less likely the parents were to perceive their adoption as successful.

In summary, only the blocks of variables for the child's antecedent variables and the parents' intervening variables alone significantly contributed to explaining the 
variance in the adoptive parents' perceived level of being realistic about the problems they would encounter. Additionally, the full model was significant in explaining the variance in the dependent variable. Question 4: Influence of Antecedent, Intervening, and Independent Variables Upon the Adoptive Parents' Level of Satisfaction with the Adoption Experience

The full model explained 408 of the variance in the adoptive parents' level of satisfaction with the adoption, which was a significant proportion $(\mathrm{F}(35,317)=5.97, \mathrm{p}=$ $.000)$. Therefore, it was appropriate to proceed to interpretation of the main effects.

The results of the adoptive parents' antecedent variables alone on the dependent variable of level of satisfaction with the adoption experience were not significant $(F(7,345)=.588, p=.765$. Only 18 of the variance in the adoptive parents' perception of their level of satisfaction with the adoption experience can be explained by the adoptive parents' antecedent variables $\left(R^{2}\right.$ $=.012)$.

In the next block, the child's antecedent variables were added. The results indicated that the adoptive child's antecedent variables accounted for an additional 9.78 beyond that accounted for solely by the adoptive parents' antecedent variables alone. This was a significant change $(F(10,342)=3.66, p=.000$. In this model 118 of the 
variance in the dependent variable can be explained by the adoptive parent and adoptive child's antecedent variables $\left(R^{2}=.109\right)$.

Next, the effect of the adoptive parents' intervening variables was analyzed. The results indicated that the adoptive parents' intervening variables accounted for an additional $24 \%$ of the variance beyond that accounted for by the antecedent variables alone. Again, this was a significant change $(F(5,347)=24.87, p=.000$. When adding the adoptive parents' intervening variables to the equation, 358 of the variance in the adoptive parents' level of satisfaction with the adoption experience was explained $\left(\mathrm{R}^{2}\right.$ $=.353)$.

The effect of the adoptive child's intervening variables was analyzed next. The results indicated that the child's intervening variables accounted for an additional 48 of the variance beyond that accounted for by the antecedent variables and the adoptive parents' intervening variables. Again, this was a significant change $(F(12,340)=1.93$, $p=.031$. When adding the adoptive child's intervening variables to the equation, 408 of the variance in the adoptive parents' level of satisfaction with the adoption experience was explained $\left(R^{2}=.397\right)$.

The effect of adding the independent variable, service, was added next. The results indicated that the independent variable accounted for a minimal increase in the percent of 
the variance beyond that accounted for by the antecedent and intervening variables alone $(R$ square change $=.001)$. This was not a significant change $(F(1,351)=.308, p=.580$. The beta weights in the full model were analyzed to determine the relative importance of the variable. The largest beta weight was .364 and was again calculated for the variable of whether the adoptive parents were realistic about the problems they would encounter. The next highest beta weights in order of strength were family and friend support (.238), child's behavioral problems (-.174), and whether the child was a member of a sibling group (-.124). The remaining beta weights were all less than .09 . The analysis of the beta weights reveals that as the adoptive parents' level of being realistic about problems and their level of support increased, the more likely they were to be satisfied with their adoption experience. However, the more likely the child was reported to have behavior problems and if the child had siblings, the less likely the adoptive parents' were to be satisfied with their adoption experience.

In summary, this research question had three separate blocks of variables that significantly contributed to explaining the variance in the adoptive parents' perceived satisfaction with their adoption experience. The three sets of significant blocks were the child's antecedent variables, 
the parents' intervening variables, and the child's intervening variables.

Findings that were replicated in each of the first four research questions determined that neither the parents' antecedent variables or the independent variable alone were significant in explaining the variance in the dependent variables (See Table 15). However, all four research questions revealed that the full model, the child's antecedent variables and the parents' intervening variable blocks were significant individually in explaining the variance in the dependent variables. Additionally, the child's intervening variables alone were only significant in explaining the variance for the final question which examined satisfaction with the adoption experience as the dependent variable.

Interestingly, the analysis of the beta weights of the 35 variables resulted in the same findings in three of the four equations (See Table 16). The analysis revealed high levels of beta weights and in the same order of strength for the following three variables: (1) level of realism about problems they would encounter; (2) family and friend support; and (3) behavioral problems of the child. The two other variables that were found to have high beta weights included the child's age and whether the child was a member of a sibling group. 
Zero-order correlations were computed between the four dependent variables and the results reveal high correlations between all of the variables (See Table 17). From these results, it appears that the four dependent variables measure the same construct which would explain why similar results recurred in the four research questions.

Question 5: The Relationship Between Utilization of Services and Level of Satisfaction with the Adoption Experience

Question 5 examines whether the type of postplacement service used impacts on the adoptive parents' level of satisfaction with the adoption experience. For this question, the dependent variable was the adoptive parents' perceived level of satisfaction with the adoption experience. The dependent variable was measured by the adoptive parents using a 7-point Likert scale, with one being strongly disagree, 4 being neutral, and 7 being strongly agree. The independent variables were the 36 individual postplacement services.

Each postplacement service was recoded into two groups by utilizing dummy coding. The first group included those who used a specific postplacement service and were dissatisfied, those who did not use the specific postplacement service but needed it, and those who did not need the service. The second group was all families who 
Table 17

Zero-Order Correlation of the Dependent Variables

Correlations: Adopagai Realisti Successa Satisfex

Adopagai

1.000

$.5389 * *$

$.7855 * *$

$.6546 * *$

Realisti

$.5389 * *$

1.000

$.5101 * *$

.4897 **

Successa

.7855 **

$.5101 * *$

1.000

$.6887 *$ *

Satisfex

$.6546 * *$

.4897 * *

.6887 **

1.000

1 - tailed Signif: * -.01 ** - .001 
used a specific postplacement service and were satisfied with the service.

Multiple regression analysis was appropriate for this question as there was one continuous dependent variable and multiple categorical independent variables. The intent was to determine the effect of each postplacement service as a predictor of the adoptive parents' perceived satisfaction with their adoption experience. Table 18 presents the results of the multiple regression analysis examining the effects of these variables.

The $\mathrm{R}^{2}$, the coefficient of multiple determination, measures the percentage of the variation in the dependent variable which is explained by variations in the independent variables taken together (Pedhazur, 1982). With $\mathrm{R}^{2}=.15$, 158 of the variance in the adoptive parents' perceived satisfaction with the adoption experience can be explained by the combined influence of the postplacement services that are used.

Table 18 presents the results of the multiple regression with a rank ordering from most important to least important of the adoptive parents' perception of adoption satisfaction on selected postplacement services. The rank ordering is based upon the absolute beta weight for each postplacement service. 
Analysis of Adoptive Parents' Perception of Adoption

Satisfaction on selected Postplacement Services (Multiple Regression)

\begin{tabular}{|c|c|c|c|}
\hline Postplacement Service & B & Beta & $t$ \\
\hline Crisis Intervention & -1.783 & -.230 & $-3.920 *$ \\
\hline Residential Placement & -.662 & -.111 & -1.793 \\
\hline Training to Care for Child & .520 & .098 & 1.530 \\
\hline Routine Medical Care & -.322 & -.097 & -1.391 \\
\hline Life Planning & .707 & .096 & 1.627 \\
\hline Family Counseling & -.418 & -.093 & -1.211 \\
\hline Special Medical Equipment & .433 & .079 & 1.220 \\
\hline Respite Care & -.457 & -.078 & -1.345 \\
\hline Baby-sitting & .450 & .072 & 1.203 \\
\hline Tutoring & -.453 & -.066 & -1.046 \\
\hline Maintenance Subsidy & .232 & .064 & 1.097 \\
\hline Parent Education Training & .275 & .063 & .997 \\
\hline Support Group & -.314 & -.062 & -1.019 \\
\hline Legal Aid & .455 & .062 & 1.093 \\
\hline Physical Therapy & .352 & .060 & .827 \\
\hline Dental Care & .186 & .056 & .775 \\
\hline Day Care & .279 & .052 & .841 \\
\hline Special Educational Services & .208 & .049 & .720 \\
\hline After School Activities & .313 & .048 & .777 \\
\hline Occupational Therapy & -.281 & -.048 & -.643 \\
\hline Child Counseling & .154 & .041 & .553 \\
\hline Advocacy Training & .262 & .036 & .586 \\
\hline \multicolumn{4}{|l|}{ Drug/Alcohol Treatment } \\
\hline (Inpatient) & -.757 & -.034 & -.441 \\
\hline Job Training & -.529 & -.034 & -.541 \\
\hline \multicolumn{4}{|l|}{ Drug/alcohol Treatment } \\
\hline (Inpatient) & -1.038 & -.033 & -.378 \\
\hline Intensive Home-Based Services & -.279 & -.032 & -.534 \\
\hline Therapeutic Day Care & .326 & .031 & .512 \\
\hline Transportation & -.198 & -.031 & -.534 \\
\hline Nonrecurring Final Expenses & .099 & .030 & .519 \\
\hline Health Insurance & -.094 & -.028 & -.403 \\
\hline Homemaker Services & .426 & .014 & .218 \\
\hline Home Nursing & .171 & .012 & .189 \\
\hline Marital Counseling & .078 & .011 & .177 \\
\hline Money Other Than Subsidy & .070 & .010 & .185 \\
\hline Speech or Language Therapy & -.032 & -.008 & -.119 \\
\hline Medical Subsidy & .017 & .005 & .084 \\
\hline $.14588, \underline{F}(36,316)=1.49$ & & & \\
\hline
\end{tabular}


of adoptive parents' perceived satisfaction with their adoption experience. Crisis intervention had a beta of .230 and was the only postplacement service with a significant $t$ level of less than .05 . The remaining five most important services in order of importance in predictive ability were residential placement (.111); training to care for child (.098); routine medical care (.097); life planning (.096); and family counseling (.093).

The services which had the lowest beta weights and thus the least important predictive ability of perceived satisfaction, in order of least importance were medical subsidy (.005); speech or language therapy (.008); money other than monthly subsidy $(.010)$; marital counseling (.011); home nursing (.012); and homemaker services (.014). The findings show that the utilization of postplacement services contributed $15 \%$ to the variance in the adoptive parents' perceived levels of satisfaction with their adoption experience. The results of the regression analysis indicate that there were not significant differential outcomes on the level of satisfaction with the adoption experience based upon which specific postplacement services were utilized. Out of 36 postplacement services, only one, crisis intervention services, had a statistically significant impact on the adoptive parents' perceived level of satisfaction with the adoption experience. The remaining 35 postplacement services did not have significant 
statistical influence to predict the adoptive parents' perceived satisfaction with the adoption experience.

\section{Research Hypotheses.}

Hypothesis 1: The Relationship Between Successful Adoptions and the Adoptive Parents' Desire to Adopt Another Special Needs Child

Hypothesis 1 states that adoptive parents who rate their adoption as successful are more likely to express a desire to adopt another special needs child. For this hypothesis, the independent variable was the adoptive parents' perception of the success of their adoption. The dependent variable was the adoptive parents' perception of their level of willingness to adopt another special needs child. Both the independent and dependent variables were measured by the adoptive parents using a 7-point Likert scale, with one being strongly disagree, 4 being neutral, and 7 being strongly agree. Two analyses were conducted to test this hypothesis: a simple correlational analysis and a multiple regression.

Correlational analyses is the appropriate statistical technique to conduct to determine the relationship between two continuous variables (Weinbach \& Grinnell, 1987). Two correlation analyses were conducted, one without controlling for any variables, and one controlling for age. The decision to control for age was based on a number of returned surveys where the adoptive parents provided 
unsolicited qualitative comments that they would not adopt again due to their age.

The first analysis did not control for age and looked solely at the relationship between the adoptive parents' perceptions of the success of the adoption and their willingness to adopt again. The scattergram depicted a positive linear relationship. The correlation between the independent variable and the dependent variable for the 460 families providing data on these two variables was $r=.796$, $p<.0000$. This indicates the presence of a fairly strong significant positive relationship.

The coefficient of determination $\left(r^{2}\right)$ was .633 . Thus, 638 of the variance in the adoptive parents' perceived willingness to adopt another special needs child can be explained by their perception of the success of their adoption without controlling for any variables.

The second analysis also divided the respondents into two categories according to age of the respondents and was controlling for the adoptive parents' age.

Hierarchical multiple regression analysis was utilized to analyze the collective and separate effects of one continuous independent variables (success) and one categorical independent variable (adoptive parents' ages) on a continuous dependent variable (willingness to adopt again) (Pedhazur, 1982). Hierarchical multiple regression analysis was computed to determine the effect the predictor 
variables, perception of successful adoptions and the adoptive parents' ages, had on the dependent variable, willingness to adopt again (Devore \& Peck, 1993).

The analysis controlled for families with at least one parent who was at least 50 years of age. The age of 50 was selected as it approximates the end of childbearing age for women. The categorical variable of adoptive parents' ages was dummy coded in order to perform the hierarchical multiple regression analyses. Group one included those cases where either the adoptive mother or father were at least age 50. Group two consisted of single parent families where the parent was less than 50 and two-parent families where both were less than age 50 .

The multiple regression was conducted using the "enter" method to control the order of entry of the variables. In order to predict the influence of the predictor variables on the dependent variable, the exogenous variable of parents' age was entered first followed by the endogenous variable of the adoptive parents' perception of the level of successful adoption. Table 19 presents the results of the hierarchical multiple regression computed while controlling for the adoptive parents' age.

In the first run, the results of the adoptive parents' age alone on the dependent variable of willingness to adopt another special needs child showed that this model explained .68 of the variance in perception of willingness to adopt 
Table 19

Analysis of Adoptive Parents' Perception of Willingness to Adopt Again by Perception of Success of the Adoption Controlled by Age of the Adoptive Parents (Multiple Regression)

\begin{tabular}{lrrr}
\hline Independent Variable & B & Beta & $t$ \\
\hline & & & \\
Parents' Age & -.099 & -.026 & -.839 \\
Success of Adoption & .964 & .789 & $25.063 *$ \\
$\mathrm{R}^{2}=.63, \underline{F}(2,379)=316.93 *$ & & & \\
\hline
\end{tabular}

$* \underline{p}<.001$ 
again, which was not a significant proportion $(F(1,380)=$ $2.16, \mathrm{p}=.143)$. Less than 18 of the variance in the adoptive parents' perception of their willingness to adopt can be explained by the adoptive parents' age $\left(R^{2}=.006\right)$. In the next block, the adoptive parents' perception of success of the adoption was added. The effect of the adoptive parents' perception of the success of their adoption was analyzed by testing the increment in the proportion of variance of the dependent variable that the perception of success accounted for beyond that accounted for by the adoptive parents' age. The results indicated that the adoptive parents' perception of success accounted for an additional $62 \%$ beyond that accounted for solely by the adoptive parents' age alone. The results showed that $R^{2}$ change $=.620$ and that the cumulative $\mathrm{R}^{2}=.626$. The model resulted in a significant proportion $(F(2,379))=316.93$, $\mathrm{p}=.000)$.

Based upon the correlation and multiple regression analyses, it was determined that the adoptive parents' perception of the success of their adoption does impact on their desire to adopt another child, regardless of the adoptive parents' age. 
Hypothesis 2: The Relationship Between Adequate Information

\section{About the Child Prior to Placement and Level of Realism}

\section{About Problems}

Hypothesis 2 states that adoptive parents who believe that they received adequate information about the child prior to placement are more likely to perceive that they were more realistic about the problems they would encounter during the adoption process. For this hypothesis, the independent variable was the adoptive parents' perception that they received enough information about their adoptive child before the child was placed with them for adoption. The dependent variable was the adoptive parents' perception, looking back over the adoption experience, of how realistic they were about the problems they would encounter. Both the independent and dependent variables were measured by the adoptive parents using a 7-point likert scale, with one being strongly disagree, 4 being neutral, and 7 being strongly agree.

The first step in assessing the association between two variables is to utilize a scattergram. The scattergram with the variables adequate information and level of realism were analyzed to depict the strength and direction of the relationship between the two variables. After analyzing a scattergram, it is appropriate to quantify the strength of the association by calculating a summary index (Norusis, 1990). Correlational analyses was conducted to determine 
the relationship between two continuous variables and to determine statistically what the scattergram visually displayed (Weinbach \& Grinnell, 1987).

A Pearson's product moment correlation was computed to determine the strength and the direction of the linear association between the independent and dependent variables (Kuzma, 1992). Additionally, through the use of $\mathrm{R}^{2}$, correlation analysis attempted to predict a value of one variable from the knowledge of a value of the other variable (Weinbach \& Grinnell, 1987). The correlation computation was computed only to determine the strength and direction of the bivariate association and was not an appropriate statistical method to imply causation or explain why the variables tended to covary.

Through a visual analysis of the scattergram, it was concluded that the relationship between the two variables was positively linear although it was weak.

The coefficient of determination $\left(R^{2}\right)$ was computed to be .142 . This analysis reveals that 148 of the variance in the dependent variable can be explained by its relationship to the independent variable.

The correlation between the independent variable and the dependent variable for the 462 families providing data on these two variables was $r=.377, p<.0000$. This indicates the presence of a statistically significant albeit weak positive relationship. 
Hypothesis 2 was supported. The results of the statistical analyses on this hypothesis indicate that the more the adoptive parents perceived that they had adequate information about their child prior to placement, the more they perceived that they were realistic about the problems they encountered. Additionally, 148 of the variance in the adoptive parents' perception of their level of realism regarding the problems they would encounter is explained by the adoptive parents' perception that they received adequate information about their adoptive child. Although there appears to be a weak relationship between the two variables, caution must be used to ensure that these results do not imply causation.

Hypothesis 3: The Relationship Between Use and Satisfaction With Postplacement Services and Level of Success of the

\section{Adoption}

Hypothesis 3 states that adoptive parents who use and are satisfied with postplacement services are more likely to perceive their adoption as successful. For this hypothesis, the independent variables were the adoptive families' use and satisfaction of 36 separate postplacement services and the dependent variable was the adoptive parents' perceived level of success of the adoption.

The appropriate statistical technique for hypothesis three was ANOVA since there was one continuous dependent variable and one categorical independent variable. The 
purpose of the ANOVA statistical technique was to test the hypothesis that the group means of the dependent variable were equal (Norusis, 1990).

The independent variables were recoded into two groups. The first group included those who used a specific postplacement service and were dissatisfied, those who did not use the specific postplacement service but needed it, and those who did not need the service. The second group was all families who used a specific postplacement service and were satisfied with the service.

Thirty six separate ANOVA computations were computed using each specific postplacement service with the adoptive parents' perceived level of success of the adoption. Table 20 presents a summary of the results for the 36 ANOVAs including the mean score for each group, the eta and the $p$ level for each postplacement service. Table 21 presents further data from the analysis of variance for those services that were statistically significant.

It was hypothesized that of the two groups, group two consisting of those that used a service and were satisfied, would probably be more likely to have a higher mean as compared to group one which included three subgroups, two of which one would expect to have negative feelings: those who were dissatisfied with the use of the service and those that needed the service but did not use it. Interestingly, 3 of the 36 postplacement services had statistically significant 
Table 20

Perception of Successful Adoption by Selected Postplacement Services (ANOVA)

\begin{tabular}{lccc}
\hline & $\begin{array}{c}\text { Group } 2 \\
\text { Mean Score }\end{array}$ & $\begin{array}{c}\text { Group 1 } \\
\text { Mean Score }\end{array}$ & Eta \\
Usedplacement Service & $\begin{array}{c}p \\
\text { Ull Others }\end{array}$ & level \\
\hline
\end{tabular}

\begin{tabular}{|c|c|c|c|c|}
\hline Homemaker Services & 6.75 & 6.12 & .04 & .385 \\
\hline Physical Therapy & 6.61 & 6.05 & .11 & .020 \\
\hline Special Medical Equipment & 6.52 & 6.05 & .10 & \\
\hline Home Nursing & 6.50 & 6.12 & .04 & \\
\hline Advocacy Training & 6.50 & 6.14 & .06 & \\
\hline Training to Care for Child & 6.39 & 6.09 & .07 & \\
\hline Baby-sitting & 6.38 & 6.08 & .06 & \\
\hline Speech or Language Therapy & 6.34 & 6.02 & .09 & .064 \\
\hline Money (Besides Subsidy) & 6.33 & 6.09 & .04 & \\
\hline Life Planning & 6.33 & 6.08 & .04 & $.3 \xi$ \\
\hline Occupational Therapy & 6.29 & 6.06 & .05 & \\
\hline Day Care & 6.26 & 6.10 & .04 & .43 \\
\hline Respite Care & 6.26 & 6.11 & .03 & .52 \\
\hline Legal Aid & 6.24 & 6.12 & .02 & .68 \\
\hline Therapeutic Day Care & 6.23 & 6.11 & .01 & .772 \\
\hline Health Insurance for Child & 6.22 & 5.96 & .09 & .068 \\
\hline Maintenance Subsidy & 6.21 & 5.83 & .12 & .01 \\
\hline Nonrecurring Final Expenses & 6.21 & 6.00 & .07 & .13 \\
\hline Routine Medical Care & 6.20 & 5.95 & .08 & .08 \\
\hline After School Activities & 6.19 & 6.09 & .02 & .678 \\
\hline Medical Subsidy & 6.17 & 6.06 & .04 & .425 \\
\hline Dental Care & 6.17 & 6.00 & .05 & .256 \\
\hline Parent Education Training & 6.17 & 6.11 & .02 & .74 \\
\hline Intensive Home-Based Services & 6.14 & 6.10 & .00 & .92 \\
\hline Special Educational Services & 6.07 & 6.11 & .01 & .827 \\
\hline Support Group & 6.02 & 6.12 & .02 & .612 \\
\hline Child Counseling & 5.97 & 6.12 & .05 & .325 \\
\hline Transportation & 5.94 & 6.11 & .03 & .526 \\
\hline Marital Counseling & 5.92 & 6.14 & .03 & .466 \\
\hline Residential Placement & 5.85 & 6.18 & .06 & .192 \\
\hline Family Counseling & 5.79 & 6.17 & .09 & .046 \\
\hline Tutoring & 5.73 & 6.10 & .06 & .193 \\
\hline Job Training & 5.40 & 6.12 & .05 & .275 \\
\hline Inpatient Drug/Alcohol & 5.00 & 6.11 & .05 & .282 \\
\hline Crisis Intervention & 4.86 & 6.16 & .19 & .000 \\
\hline Outpatient Drug/Alcohol & 2.00 & 6.12 & .13 & .005 \\
\hline
\end{tabular}

Note. Participants asked to score responses on a Likert scale ranging from 1 to 7 . 
Table 21

Perception of Successful Adoption by 6 Statistically Significant Postplacement Services (ANOVA)

Postplacement Service

af

F

Crisis intervention

Outpatient drug/alcohol treatment

Maintenance subsidy

Physical therapy

Special medical equipment

Family Counseling

1,439
1,436
1,441
1,441
1,439
1,445

$16.37 * * *$

$8.08 * *$

$6.44 *$

5.44 *

4.48 *

4.01 *

$* \underline{p}<.05$

$* * \mathrm{p}<.01$

$* * * \underline{D}<.001$

181 
higher means for group one than group two. The postplacement services that had statistically significant higher means for group one included family counseling, crisis intervention, and outpatient drug/alcohol treatment.

The largest variance between the two means for any specific postplacement service was outpatient drug/alcohol treatment where the mean for group one was 6.12 and the mean for group two was 2.00. However, the size of the sample of group two was only one child which makes this finding severely limited.

The analysis of variance revealed that six postplacement services had significant levels (see Table 20). These services were crisis intervention, $F(1,439)=$ 16.37, $\mathrm{p}<.001 ; \mathrm{drug} / \mathrm{alcohol}$ treatment outpatient, $\mathrm{F}(1$, $436)=8.08, p<.01$; maintenance subsidy, $F(1,441)=6.44$, $\mathrm{p}<.05$; physical therapy, $\mathrm{F}(1,441)=5.44, \mathrm{p}<.05 ;$ special needed medical equipment, $F(1,439)=4.48, \mathrm{p}<.05 ;$ and family counseling $F(1,445)=4.01, p<.05$.

The findings regarding this hypothesis reveal that the means for both groups relative to the perceived success level by each specific postplacement service are in the high range without tremendous variance. The findings further reveal that out of the 36 postplacement services, only 6 were found to be statistically significant. Therefore, this hypothesis was not fully supported by the findings. 
Chapter 5

Discussion

\section{Summary of the study}

This research was designed with three specific purposes for learning more about special needs adoptions in Florida. The primary purpose was to conduct descriptive research on special needs adoptive parents and children. The secondary purpose was to conduct exploratory research to provide a beginning understanding of the adoption experiences of special needs families. The third purpose was to identify, examine and assess the relationship of empirically and conceptually relevant variables regarding special needs children and their adoptive families. Areas examined include demographic data, background, adoptive experiences and service utilization as a means to provide a comprehensive assessment for intervention research directed at increasing postplacement adoption successes. To do this, the study analyzed the relative influence of possible determinants of special needs adoptive parents' perceived adoption experiences and outcomes with primary focus on postplacement service needs and usage.

Adoptive parents who responded to this survey were primarily white, middle age, college educated and married. The majority of the women worked outside of the home. For both mother and fathers who worked outside of the home, the majority worked in professional positions. The mean gross 
family income ranged from $\$ 20,000$ to $\$ 30,000$. Sixty-three percent had at one time been foster parents and of those, 848 of them had fostered their adoptive child. The families had a mean of 1.64 biological children and the majority of them had adopted only one child.

The children they adopted were primarily white male children with an average age of 9.8 years who were placed in a regular elementary school setting. The majority of children met the criteria for more than one type of special need.

The most common reason the children entered foster care, at a mean age of 2.26 years, was due to neglect. They remained in foster care for an average of 1.57 years and had an average of 2.52 relative or foster care placements prior to adoptive placement in their current home. Although few had been placed in a residential treatment program, a large majority of them had either previously or still presently suffered with psychological/emotional or behavioral problems.

The overwhelming majority of the children ( 848 ) had siblings; however only $23 \%$ were placed for adoption with their siblings. Further, of those who had siblings and were placed separately, 728 of the children did not keep in any type of contact with their sibling.

Although many adolescents enter foster care, no child over the age of 12 was listed in this sample as entering 
foster care. This finding was surprising since the instruction to the adoptive parents was to complete the survey on the oldest adoptive child who was still living at home. The young age of the children reported in this study appears to be indicative of the fact that the majority of children who are placed for adoption are younger in spite of the push to place older children for adoption.

Overwhelmingly the adoptive parents reported that their adoptions were successful and they were satisfied with their adoption experience. The parents indicated that the adoption agency was more helpful to them prior to the adoption finalization than after.

Hierarchical multiple regression was used to test the effect the predictor variables had on four dependent variables: willingness to adopt another special needs child, successful adoption, satisfying experience, and realism about problems. It was determined that the full model and the child's antecedent and the adoptive parents' intervening variable blocks were significant in explaining the variance in all four of the dependent variables. The child's intervening variables alone were only significant in explaining the variance for one dependent variable, satisfaction with the adoptive experience.

It was determined that the adoptive parents' perception of the success of their adoption does impact on their desire 
to adopt another child regardless of the adoptive parents' age.

The parents did not feel strongly that the agency revealed all of the information they knew about the child. Interestingly, the parents reported that they strongly felt the adoption agency did not exaggerate the adoptive child's problems. The research also found that the more the adoptive parents perceived that they had adequate information about their child prior to placement, the more they perceived that they were realistic about the problems they encountered.

One disturbing finding was that a significant amount of families reported they did not receive specific information about their adoptive child that one would expect that they should know. Between 20 and 45 families contend that they did not know the reason their child entered foster care, the length of time spent in foster care, the number of foster care/relative placements, if the child had previous adoptive placements, and whether the child had ever been in a residential treatment center. These findings suggest that if the social service agencies are providing the adoptive parents with the relevant background information on the child prior to placement, the adoptive parents are not effectively and appropriately processing the information. The postplacement services that were rated as least used and satisfied with were outpatient and inpatient 
drug/alcohol treatment, homemaker services, and job training. Since these are services that would be primarily used by older children and the mean age of children in this study was 9.8 years, the results are not surprising and are consistent with logical use of services by age appropriate clients.

The research also showed that adoptive parents who use and are satisfied with postplacement services are more likely to perceive their adoption as successful for only six services: crisis intervention, outpatient drug/alcohol treatment, maintenance subsidy, physical therapy, special medical equipment, and family counseling. However, only one service, crisis intervention, was shown to have a significant impact on the adoptive parents' perceived level of satisfaction with the adoption experience. Thus, although adoptive parents perceive a need for postplacement services and the professional literature supports the need for such services, this research study found that the effect of postplacement services on adoption outcomes was minimal. Therefore, further research needs to be conducted to determine postplacement services effectiveness in ensuring positive outcomes.

Discussion of the Findings

The children in this studied remained in foster care for an average of 1.57 years. This figure is substantially 
lower than the 3.5 to 5.5 years found by the Office of Inspector General (1991).

The rate of foster parent adoption was found to be higher in this study than in other national research. Although the findings regarding the rate of foster parent adoptions has been inconsistent, rates in the literature range from a low of 408 to a high of 808 (Anderson, 1990; Barth \& Berry, 1988; Office of Inspector General, 1988). The results of this study reveal that 638 of the respondents had at one point been foster parents and of that number 848 had fostered their child prior to the adoption placement. Findings in this study differed from Proch (1982) in relation to children understanding the difference between adoption and foster care. Proch interviewed both adoptive parents and children and found that the two services were blurred in children's views. This study did not interview the adoptive children but the findings revealed that adoptive parents perceived that their children understood the difference between the two types of services.

The preponderance of the literature details the increased special needs of the children entering foster care and adoptive placements; however, this study revealed higher rates of children having multiple special needs. Gilles (1995) was the first to examine the rate of multiple needs for adoptive children. He found that 578 of the adoptive children placed after 1990 had multiple special needs. 
Similarly, the data from this study reveal that $63 \%$ of the children in the sample met the criteria for having more than one special need.

Descriptive findings related to the adoptive children from this study were similar to the study by Sedlak and Broadhurst (1993) which consisted of a nationally representative sample of 2,200 children adopted throughout the United States. Although the descriptive findings of this study are similar to those of Sedlak and Broadhurst, caution must be used when comparing the results of the two studies since two totally different samples were utilized. They found higher rates of white and Hispanic children than this study. On the contrary, this study had a slightly higher rate of African American children.

The rate of children's diagnosed problems was much higher in this study when combining diagnosed problems that the child had currently or had previously been diagnosed with than that found by Sedlak and Broadcast (1993). Emotional or psychological problems accounted for only $43 \%$ in Sedlak and Broadhurst's study and 618 in this study. Educational problems were diagnosed in $30 \%$ of Sedlak and Broadhurst's study and $50 \%$ in this study. Sedlak and Broadcast found 228 had special medical needs while this study found $38 \%$. The reasons for the children entering foster care was similar between the two studies. 
Sedlak and Broadcast (1993) found a slightly higher rate of married couples and same race placements, and a lower rate of foster parent adoptions. Findings that were similar between the two studies were in relation to adoptive parents' mean ages.

The perception of the adoption being successful fell within the range of other studies. Eighty-one percent of the respondents in this study felt their adoption was successful as compared to other studies in which the success ranged from 708 to 908 (Barth \& Berry, 1990; Hoopes, 1990, Rosenthal, Groze \& Curiel, 1990; Urban Systems, 1985).

Findings from this study are different from Unger et al. (1988) in relation to adoptive parents' willingness to adopt another special needs child. This study found that $30 \%$ either agreed or strongly agreed that they would adopt again while Under et al. found that $43 \%$ were willing to adopt another special needs child.

The information on disruptions and dissolutions gained in this study is limited to a small sample of the families responding $(8 \%)$. No information was gathered regarding the children that disrupted/dissolved other than if they were a member of a sibling group and whether the placement of the siblings was maintained following the disruption/dissolution of one of the children.

A finding that has been replicated in many studies is that adoptive parents who have unrealistic expectations of 
their adoptive child are at a higher risk of disruption/dissolution. Concern must be raised in the findings of this study since $26 \%$ of the respondents either strongly disagreed or disagreed that they were realistic about the problems they would encounter with their adoptive child.

Another predictor of increased disruption/dissolution rates found in the literature is the lack of preparation or training and lack of sufficient background information on the child (Barth, 1988; Barth \& Berry, 1988; Nelson, 1985; Schmidt et al., 1988; Urban Systems, 1985). Concern is raised since in this study, $30 \%$ felt they did not have sufficient information about the child.

Berry (1990) found that satisfaction with agency preparation was the second most critical predictor of the adoptive parents' satisfaction with the adoption process. In this study, 338 did not have any type of adoption training prior to placement. The need for mandatory training is intensified further by the findings in this study whereby 718 of those who did attend preservice adoption training felt that they were adequately prepared to adopt.

The previously held belief that once an adoption was finalized the family would no longer want contact with the adoption agency has been challenged. This study confirms prior research that reveals that some adoptive parents 
believe there should be ongoing mandatory contact with the adoption agency after finalization. It is interesting to note that the adoptive parents' views on mandatory follow-up werenot on the negative side and in fact, the majority of the parents felt either neutral or somewhat agreed with the idea of mandatory contact following the adoption finalization.

Utilization of postplacement services in this study's sample was high as evidenced by the families utilizing a mean of 5.6 postplacement services. In only 178 of the families was no postplacement service used other than subsidy which is much lower than the $45 \%$ who received no services other than subsidy in Gilles' study (1995).

When identifying barriers to obtaining needed services Watson (1991) found $32 \%$ did not know what services were available and 298 did not know where the right service was located. In this study, adoptive parents were asked to rate specific barriers on a four point Likert scale ranging from it being no problem to a big problem. Combining those responses that identified a barrier as being anywhere from a small problem to a big problem, knowing what services were available was rated the largest problem (60\%) and location of services was rated the third (478). Having no money was rated as the second largest problem in this study by $56 \%$ of the respondents. 
Satisfaction with services used was higher in this study in contrast to Watson's study (1991). This study reported $65 \%$ of the respondents were satisfied as compared to a 518 satisfaction rate that watson found. This study found some similarities among other studies in relation to the postplacement services most needed (Gilles, 1995; Marcenko \& Smith, 1991; Walsh, 1991; Watson, 1991). Gilles reported the top three service needs were mental health services, respite care, and tutoring/educational services. Marcenko and Smith revealed that adoptive parents most needed respite care, life planning, and support groups. Walsh and Watson found that the top three needed services were special education, medical services, and money other than subsidy. This study found tutoring, money besides subsidy, and support groups were the top three services needed.

Although other studies (Anderson, 1990; Barth \& Berry, 1988; Marcenko \& Smith, 1991) showed that adoptive parents were not satisfied with clinical interventions or that these interventions were not effective, this study had contradictory findings. This study identified those services that adoptive families used and were satisfied with and found rates of $26 \%$ for child counseling, $15 \%$ for family counseling, and 68 for marital counseling. This supports McDonald et al. (1991) who found that mental health services 
was the most frequently used service used by 418 of their sample.

Findings in this study regarding very high levels of support from friends and family confirm the findings of Rosenthal et al. (1990).

An encouraging finding that was replicated in this study from Bartholet (1993) is that the majority of adoptive parents would have still adopted their child without any type of adoption subsidy.

Implications for Social Welfare

The literature reports that the number of children entering foster care, the number of special needs adoptions, and the number of adoption disruptions and dissolutions are all on the increase (Barth et al., 1986; Brooks, 1991). Families are confronted with a myriad of unique social problems that are tearing away at the very core of parents' abilities to effectively raise their own children. Families are increasingly becoming dysfunctional due to the social pressures of increased divorce, drug usage, unemployment, crime, and poverty.

A finding from this study that has also been documented in previous research is that the adoptive parents perceive they have a need for postfinalization resources throughout the life cycle of the adoption process (APWA, 1991a; Barth et al., 1986; CWLA, 1988; Gilles, 1995; Grabe \& Sim, 1990; Hartman, 1984; LePere, 1987; Levine \& Salles, 1990; NACAC, 
1990). Although the findings in this study of the effectiveness of postplacement services in ensuring positive outcomes was disappointing, social service agencies have an obligation to provide services and support that can be empirically proven to optimize the opportunities for special needs adoptive families to stabilize and bond.

Pathways must be opened to innovative improvements that can be developed to help special needs adoptive families. A continuum of comprehensive support services is necessary to assist families in having successful outcomes.

It is simplistic to expect that the same intervention will have identical effectiveness and consequences for every special needs adoptive family. The characteristics of special needs adoptive children and their families will have an impact on the perceived need, utilization and ultimate outcome of an intervention. Depending upon the individual uniqueness of each child and adoptive family, there will be different outcomes. Thus the intervention must meet the social, psychological, and behavioral needs of the adoptive family.

Anecdotal and research data indicate that adoptive families have a wide range of experiences and needs. Not every special needs adoptive family will seek out or even need the same intervention. Therefore, innovative approaches need to be developed to support this alternative family structure. 
The findings contained in this study document a significantly larger number of children who have been diagnosed with psychological, emotional, educational, and behavioral problems as compared to other studies. Not surprisingly then, this study has also documented that there is a higher rate of multiple special needs of the adoptive children sampled as compared to other research studies. Therefore, this study strongly indicates the need for interdisciplinary collaboration to develop holistic interventions. A multi-disciplinary approach through the health, mental health, child welfare, and education systems is warranted. Only by providing a multi-systemic approach to problem-solving can the problematic situations and experiences faced by special needs adoptive families be addressed appropriately without a piecemeal or bandaid approach .

Prevention programs need to become a priority for those agencies servicing special needs adoptive families. Social service agencies must take affirmative actions to provide supportive services to the adoptive families throughout the families' lives and not at points when a crisis has been identified. Cost estimates designed to improve successful adjustment and adaptation are very favorable when compared to the alternatives of disruption and dissolution. 
The primary barrier to accessing services that was documented in this study and also found in one other study is that adoptive parents do not know what services are available to them. That barrier could easily be eliminated with minimal costs by the creation of a resource directory that could be provided to all adoptive parents describing what resources are available to them.

This study replicated other research that found that adoptive parents do not feel that they have been provided all the information about a child. Often adoptive parents are told the information verbally, but they do not remember what is told to them. Social workers could easily eliminate this problem by providing all background information in writing to the adoptive parents and by allowing adoptive parents to read and receive copies of all important information found in the child's case record. Once the adoptive parents feel they have received sufficient information, they will be able to be more realistic about the problems they will encounter which will increase the likelihood of a successful outcome. In order to assist adoptive parents in being as realistic as possible about potential problems, it is imperative that agencies provide mandatory preservice training that is focused on providing realistic and relevant topics.

There was a lower level of willingness to adopt another special needs child as compared to other studies. Social 
service agencies need to investigate the reasons why these parents are not interested in adopting again and try to develop remedies to those impediments.

In Florida, foster parents were a larger adoptive resource pool than in other studies. Therefore social service agencies need to pay special attention to the initial foster care placements that are made with the realization that many of these placements will turn out to be adoptive placements. The agencies need to continue to support the foster parents in their decisions to adopt their foster children.

This study documented a significantly higher use of postplacement services as compared to other national studies. The services that were listed as being needed the most are special educational services, money other than subsidy, after school activities, and support groups. The educational services and after school activities can be developed through collaborative efforts with the school system which at the current time in Florida is not shouldering as massive funding cuts as are the social services programs. Support groups can be developed by the adoption agencies with minimal funding and support.

With the projected continued increase for the need for foster care services and special needs adoptive placements policy makers and program developers must advocate for additional money to develop programs that are empirically 
proven to be cost effective. However, the reality in America is that there is a current climate of economic conservatism to fund social programs. If new funding cannot be made available to develop needed programs, decision makers need to consider funding only those services that have been shown to have a positive effect on successful adoption outcomes. Thus there is an urgency to strengthen the role of intervention research.

\section{Limitations of the Study}

The experiences of these 474 special needs adoptive families are illuminating. Nevertheless, the crosssectional design utilized allows for examination of variables at only one point in time and represents the experiences of a select group of adoptive families.

The empirical data on special needs adoptive families in Florida is extremely limited in relation to demographic data and totally absent in regards to their experiences throughout the adoption process and their use and need for postplacement services. There was no way to determine in what ways or the extent the respondents differed from the families who did not respond to the survey in relation to their opinions, experiences, and demographic data.

Research was conducted on a sample who by their very definition had special needs because they had adopted older or minority children or children with special physical, emotional, or mental handicaps. All of the children 
included in the sample had some type of preidentified special need and therefore it is not surprising that these children and their families may need additional services to improve their chances for a positive outcome.

The sample involved only adoptive families of special needs children from Florida who currently receive at least one postplacement service - maintenance and/or medical subsidy. The findings are generalizable to other families who adopted special needs children from Florida and who receive a subsidy. The findings are limited in generalizing to nonspecial needs children, families who adopt children from other areas of the country or internationally, and families who do not require adoption maintenance and/or medical subsidy.

There was a lack of observer objectivity. The findings of the study were based on the perceptions expressed by the adoptive parents and did not include the perceptions of the adoptive child. The results were based solely on self report rather than direct observation (Rubin \& Babbie, 1993). Further, the potential for social desirability bias in the ways the adoptive parents answered the survey needs to be considered.

The data reflects what the adoptive parents perceived their needs to be and was not based on actual documented need. It was not possible to determine if the need for specific services actually was valid or if the adoptive 
parents may have felt the service would be good for the child or family to have. Some of the reported needs may have been desires and not necessities for successful adoption outcomes. However, if one agrees with the definition for the purpose of postplacement services that Barth (1988) offers, "to offer needed and desired assistance", the desire for the service is sufficient to demonstrate a need.

Since the data reflect the subjective perceptions of the adoptive parents, they donot necessarily reflect what the adoption agency has documented in their records (Rosenthal \& Groze, 1992). Therefore, information on the adoptive child such as number of previous foster care placements, age at entry into foster care and other related information may not be entirely accurate. However, previous research on adoption using parent reports was found to have adequate reliability and validity (Kadushin, 1970; Rosenthal \& Groze, 1992).

This study utilized a descriptive and exploratory design and therefore the findings are only tentative and cannot be considered explanatory. Although the findings do serve to assist in clarifying which factors impact on adoption outcomes and service needs and usage, no causality can be determined.

Nonetheless, the findings have expanded the knowledge base in numerous ways. The study gave context to the life- 
long process of adopting a special needs child, challenged some commonly held beliefs about "forever families" and "living happily ever after", confirmed some predictors of successful outcomes, analyzed the usage and satisfaction level of existing postplacement services, and documented the need for ongoing postplacement service. Implications for Future Research

Previous adoption research focused primarily on adoptees receiving clinical and casework interventions with a paucity of research to examine the effectiveness of those interventions. This research was an effort to build upon the professional literature regarding special needs adoptions by focusing on descriptive and intervention research.

The social work profession is finally realizing that special needs adoption is a life-long process that is substantially different than nuclear biologically-formed families. To understand the unique circumstances of special needs adoptive families, research needs to be conducted comparing special needs families with intact biological families. This focus can be taken farther by conducting outcome studies with larger sample sizes with heterogeneous subgroups. The subgroups that could be compared to see how they differ could include heterogeneous sets of children such as special needs adoptive children, children living in relative placements, children living in birth families and 
stepparent families, and children living in long-term foster care.

In order to broaden the knowledge base further in the area of special needs adoption, research needs to be conducted with a focus on prevention. The themes of preparation, support, and strategies to assist families in becoming realistic about this life-long process and the problems that may be encountered should increase the likelihood of more positive outcomes.

The study of postplacement service needs and usage has been largely ignored until now. Longitudinal studies need to be conducted to determine the pattern of service need and usage for adoptive parents and children throughout the lifelong adoption process.

While there is an intuitive appeal for development and utilization of postplacement services, there is a need to support this view with empirical research on its effectiveness. Although the literature and statistics indicate an increase in the number of special needs adoptions and resulting increase in disruptions, interventions and empirical research on their effectiveness has been largely ignored. McDonald et al (1991) concluded that the previous research on child and parent characteristics as predictors of unsuccessful adoptions reinforces a conservative intervention approach. They argue for the necessity to undertake research that examines the 
impact of specific services and interventions. This type of research would be strengthened by employing standardized and normed measures such as the Achenbach Child Behavior Checklist (Barth, 1991).

Children are our future. Inherent in this focus is the need to provide special needs adoptive families with the tools and resources needed to strengthen and support their families throughout all stages of the family life cycle. To that end, these areas of research await further study. 
Adoption Assistance and Child Welfare Act of 1980, P.L. 96-272, (1980).

Ainsworth, M. (1979). Infant-mother attachment. American Psychologist, 34, 932-937.

American Public Welfare Association. (1991a, February). Post-legal adoption services. (Brief No. 16). Washington, DC: Author.

American Public Welfare Association. (1991b, June). Update II - Reimbursement of nonrecurring adoption expenses. (Brief No. 17). Washington, DC: Author.

Anderson, Josephine. (1990). Holding therapy: A way of helping unattached children. In P. Grabe (Ed.), Adoption resources for mental health professionals (pp. 87-97). New Brunswick, NJ: Transaction Publishers.

Anderson, Judith. (1990). Changing needs, challenging children. In North American Council on Adoptable Children (eds.), The Adoption Assistance and Child Welfare Act of 1980: The first ten years (pp. 41-48/). St. Paul, Minnesota: Author.

Ashton, J. (1994). Post Adoption Services: A comprehensive approach. Paper presented at the annual conference of the North American Council on Adoptable Children, San Jose, CA. 
Avery, R., \& Mont, D. (1992). Financial support of children involved in special needs adoption: A policy evaluation. Journal of Policy Analysis and Management, $\underline{11}(3), 419-421$.

Backhaus, K. (1989). Training mental health practitioners in postadoption work. Child Welfare, 58(1), $61-68$.

Barth, R. (1988). Disruption in older child adoptions. Public Welfare, Winter, 23-29.

Barth, R. (1991). Research on special needs adoption. Children and Youth Services Review, 13(5/6), 317-321.

Barth, R., \& Berry, M. (1988). Adoption and disruption: Rates, risks and responses. New York: Aldine de Gruyter.

Barth, R., \& Berry, M. (1990). A decade later: Outcomes of permanency planning. In North American Council on Adoptable Children (eds.), The Adoption Assistance and Child Welfare Act of 1980: The first ten years (pp. 7-39). St. Paul, Minnesota: Author.

Barth, R., Berry, M., Carson, M., Goodfield, R., \& Feinberg, B. (1986). Contributors to disruption and dissolution of older-child adoptions. Child Welfare, 65(4), $359-371$.

Barth, R., Berry, M., Yoshikami, R., Goodfield, R., \& Carson, M. (1988). Predicting adoption disruption. Social Work, $33,227-233$. 
Bartholet, E. (1991). Where do black children belong? The politics of race matching in adoption. University of Pennsylvania Law Review, 139(5), 1163-1265.

Benton, B., Kaye, E., \& Tipton, M. (1985). Evaluation of state activities in regard to adoption disruption. Washington, DC: Urban Systems Research and Engineering.

Berry, M. (1990). Preparing and supporting special needs adoptive families: A review of the literature. Child and Adolescent Social Work Journal, I(5), 403-418.

Berry, M., \& Barth, R. (1990). A study of disrupted adoptive placements of adolescents. Child Welfare, $\underline{69}(3)$, 209-225.

Boneh, C. (1979). Disruptions in adoptive placement: A research study. Massachusetts Department of Public Welfare. Office of Research Evaluation.

Bourguignon, J. \& Watson, K. (1988). After adoption: A manual for professionals working with adoptive families. (DHHS Grant No. 90-CO-0287). Illinois: Illinois Department of Children and Family Services.

Boyne, J., Denby, L., Kettenring, J., \& Wheeler, W. $(1984)$. The shadow of success: A statistical analysis of outcomes of adoptions of hard-to-place children. Westfield, NJ: Spaulding for Children.

Brinich, P. M., \& Brinich, E. B. (1982). Adoption and adaptation. The Journal of Nervous and Mental Disease, $\underline{170}(8), 489-493$. 
Brodzinsky, D., \& Schechter, M. (1990). Preface. The psychology of adoption. New York: Oxford University Press.

Brooks, H. (1991). Families who adopt special needs children: A descriptive and exploratory study. Unpublished doctoral dissertation, University of Tennessee, Knoxville.

Brown, A. (1995). Special needs adoptions in Florida: A descriptive and exploratory study. Unpublished manuscript.

Bussiere, A. (1990). Implementation of P.L. 96-272: Adoption assistance. In North American Council on Adoptable Children (eds.), The Adoption Assistance and Child Welfare Act of 1980: The first ten years (pp. 75-86). St. Paul, Minnesota: Author.

Child Welfare League of America. (1988). Standards for adoption service. Washington, DC: Child Welfare League of America.

Chiles, L. (1995, November 13). Governor calls for corporate partners to promote adoption. Press release.

Cohen, J. (1988). Statistical power analysis for the behavioral sciences ( 2 nd Ed.). New Jersey: Lawrence Erlbaum Associates.

Cohen, J. (1984). Adoption breakdown with older children. In P. Sachdev (Ed.), Adoption: Current Issues and trends (pp. 129-139). Toronto: Butterworths. 
Cohen, J. \& Westhues, A. (1990). Well-functioning families for adoptive and foster children. Toronto: University of Toronto Press.

Cole, E. (1987). Adoption. In A. Minahan (Ed.), Encyclopedia of social work, (pp. 67-75). Maryland: National Association of Social Workers.

Cole, E. (1995, February). Managing Family Centered Practice. Symposium conducted at the Florida HRS Child Welfare Supervisors and Program Administrators Advanced Training Institute.

Cole, E., \& Donley, K. (1990). History, values, and placement policy issues in adoption. In D. Brodzinsky, \& M. Schecter (Eds.), The psychology of adoption (pp. 273-294). New York: Oxford University Press.

Coyne, A., \& Brown, M. (1986). Relationship between foster care and adoption units serving developmentally disabled children. Child Welfare, 65, 189-198.

Devore, J., \& Peck, R. (1993). Statistics: The exploration and analysis of data (2nd Ed.). Belmont, CA: Duxbury Press.

Edna McConnell Clark Foundation. (1991). Keeping families together: Facts on family preservation services. New York, NY: Author.

Fales, M. (1985). Adoption assistance: How well is it working? Permanency Report, 3, 3. 
Fanshel, D. (1978). Status changes of children in foster care: Final results of the Columbia University longitudinal study. Child Welfare, 55(3), 143-171.

Feigelman, W., \& Silverman, A. (1983). Chosen children: New patterns of adoptive relationships. New York: Praeger.

Festinger, T. (1986). Necessary risk: A study of adoptions of disrupted adoptive placements. Washington, DC: Child Welfare League of America.

Festinger, T. (1990). Adoption disruption: Rates and correlates. In D. Brodzinsky, \& M. Schecter (Eds.), The psychology of adoption (pp. 201-218). New York: Oxford University Press.

Flango, V., \& Flango, C. (1993). Adoption statistics by state. Child Welfare, 72(3), 311-319.

Fowler, F. (1993). Survey research methods. (2nd Ed.). Newbury Park: Sage Publications.

Gill, M. (1978). Adoption of older children: The problems faced. Social Casework, 59(5), 272-278.

Gilles, T. (1995). Adoption assistance in America: A programmatic analysis fifteen years after implementation. St. Paul, Minnesota: North American Council on Adoptable Children.

Grabe, P. (1990). Adoption resources for mental health professionals. New Brunswick, NJ: Transaction Publishers. 
Grabe, P., \& Sim, S. (1990). The definitions. In P. Grabe (Ed.), Adoption resources for mental health professionals (pp. 51-75). New Brunswick, NJ: Transaction Publishers.

Grotevant, H., \& McRoy, R. (1990). Adopted adolescents in residential treatment: The role of the family. In D. Brodzinsky \& M. Schechter (Eds.), The psychology of adoption (pp 167-186). New York: Oxford University Press.

Groze, V. (1986). Special needs adoption. Children and Youth Services Review, $\underline{8}(4), 363-373$.

Hartman, A. (1984). Working with adoptive families beyond placement. New York: child Welfare League of America, Inc.

Hartman, A., \& Laird, J. (1987). Family practice. In A. Minahan (Ed.), Encyclopedia of Social Work (18th ed., pp. 575-587). Silver Springs, MD: National Association of Social Workers.

Hartman, A., \& Laird, J. (1990). Family treatment after adoption: Common themes. In D. Brodzinsky, \& M. Schecter (Eds.), The psychology of adoption (pp. 221-239). New York: Oxford University Press.

Health and Rehabilitative Services. (1992, December). outcome evaluation report: A further step toward accountability. Tallahassee, Fl: Author. 
Health and Rehabilitative Services. (1994, June). [Adoptions and related services yearly report for fiscal year 1993-94. Unpublished raw data.

Health and Rehabilitative Services. (1995, August). [Adoptions and related services monthly report]. Unpublished raw data.

Hoopes, J. (1990). Adoption and identity formation. In D. Brodzinsky, \& M. Schecter (Eds.), The psychology of adoption (pp. 144-166). New York: Oxford University Press. Howard, J., \& Smith, S. (1994). Services to adoptive families at risk of dissolution: The adoption preservation project in Illinois. Paper presented at the annual conference of the North American Council on Adoptable Children, San Jose, CA.

Howe, D. (1988). Survey of initial referrals to the post adoption centre. Adoption and Fostering, 12(1), 13-36. Howe, D. (1990a). The post-adoption centre: The first three years. Adoption and Fostering, 14 (1), 27-35.

Howe, D. (1990b). The consumers' view of the post adoption centre. Adoption and Fostering, 14 (2), 32-36.

Interagency Task Force on Adoption. (1988). America's awaiting children. (Available from United States office of Personnel Management, Washington, DC).

Jaffee, B., \& Fanshel, D. (1970). How they fared in adoption: A follow-up study. New York: Columbia University Press. 
Joe, B. (1979). Public policies toward adoption. (Contract No. 105-75-1113). Washington, DC: The Urban Institute.

Johnson, D., \& Fein, E. (1991). The concept of attachment: Applications to adoption. Special Issue: Research on special needs adoption. Children and Youth Services Review, 13(5-6), 397-412.

Kadushin, A. (1967). Reversibility of trauma: A follow-up study of children adopted when older. Social Work, $12,22-33$.

Kadushin, A. (1970). Adopting older children. NY: Columbia University Press.

Kadushin, A. (1980). Child welfare services (3rd ed.). New York: Macmillan.

Kadushin, A. (1984). Principles, values and assumptions underlying adoption practice. In P. Sachdev (Ed.), Adoption: Current issues and trends. Toronto: Butterworths .

Kadushin, A., \& Seidl, F. (1971) Adoption failure: A social work postmortem. Social Work, 16, 32-38.

Kagan, R., \& Reid, W. (1986). Critical factors in the adoption of emotionally disturbed youths. Child welfare, $\underline{65}(1), 63-73$.

Kalton, G. (1983). Introduction to survey sampling. Newbury Park, CA: Sage Publications. 
Katz, L. (1986). Parental stress and factors for success in older-child adoption. Child Welfare, 65(6), 569578 .

Kirk, H. D., (1964). Shared fate. New York: Free Press.

Kornitzer, M. (1968). Adoption and family life. New York: Humanities Press.

Kroll, J. (1995, Spring). White House briefing. Adoptalk, 1 .

Kroll, J., \& Frank, R. (1990). Implementation of P.L. 96-272: Adoption assistance. In North American Council on Adoptable Children (eds.), The Adoption Assistance and Child Welfare Act of 1980: The first ten years (pp. 75-86). St. Paul, Minnesota: Author.

Kuzma, J. (1992). Basic statistics for the health sciences. Mountain View: CA: Mayfield Publishing Company. LePere, D. (1987). Vulnerability to crises during the life cycle of the adoptive family. Journal of Social Work and Human Sexuality, $\underline{6}(1), 73-85$.

Levine, E., \& Salles, A. (1990). Critical phases among adoptees and their families: Implications for theory. Child and Adolescent Social Work Journal, $7(3), 217-232$. 
Marcenko, M., \& Smith, L. (1991). Post-adoption needs of families adopting children with developmental disabilities. Special issue: Research on special needs adoption. Children and Youth Services Review, 13(5-6), 413424 .

McCubbin, H., \& Patterson, J. (1983). Family transitions: Adaptation to stress. In H. I. McCubbin and C. R. Figley (Eds.), Stress and the family. Volume I: coping with normative transitions. NY: Brunner/Mazel.

McDonald, T., Lieberman, A., Partridge, S. \& Hornby, H. (1991). Assessing the role of agency services in reducing adoption disruptions. Special issue: Research on special needs adoption. Children and Youth Services Review, 13(5$6), \quad 425-438$.

Meezan, W., \& Shireman, J. (1982). Foster parent adoption: A literature review. Child Welfare, 61(8), 525535 .

Minuchin, S. (1974). Families and family therapy. Cambridge, MA: Harvard University Press.

Murray, L. (1984). A review of selected foster care adoption research from 1978 to mid-1982. Child Welfare, $\underline{63}(2), 113-124$.

Naatrin Update. (1995, Spring). Adoptalk, 4. National Council for Adoption. (1995). Fact Sheet. (Available from National Council for Adoption, 193017 St. N.W., Washington, D.C. 20009-6207). 
Nelson, E. (1985). On adoption's frontier: A study of special needs adoptive families. NY: Child Welfare League of America.

North American Council on Adoptable Children. (Ed.) (1990). The Adoption Assistance and Child Welfare Act of 1980: The first ten years. St. Paul, Minnesota: Author. North American Council on Adoptable Children. (1993, Winter). Adoptalk, pp. 1-2.

Norusis, M. (1990). SPSS/PC+ 4.0 base manual. Chicago: SPSS Inc.

Office of Inspector General. (1988). Minority adoptions. Washington, DC: U.S. Government Printing Office. Office of Inspector General. (1991). Barriers to freeing children for adoption (OEI-06-89-01640). Washington, DC: U.S. Government Printing Office.

One Church, One Child of Florida. (1995). 1994-1995 annual report addendum. (Available from One Church, One Child of Florida, Inc., 2811-2E Industrial Plaza, Suite 114, Tallahassee, FL 32399).

Panacek-Howell, L. (1993). Special needs adoption in Hillsborough County. University of South Florida, Florida Mental Health Institute.

Partridge, S., Hornby, H., \& McDonald, T. (1986). Legacies of loss - visions of gain: An inside look at adoption disruptions. Portland: University of Southern Maine, Center for Research and Advanced Study. 
Pedhazur, E. (1982). Multiple regression in behavioral research. Fort Worth, TX: Harcourt Brace Jovanovich, Inc.

Phillips, R. (1988). Post-adoption services - the views of adopters. Adoption and Fostering, 12(4), 24-28.

Pinderhughes, E., \& Rosenberg, K. (1990). Familybonding with high risk placements: A therapy model that promotes the process of becoming a family. Journal of Children in Contemporary Society, 21(3/4), 209-230.

Plumez, J. (1982). Successful adoption. New York: Harmony Books.

Proch, K. (1980). Adoption by foster parents. Unpublished doctoral thesis, University of Illinois at Urbana-Champaign, Illinois.

Proch, K. (1981). Foster parents as preferred adoptive parents: Practice implications. Child Welfare, $\underline{60}(9), 617-625$.

Proch, K. (1982). Differences between foster care and adoption: Perceptions of adopted foster children and adoptive foster parents. Child Welfare, 61(5), 259-268.

Ragan, C. (1994). Subsidized adoption: A source of help for children with special needs and their families. (Available from the National Adoption Information Clearinghouse, 11426 Rockville Pike, Suite 410, Rockville, MD 20852). 
Rodriguez, P., \& Meyer, A. (1990). Minority adoptions and agency practices. Social Work, 35(6), 528-531.

Rosenberg, E. (1992). The adoption life cycle. New York: The Free Press.

Rosenthal, J., \& Groze, V. (1992). Special-needs adoption: A study of intact families. New York: Praeger.

Rosenthal, J., Groze, V., \& Curiel, H. (1990). Race, social class, and special needs adoption. Social Work, $\underline{35}(6), 532-539$.

Rosenthal, J., Schmidt, D., \& Conner, J. (1988). Predictors of special needs adoption disruption: An exploratory study. Children and Youth Services Review, $\underline{10}(2), 101-117$.

Rubin, A. \& Babbie, E. (1993). Research methods for social work (2nd Ed.). Pacific Grove, CA: Brooks/Cole.

Rudestam, K., \& Newton, R. (1992). Surviving you dissertation: A comprehensive guide to content and process. Newbury Park, CA: Sage.

Rushton, A. (1989). Post-placement services for foster and adoptive parents: Support, counseling or therapy? Journal of Child Psychology and Psychiatry and Allied Disciplines, 30(2), 197-204.

Sack, W., \& Dale, D. (1982). Abuse and deprivation in failing adoptions. Child Abuse and Neglect, $\underline{6}, 443-451$. Sawbridge, P. (1990). Post-adoption counselling: What do we actually do? Adoption and Fostering, 14(1), 31-35. 
Schmidt, D. (1986). Presentation of research findings on prevention of adoption disruption. In D.M. Schmidt (Ed.), Special needs adoptions: A positive perspective. Denver: Colorado State Department of Social Services. Schmidt, D., Rosenthal, J., \& Bombeck, B. (1988). Parents' views of adoption disruption. Children and Youth Services Review, $10(2), 119-130$. Sedlak, A., \& Broadhurst, D. (1993). Study of adoption assistance impact and outcomes: Final report (Contract No. 105-89-1607). Rockville, MD: Westat, Inc. Spencer, M. (1985). Meeting the needs for comprehensive post-legal adoption services. Permanency Report, $\underline{3},(4), 5$.

Spencer, M. (1987). Post-legal adoption services: A lifelong commitment. Journal of Social Work and Human Sexuality, $6(1), 155-167$.

Tatara, T. (1993). U.S. child substitute care flow data for fy 92 and current trends in the state child substitute care populations. (VCIS Research Notes No. 9). Washington, DC: American Public Welfare Association.

Tremitiere, B. (1979). Adoption of children with special needs: The client-centered approach. Child Welfare, $\underline{58}(10), 681-685$.

Unger, D., Deiner, P., \& Wilson, N. (1988). Families who adopt children with special needs. Children and Youth Services Review, 10(4), 317-328. 
Unger, C., Dwarshuis, G., \& Johnson, E. (1983). Adoption disruptions (DHSS Publication No. OHDS 81-30319). Washington, DC: U.S. Government Printing Office.

Urban Systems Research and Engineering. (1985). Evaluation of state activities with regard to adoption disruption: Final report. Washington, DC: Urban Systems Research and Engineering.

U.S. Department of Health and Human Services. (1980). Adoption project for handicapped children: Ohio District II (OHDS Publication No. 80-30289). Washington, DC: Author. Valentine, D., Conway, P., Randolph, J. (1987). Placement disruption: Perspectives of adoptive parents. Journal of Social Work and Human Sexuality, $6(1), 133-153$.

Vick, C. (1995, Fall). Out of sight, out of mind: The child welfare data collection problem, Adoptalk, 4 .

Waldinger, G. (1982). Subsidized adoption: How paid parents view it. Social Work, 27(6), 516-521.

Walsh, J. (1991). Assessing post adoption services: A parent survey. (United States Department of Health and Human Services Federal Grant \#90-CO-0407). Illinois: Illinois Department of Children and Family Services. Watson, K. (1991). Delivering post adoption services: The role of the public agency. (DHSS Grant No. 90-CO-0407). Illinois: Illinois Department of Children and Family Services. 
Weinbach, R., \& Grinnell, R. (1987). Statistics for social workers. New York: Longman.

Weisberg, H., Krosnick, J., \& Bowen, B. (1989). An introduction to survey research and data analysis (2nd $\mathrm{Ed}$ ). Glenview, Illinois: Scott, Foresman and Company.

Westhues, A., \& Cohen, J. (1990). Preventing disruption of special needs adoptions. Child Welfare, $\underline{69}(2), 141-154$.

Wimmer, J., \& Richardson, S. (1990). Adoption of children with developmental disabilities. Child Welfare, $\underline{69}(6), 563-570$.

Zwimpfer, D. (1983). Indicators of adoption breakdown. Social Casework, 64, 169-177. 


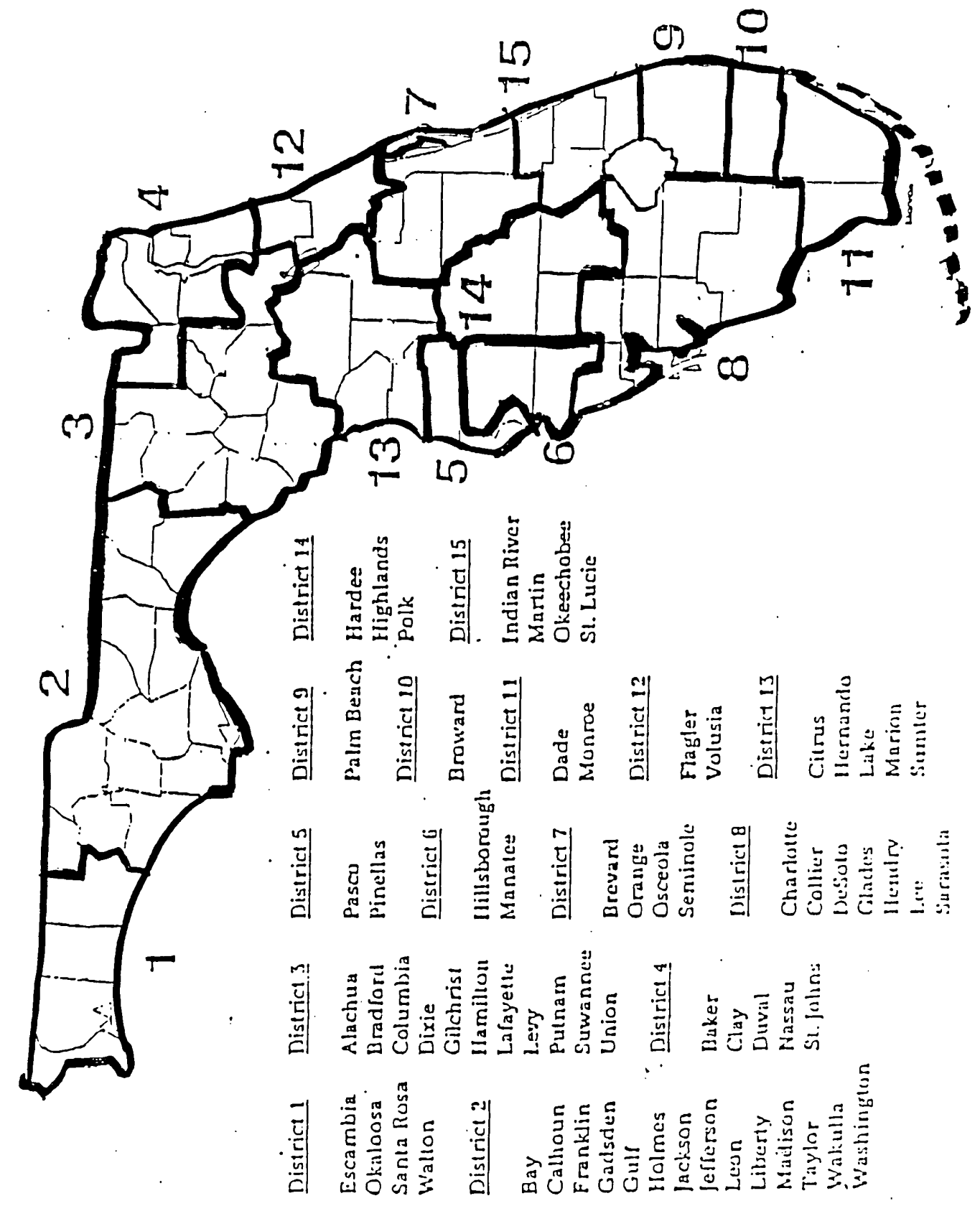


October 2, 1995

Dear Adoptive Parent(s),

We would like to ask your assistance in completing the attached survey regarding your experiences as an adoptive parent. This research will provide the Department of Health and Rehabilitative Services (HRS) with information about the experiences adoptive parents have had with postplacement services and what needs continue to be unmet. With the decreasing amount of money allocated to social services at both the state and federal levels, it is imperative that adoptive parents make their needs known so that appropriate and effective services can be developed.

This survey is being sent to a random sample of over 1,500 special needs adoptive families throughout Florida who receive adoption subsidy. The only identifying information is the HRS district that had custody of your child previous to the adoption placement. Your name is not listed anywhere on the survey and therefore, what you say is anonymous and will be held in strict confidence. Responses from individuals will not be reported to anyone. Instead, the responses received from all the adoptive families throughout the state will be combined and summarized.

Your participation in completing this survey is voluntary and will not affect the continuation of subsidy or any services you are currently receiving. Return of the survey is your consent to participate in this study. The survey should take approximately 20 minutes to complete.

Please return your survey in the enclosed pre-addressed and stamped enveloped by October 16, 1995.

Please take the time to fill out this survey to help all adoptive families! Only by hearing from adoptive parents as yourself can the social service professionals learn what is needed to keep adoptive families strong, secure, and loving. Thank you.

Sincerely,
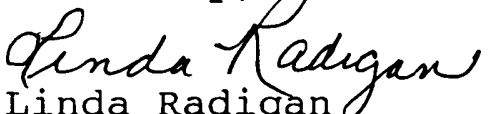

Linda Radigan 0

Assistant Secretary

Children and Family Services

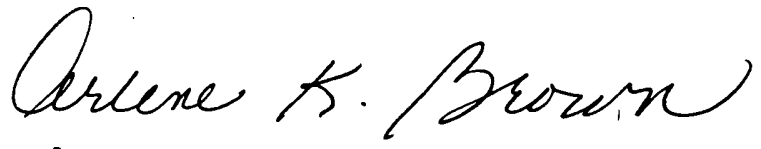

Arlene $K$. Brown

Acting Program Administrator Children and Family Services 


\section{A D O P T I O N S U R V E Y}

ALL QUESTIONS IN THIS SURVEY RELATE TO YOUR OLDEST ADOPTIVE CHILD FOR WHOM YOU RECEIVE ADOPTION SUBSIDY AND WHO IS STILL LIVING IN YOUR HOME. IF YOU HAVE MORE THAN ONE ADOPTIVE CHILD LIVING AT HOME, PLEASE ANSWER THE QUESTIONS ONLY IN RELATION TO THE OLDEST CHILD.

HRS District

\section{SERVICE PROVISION}

Below are services that adoptive families might use and/or need. Using the following scale, indicate on the line at the left of each service the number that best describes your family's experience with each service for your adoptive child. Please make sure that you answer every item and that you record only one number per service.

1. Used and dissatisfied

2. Used and satisfied

3. Not used but needed

4. Not needed

1.

Respite care

2.

Life planning

3.

Support group

4.

Baby-sitting

5.

Homemaker services

6.

Advocacy training

7.

Training to care for child

8.

Day care

9.

Therapeutic day care

10.

Residential placement (child)

11. Home nursing

12.

Counseling (marital)

13.

Counseling (child)

14.

Counseling (family)

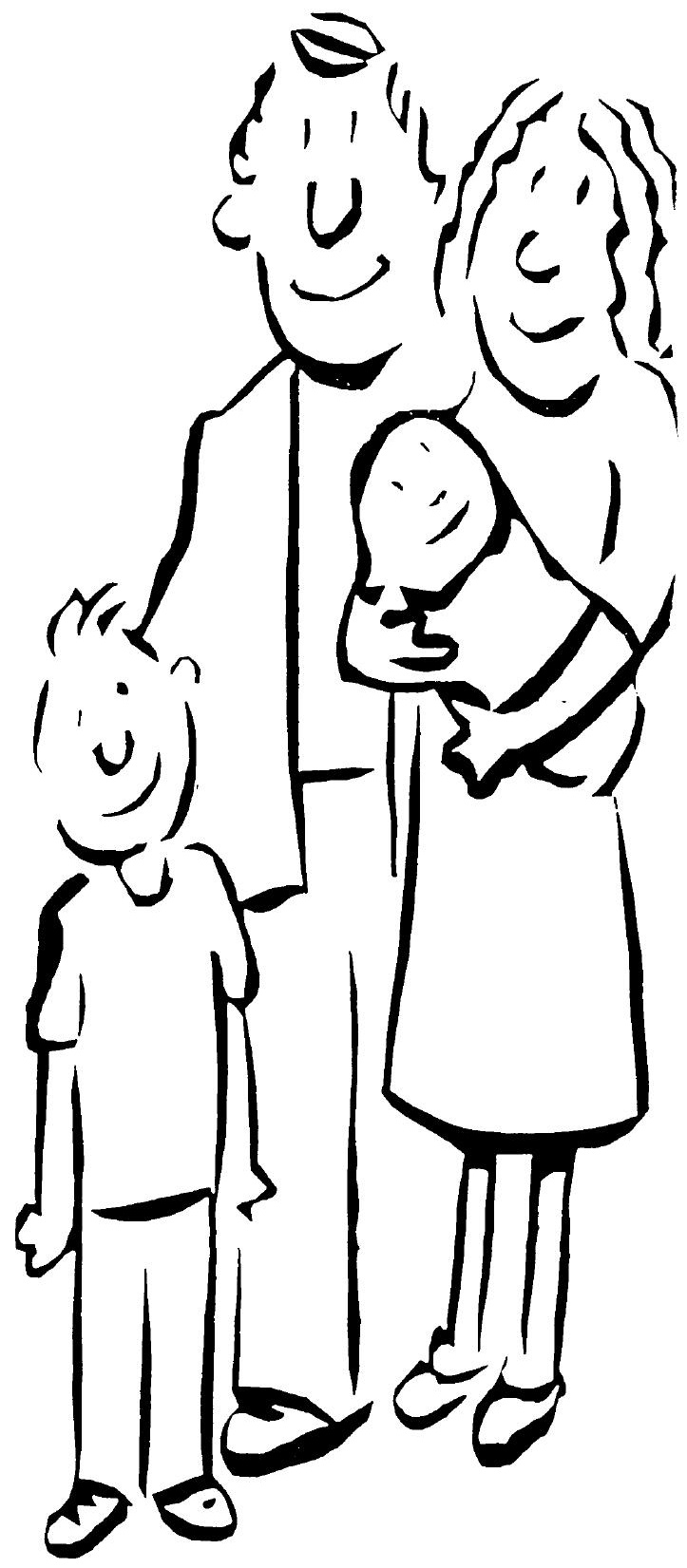


1. Used and dissatisfied

2. Used and satisfied

3. Not used but needed

4. Not needed

15. Transportation

16. Special educational services

17. Tutoring

18. After school activities

19. Health insurance (child) .

20. iDental care

21. Speech or language therapy

22. Occupational therapy

23. Physical therapy

24. Routine medical care

25. Special needed medical equipment/adaptation devices

26. Intensive home-based services

27 Reimbursement for nonrecurring adoption finalization expenses (example - attorney fees, travel, etc.)

28. Maintenance adoption subsidy

29. Medical adoption subsidy

30. Money other than the monthly adoption subsidy

31. Legal aid

32. Crisis intervention

33. Parent education/training

34. Drugs/alcohol treatment (outpatient)

35. Drugs/alcohol treatment (inpatient)

36. Job training 
The following questions pertain to services sf for adoptive families and adoptive children. Please put a check next to the most appropriate answer. Check only one item for each question.

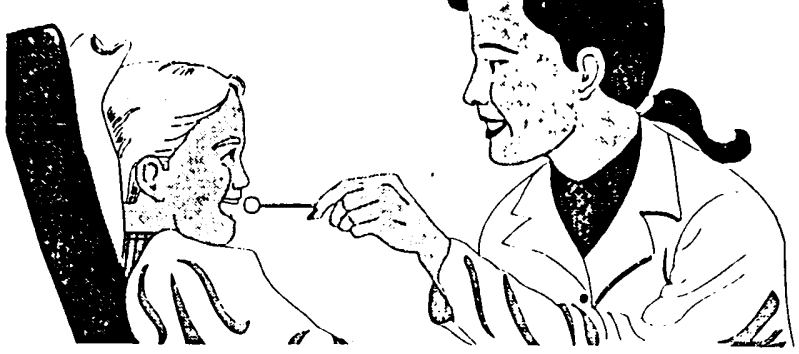

37. Have you ever belonged to an adoptive parent support group?

No, never belonged

Yes, currently belong

Previously belonged but not any longer

38. Did you go through MAPP training (Model Approach to Partnership in Parenting) or any other adoption specific training?

No (Skip to question \#40)

- Yes (Continue to question \#39)

39. Do you think the training class adequately prepared you for being an adoptive parent?

No
Yes
Not sure

40. If you have ever belonged to an adoptive parent support group or went through adoption/foster parent training, do you still keep in contact with any of the other adoptive and/or foster parents from the training or support group?

\begin{tabular}{ll} 
No \\
Yes \\
\hline
\end{tabular}

41. After adoptive placement, did you learn from the agency new information about your child that was already available to the agency?

No
$-\quad$ Yes

42. Was maintenance adoption subsidy offered to you prior to your child's adoptive placement with you?

No

- Yes 
43. Was medical adoption subsidy offered to you prior to your child's adoptive placement with you?

No

- Yes

44. Did you have the same adoption social worker from the time of placement all the way through the adoption finalization?

No

- Yes

\section{ADOPTION EXPERIENCE}

The following questions pertain to your views regarding your experience adopting the oldest child for whom you receive adoption subsidy and who is still living in your home. Using the following scale from 1 to 8 , indicate on the

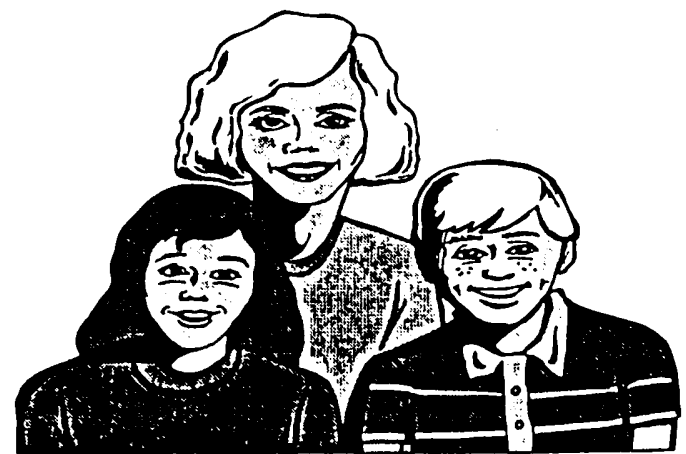

line at the left of each statement the number that best describes how you feel. The more strongly you agree with the statement, then the higher the number you record. The more strongly you disagree with the statement, then the lower the number you will record. Please make sure that you answer every item and that you record only one number per item. Remember that all your answers are strictly anonymous and confidential.

1. Strongly disagree

2. Disagree

3. Somewhat disagree

4. Neutral

5. Somewhat agree

6. Agree

7. Strongly agree

8. Not applicable

45. My adoptive child understands there is a difference between him/her being a foster child and being an adoptive child.

46.

Prior to the adoptive placement, I believe that the adoption agency told me all the information they knew about my child.

47. The adoption agency exaggerated my adoptive child's problems to me prior to placement.

48. I had enough information about my child before he/she was placed with me. 


$\begin{array}{lll} & \text { 1. } & \text { Strongly disagree } \\ & \text { 2. } & \text { Disagree } \\ \text { 3. } & \text { Somewhat disagree } \\ \text { 4. } & \text { Neutral } \\ \text { 5. } & \text { Somewhat agree } \\ & \text { 6. } & \text { Agree } \\ \text { 6. } \quad \text { Strongly agree } \\ \text { 7. } & \text { Not applicable }\end{array}$

49.

Prior to the adoption being finalized, the adoption agency was helpful to me.

50.

Since the adoption was finalized, the adoption agency has been helpful to me.

51. I believe it would be helpful for there to be mandatory follow-up by the adoption agency after an adoption is finalized.

52.

If I needed help for my adoptive child, I would know where to go to access the needed service(s).

53.

Overall, I am satisfied with all of the services I have received since the adoptive placement.

54.

My community has enough services to meet the needs of special needs adoptive children \& families.

55.

The service providers in my community understand the problems of special needs adoptive children \& families.

56.

The maintenance subsidy I receive is helpful in providing for my child's basic needs.

57.

Overall, my family supported my idea to adopt.

58.

Overall, my friends supported my idea to adopt:

59.

Looking back over the adoption experience, I was realistic about the problems I would encounter.

60.

I would have adopted this child even if I did not receive maintenance adoption subsidy for him/her.

61. I would have adopted this child even if I did not receive medical adoption subsidy for him/her.

62. Looking back over my entire experience in adopting my child, I feel it has been a satisfying experience.

63.

My adoptive child would rate his/her experience in being adopted as satisfying. 
1. Strongly disagree

2. Disagree

3. Somewhat disagree

4. Neutral

5. Somewhat agree

6. Agree

7. Strongly agree

8. Not applicable

64.

Looking back on my adoption experience, if I knew at the beginning what I know now, I would adopt my child again.

65. I feel this adoption was successful.

66. I would like to adopt another special needs child.

The following questions pertain to problems adoptive families and children have in getting services. Using the following scale, indicate on the line at the left of each problem the number that best describes your family's experience with each problem. Please make sure that you answer every item and that you record only one number per problem.
0. No problem
1. Small problem
2. Medium problem
3. Big problem

67.

Don't have the money to get services

68.

Don't have baby-sitting available

69.

Transportation problems in getting to services

70.

Service doesn't exist

71.

There is a waiting list for the service

72.

I don't have the time

73.

I am too embarrassed to access the service or to ask for help

74. I do not need help

75.

My child won't go for help

76.

The rest of my family won't go for help

77.

There are racial or ethnic problems with the services available

78. Services are not available at the right time 
o. No problem

1. Small problem

2. Medium problem

3. Big problem

79.

(4:

80.

I don't know what services are available to me

81.

Services are not located in a convenient location

'My adopted child's needs are so special that I can't find the right services

\section{CHILD INFORMATION}

The following questions pertain to only your oldest adoptive child for whom you receive adoption subsidy and who is still living in your home. Please either put a check next to the most appropriate answer or fill in the blank. Check only one item unless the question says to check all answers that apply.

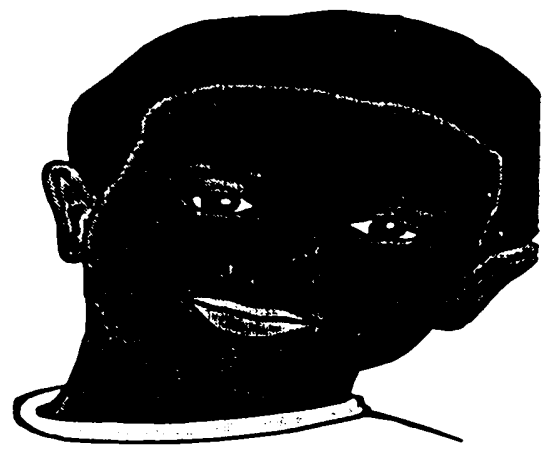

82.- What was the reason(s) for your child to be classified as a special 88. needs child? (Check all that apply)

Member of a minority group

- Over the age of eight

_ Mentally or emotionally handicapped

- Physically handicapped

_ Member of a sibling group

— Was not considered special needs

- Other (please specify)

89. Sex of your child?

— $\begin{aligned} & \text { Male } \\ & \text { Female }\end{aligned}$

90. Race of your child?

\begin{tabular}{l} 
White \\
Black \\
White Hispanic \\
$-\quad$ Black Hispanic \\
$-\quad$ Biracial (please specify) \\
$\square$ Native American \\
Asian \\
\hline$\quad$ Other (please specify)
\end{tabular}

91. Is this child the same race as your family?

No

- $\mathrm{Nes}$ 
92. Age of your child on his/her last birthday?

93. What grade in school is your child in?

94. What type of school placement is your child currently in?

Regular classroom

- Emotionally handicapped (EH)

- Severely emotionally disturbed (SED)

_ Severely learning disabled (SLD)

_ Special/alternative school

_ Vocational school

College

Not in school

95. Does your child have any biological siblings?

No (Skip to question \#98)

- Yes (Continue to question \#96)

96. Has your adoptive child been placed for adoption with all of his/her biological siblings?

No (Continue to question \#97)

- Yes (Skip to question \#98)

97. Does your child have any contact with the siblings he/she does not live with?

$\longrightarrow \quad$ No

98.- Why did your child enter foster care? (Check all that apply) 103.

Physical abuse

- Sexual abuse

- Neglect/deprivation

_ Abandonment

- Other (please specify)

_ Do not know

104. Age of your child when he/she entered foster care?

105. Total length of time your child was in foster care?

Less than 1 year
$1-2$ years
$3-4$ years
$-5-6$ years
$7-8$ years
$-9-10$ years
- Over 10 years
Do not know/not sure 
106. How many foster homes and/or relative placements did your child live in? (Include your own home if you were a foster parent to this child)

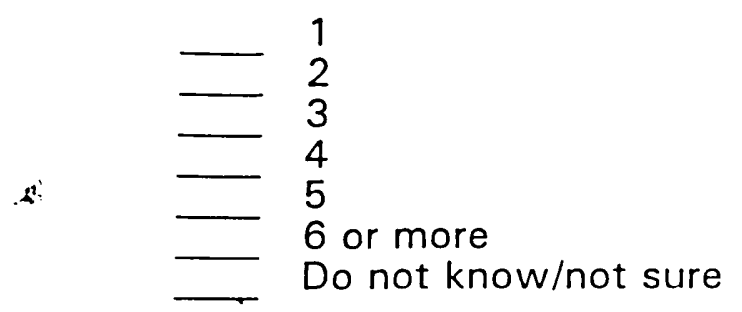

107. Was your child ever placed in a residential treatment center, therapeutic foster home or group home due to psychiatric/psychological problems?

No

Yes, prior to adoptive placement in my home
Yes, since adoptive placement in my home
Do not know

108. Did your child have any previous adoptive placements prior to placement in your home?

No (Skip to question \#110)

Y - Des (Continue to question \#109)

109. How many adoptive placements did your child have, including your home?

110. Age of your child when he/she was placed for adoption in your home?

111. Age of your child when the adoption was finalized?

112. What number adoptive placement was this child in your home?
- $1 \mathrm{st}$
- 2nd
- 3 rd
- 4 th
5 th
6 th or higher

Only adoptive child

113.- Is there any additional information you feel you needed prior to the 120. adoptive placement that would have helped? (Check all that apply)

No other information needed

Medical information

Psychological/psychiatric information

Behavioral information

Educational information

Social/background information

Biological family background

Other (please specify) 
121.- Before your child was placed for adoption with you, did he/she have

126. any of the following? (Check all that apply)

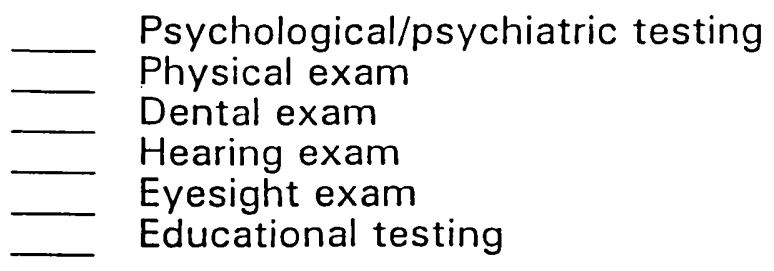

The next five questions pertain to whether or not your child has ever had any of the following diagnosed problems. Using the following scale, indicate on the line at the left of each problem the number that best describes the frequency of the problem. Please answer only one number for every problem.

1. Previously had the problem but no longer has the problem

2. Currently has the problem

3. Never had the problem

127.

Diagnosed psychological/emotional problems

128.

Diagnosed behavioral problems

129.

Diagnosed chronic medical condition

130.

Developmental disability

131.

Educational disability

\section{ADOPTIVE PARENT INFORMATION}

The following questions are general information about you and your family. Place a check next to the most appropriate response or fill in the correct number, which ever is appropriate. If

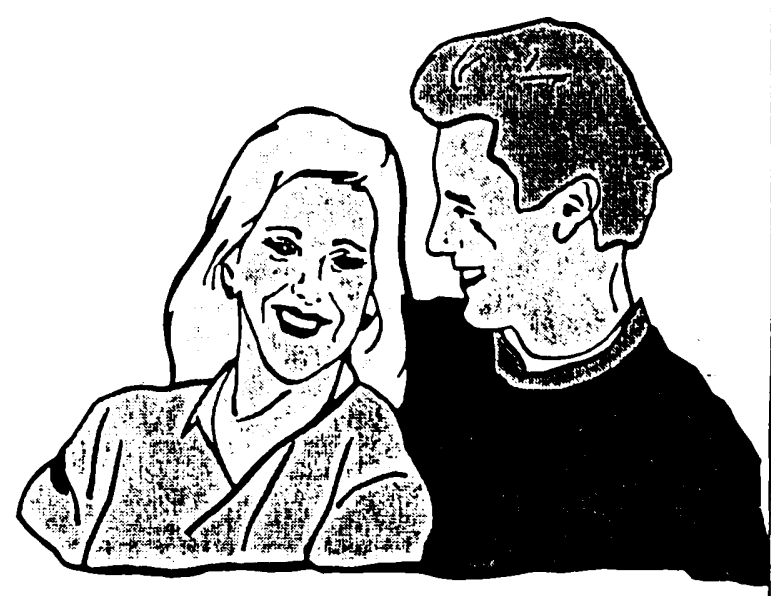
you are married, please fill in the information for both you and your spouse. If you are not married, just fill out information related to you and check "not applicable" for the other adoptive parent information.

\section{Your marital status?}

Single, never married

Living with partner

Married

Separated

Divorced

Widowed 
133. Your sex?

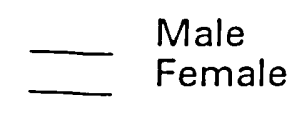

134. Age of adoptive mother at last birthday?

135. Age of adoptive father at last birthday?

136.- Highest educational grade completed. (Check one grade for each 137. parent)

$$
\text { Adoptive mother Adoptive Father }
$$

Less than high school

High school

Some college

College

Post college

Not Applicable

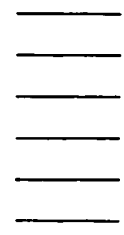

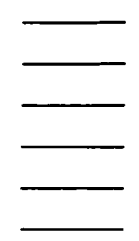

138.- Race of adoptive parents? (Check one race for each parent and

139. specify if appropriate)

Adoptive Mother

White

Black

White Hispanic

Black Hispanic

Biracial (please specify)

Native American

Asian

Other (please specify)

Not Applicable
Adoptive Father

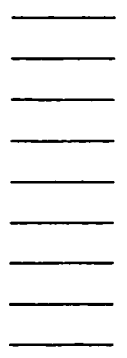

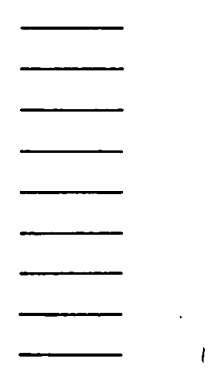

140.- How active are you in religious activities? (Check one for each 141. parent)

Adoptive Mother

Active, attend services

regularly

Moderately active, attend

services sometimes

Not active, seldom

attend services

Not applicable

Adoptive Father 
142. What is the adoptive mother's job title?

143. What is the adoptive father's job title?

144. What is your total gross family income?

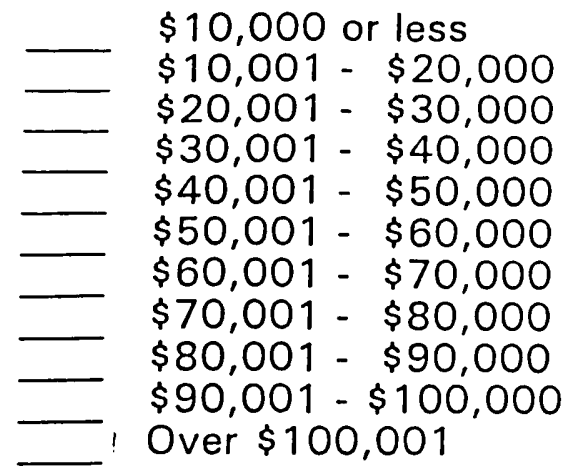

145. How many biological children do you have?

146. How many biological children are living at home now?

147. How many total children have ever been placed for adoption with you?

148. How many adoptive children are living at home now?

149. Have you ever had any children placed with you for adoption where the adoption has disrupted (prior to adoption finalization) or dissolved (after adoption finalization)?

\section{No (Skip to question \#155)}

- Yes (Continue to question \#150)

150.- How many children disrupted (prior to adoption finalization) and how 151. many children dissolved (after adoption finalization)?

\section{Disrupted
Dissolved}

152. Was the child(ren) whose adoption disrupted/dissolved part of a sibling group placed for adoption with you?

No (Skip to question \#155)

- Yes (Continue to question \#153)

153. Were you able to maintain the adoption of at least one of the siblings while the other adoptive children disrupted/dissolved?

No
- 
154. Did the supervising adoption agency tell you that in order for you to 1: keep at least one of the adoptive children that you had to keep all of the siblings?

$-\begin{array}{ll}\text { No } \\ \text { Yes }\end{array}$

155. What type of adoption agency completed your home study?

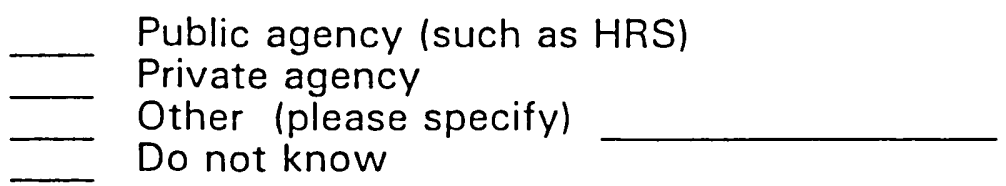

156. What type of adoption agency had custody of your adoptive child prior to being placed in your home?

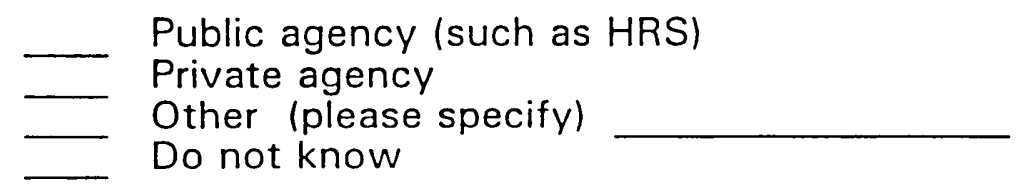

157. What county did you live in when your adoptive home study was completed? (If you did not live in Florida when the home study was completed, put the state that you lived in)

158. Have you ever adopted a child privately/independently through either an attorney or a physician?

No (Skip to question \#160)

- Yes (Continue to question \#159)

159. How would you compare the private adoption process to adoption through an agency?

Private adoption was easier

- Private and agency adoptions were about the same

- Private adoption was more difficult

160. Are you now or have you ever been a foster parent to any child?

No (Skip to question \#165)

- Yes, currently am a foster parent (Continue to question \#161)

- Yes, previously was a foster parent but not now (Continue to question \#161) 
161. What was your main reason for wanting to become a foster parent? (Check only one)

To help children

Religious calling
For a playmate for other children in my home
Companionship for me and/or my spouse
The child is my relative
I knew the child and did not want him/her placed in a foster
home where the family was a stranger
As an avenue or easy way to adopt
Other (please specify)

162. Were you a foster parent to your adoptive child before he/she was placed on adoptive status with you?

No (Skip to question \#165)

- Yes (Continue to question \#163)

163. How long were you a foster parent for your adoptive child before he/she was placed on adoptive status with you?

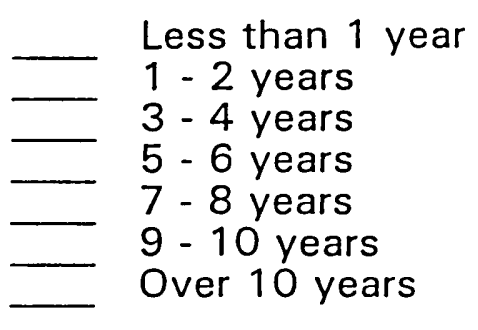

164. What was the reason you chose to adopt your child rather than continue to be a foster parent? (Check only one)

Wanted to adopt versus being a foster parent
- I had no intention to adopt but I became attached to the child and did not want him/her to leave If I did not adopt, the agency would place the child for adoption elsewhere I felt obligated and/or guilty I felt pressured by the agency to adopt I could not adopt one child if I did not adopt all the siblings Other (please specify)




\section{OPEN-ENDED QUESTIONS:}

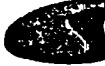

$\sqrt{4+3}$

The following are very important questions that do not have answers already given. Please read the question and provide in your own writing how you feel about each situation. If you need more room, please feel free to continue your answers on the back of this page.

165. What is the biggest concern you have had as an adoptive parent since the adoption has been finalized?

166. What is the biggest concern your adoptive child has had since the adoption has been finalized?

167. What could your adoption agency or social worker have done differently to make your experience as an adoptive parent more successful and satisfying?

168. If the agency were to develop some special services for adoptive families, what would you suggest? 
A-3. Completed Adoption Survey Daily Return Response Rates

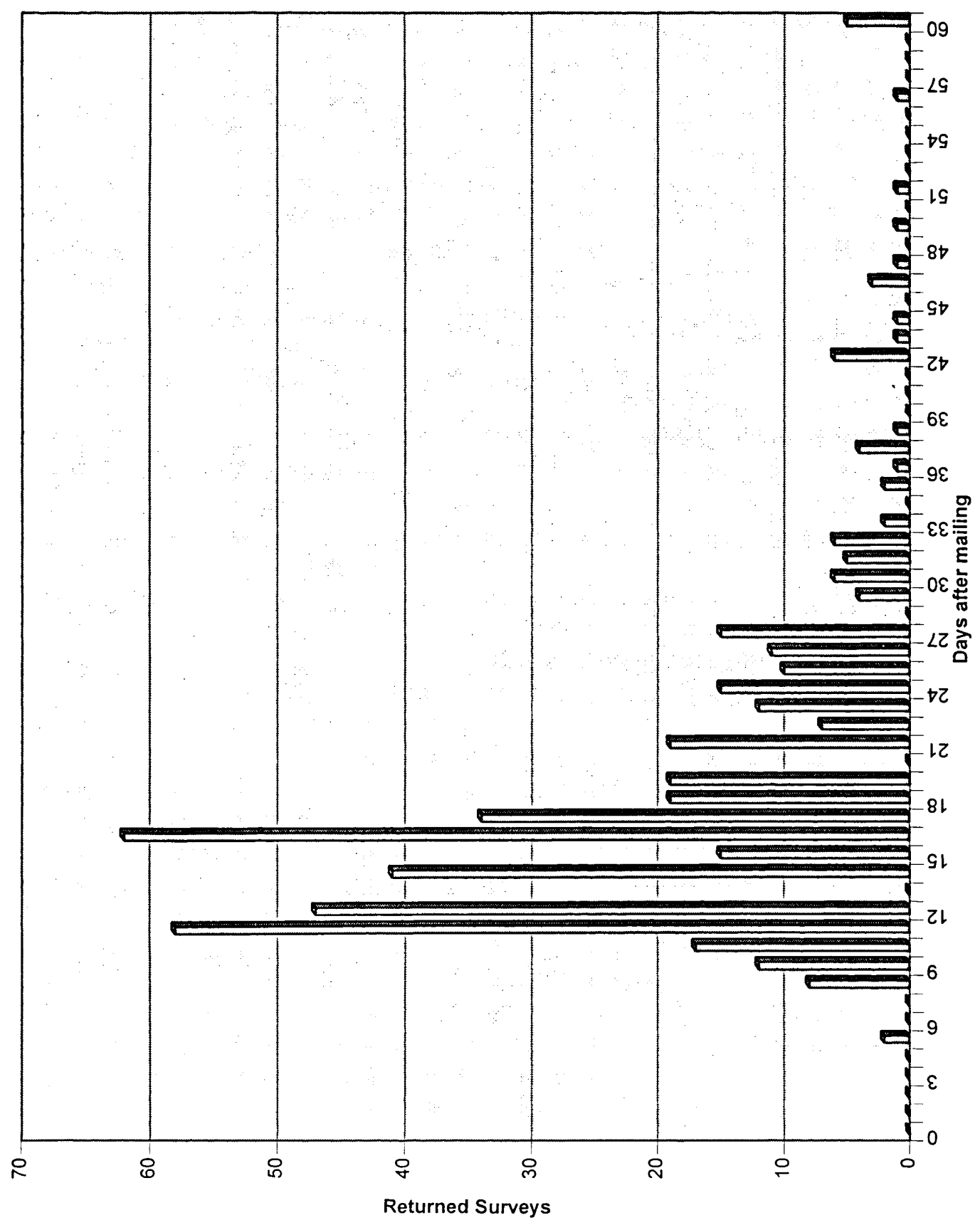




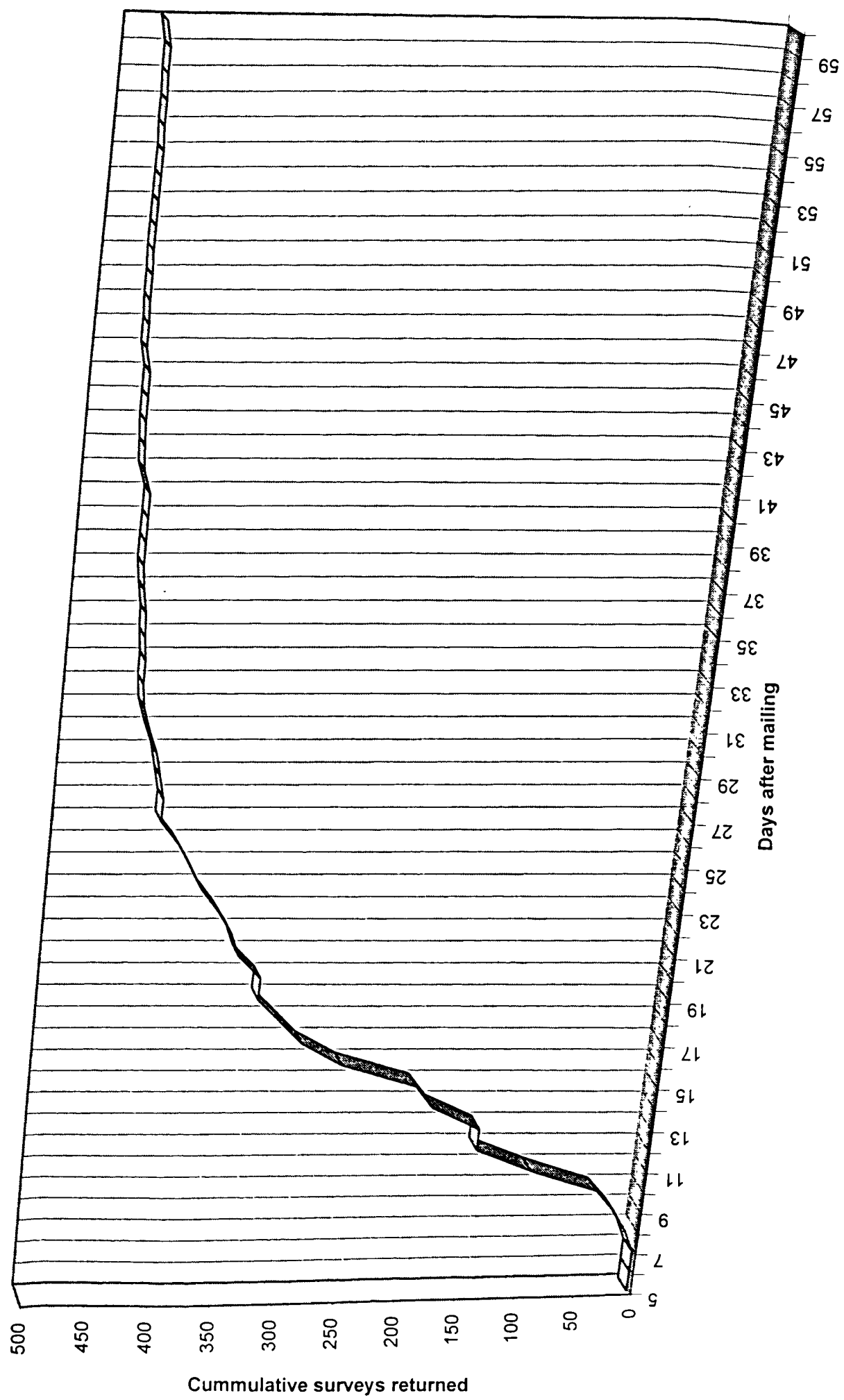


July 23, 1952

1974

$1974-1982$

$1982-1984$

$1984-1985$

$1985-1986$

$1986-1991$

$1991-1994$

1993

$1994-1995$

$1994-1995$
Born, Hollywood, Florida

B.A., Sociology

University of Florida

Gainesville, Florida

Social Worker

Florida Department of Health and

Rehabilitative Services,

Economic Services and Children and

Families

Unit Supervisor

Florida Department of Health and

Rehabilitative Services

Adoption and Related Services

Program Analyst

Florida Department of Health and

Rehabilitative Services

Children's Mental Health

Direct Services Supervisor

Florida Department of Health and

Rehabilitative Services

Child Welfare and Juvenile Justice

Human Services Program Supervisor II

Florida Department of Health and Rehabilitative Services

Child Welfare and Juvenile Justice

Program Operations Administrator Florida Department of Health and Rehabilitative Services

Child Welfare

M.S.W., Social Work

Florida International University Miami, Florida

Acting Program Administrator Florida Department of Health and Rehabilitative Services Children and Families

Graduate Teaching Assistant Florida International University Miami, Florida 
Brown, A., (October, 1993). Speaker at conference entitled Enhancing Families Through Community Partnerships, Ft. Lauderdale, Florida.

Brown, A., (September, 1994). System Reforms: Title IV-E Collaboration Between University, Public Agency, and Community. Presentation at conference entitled Expanding Partnerships for Vulnerable Children, Youths and Families, Tyson Oaks, Virginia.

Brown, A., (April, 1995). Speaker at conference entitled Building Families Through Community Partnerships, Ft. Lauderdale, Florida.

Brown, A., (October, 1995). Permanency Planning and Adoption. Presentor at conference entitled Child Welfare Supervisors and Administrators' Advanced Case-Based Training, Ft. Lauderdale, Florida.

Brown, A., Walker, R., \& Briar, S. (in press). Benefits and effects of a Title IV-E funded MSW program. In K. Briar (Ed.), Expanding Partnerships for Vulnerable Children, Youth and Families. Alexandria, VA: Council on Social Work Education. 